\title{
Photo-/thermal synergies in heterogeneous catalysis: towards low-tempera- ture (solar-driven) processing for sustainable energy and chemicals
}

\author{
Nicolas Keller, ${ }^{\mathrm{a}, *}$ Javier Ivanez, ${ }^{\mathrm{a}}$ James Highfield, ${ }^{\mathrm{b}}$ Agnieszka M. Ruppert ${ }^{\mathrm{c}, *}$
}

1. Institut de Chimie et Procédés pour l'Energie, l’Environnement et la Santé (ICPEES), CNRS, Université de Strasbourg, 25 rue Becquerel 67087 Strasbourg, France.

2. Independent consultant, Singapore.

3. Institute of General and Ecological Chemistry, Faculty of Chemistry, Łódź University of Technology, ul. Żeromskiego 116, 90-924 Łódź, Poland.

\footnotetext{
* Corresponding author : nkeller@unistra.fr
}

\begin{abstract}
There is growing recognition that cooperative effects exist under dual-mode (photo-thermal) heterogeneous catalytic excitation that offer genuine prospects in the transition to a sustainable energy and chemicals economy. Solar beams can act as practical combined source of photons and heat (via non-radiative relaxation after optical absorption) and lead to process intensification. This review provides a critical update and appraisal of advances in photo-/thermal synergies in catalysis, now a burgeoning field. It begins by classifying possible co-excitation synergies now driving a paradigm shift in catalyst design towards inclusion of pan-spectral absorbers, e.g., narrow-gap semiconductors and/or plasmonic nanoparticulate metals. Photo-thermo- (micro)reactors and concentrators are surveyed and the photophysics of electronic excitation is briefly outlined. Emphasis is on the impact of dual-mode excitation on selected processes of importance in tomorrow's solar-biorefineries, i.e., process hydrogen generation by oxygenate(s) reforming, specialty compounds by oxygenates conversion, $\mathrm{CO}_{2}$ reduction/hydrogenation for solar fuels, and FischerTropsch synthesis for renewable hydrocarbons.
\end{abstract}

Keywords : Photocatalysis ; thermal catalysis ; solar biorefinery ; light-to-heat conversion ; excitation synergy 


\section{Introduction}

In his 2004 talk enumerating the 10 great challenges facing humanity in the $3^{\text {rd }}$ Millenium, Nobel Laureate and founder of modern nanoscience pioneer Richard Smalley placed energy at the top of the list. He advised divestiture of fossil fuels in favour of sustainable, environmentally benign alternatives, in which he envisioned a key role for future nano-technologies based on the controlled assembly of nanometre-scale structures [1]. A heterogeneous catalyst can fairly be termed the archetype of an 'applied nanomaterial'. Modern petrochemical processing was founded largely on their early exploitation and the industry has evolved to today's high level of efficiency due largely to historic advances in performance of these remarkable solids. Much of this was done with only marginal understanding of their workings prior to the advent of in-situ surface characterization, high-resolution imaging tools, and theoretical (computational) modeling [2,3].

A difficult transition must now be made from fossil-based (mainly crude oil/natural gas) resources towards a sustainable, $\mathrm{CO}_{2}$-neutral, and environmentally benign energy economy. This will involve a massive and urgent development in 'next-generation' bio-based processing that avoids resource competition with food and feed agriculture. Biomass is considered the only sustainable source of energy and organic carbon for today's technological society, so that it is pivotal to industrial renewal. At a time of increasing concern about greenhouse gases in an economic climate of rising energy demand, biomass offers, in principle, a $\mathrm{CO}_{2}$-neutral and vital contingency supply of resources. It should provide the basis of new sustainable value chains towards renewables such as biofuels, fuel additives, and specialty (high value-add) chemicals, including the so-called platform molecules. The prospects for a future bio-based economy have been addressed in excellent recent reviews [4-8].

The challenges associated with conversion of intractable lignocellulosic materials, e.g., forest wastes, agricultural residues, municipal paper waste and food residues, into chemicals are complex due to the wide variety of feedstocks and to the large panel of possible products. These involve 
multi-step catalytic reactions and processes that will test the resourcefulness of specialists working in a future 'biorefinery'. The International Energy Agency IEA defines the biorefinery as the location for sustainable processing of biomass into a spectrum of marketable products and energy. The techno-economics and ideal capacity of any bio-based installation will be highly dependent on efficient pre-processing of recalcitrant solid lignocellulosic feedstock [9]. All wastes should be minimized and/or valorized [10], and a major shift towards green chemical processing is necessary to mitigate the environmental footprint and globally to increase the carbon efficiency.

Solar energy is one of the ideal, albeit intermittent, sources of renewable energy, with the potential to meet the projected energy demand. Its harnessing and integration (photonic and thermal) into catalytic processing will undoubtedly play a major role in the establishment of an environmentally benign $\mathrm{CO}_{2}$ neutral 'renewable-based chemicals' industry. Furthermore, the benefit that accrues by linking solar and bio-resources is obvious. For example, solar hydrogen can be stored in practical liquid form (as methanol) by reaction with a 'bio-pool' of virtually pure $\mathrm{CO}_{2}$, e.g., as a by-product of fermentation ethanol. Access to the combined infrastructure will also promote the exploitation of synergies of photo-/thermal activation over heterogeneous catalysts, in which optical and thermal (photonic) power can be supplied simultaneously by the directed beam of a 'low-power' (x5 x50) solar concentrator. With a suitable absorber/receiver, this class of device is sufficient to drive many industrial catalytic processes $\left(\mathrm{T}<500{ }^{\circ} \mathrm{C}\right)$ but is a more amenable (portable) and versatile tool as compared to static (dish, tower) types.

Special interest in cooperative effects in photo-/thermal activation, for which there is growing evidence, forms the basis of this review article. Its investigation is driven by the imperative of accelerating reaction rates (reducing processing time) under fixed conditions and/or attaining the same product yields at lower temperature or under milder conditions. Advances which lead to improved ('greener') process sustainability with reduction in environmental and energetic footprint will be vital to the success of future solar-biorefineries. This will be largely underpinned by fundamental advances and major reorientation (towards hydrogenolysis and hydrodeoxygenation) in heterogeneous catalysis and related process engineering. 
Section 2 introduces the strengths, limitations, and complementarity of photo- and thermobased activation modes in heterogeneous catalysis, while Section 3 emphasizes the need for a standardized terminology to distinguish the processes involved, and itemizes the various synergies possible in dual (simultaneous) excitation. Section 4 identifies catalyst design strategies premised on the search for novel materials with pan-spectral optical response to exploit the widest possible range of solar energy harvesting, and to provide an optimum balance of electronic effects, e.g., visible-induced charge carrier generation in semiconductors, 'hot electron' promotion in plasmonic nano-particulate metals, etc. Due attention is also given to high-efficiency non-radiative (thermal) conversion as a key element of 'optical heating'. This new approach to localized heating, evolving out of established solar-thermal technology, marks a paradigm shift in catalytic reaction engineering.

Section 5 presents an outlook for the transition from state-of-the-art photo-thermo- reactor technologies, mainly lab (lamp)-based at present, to field applications under actual solar illumination. The use of low-power concentrators will be indispensable for exploitation of this renewable resource at a commercially relevant degree of energy intensification. Section 6 briefly outlines the fundamental photo-physics of electronic excitation and the distinction between fast and slow relaxation in (localized) heat generation.

Figure 1 illustrates the wide span of novel applications in Energy and Environment, from which examples of photo-thermo- catalysis taken from the literature (and presented in Section 7) are selected on the basis of their expected importance in future solar biorefineries centered on platform chemicals bio-ethanol and solar methanol. Sub-topics include refinery process $\mathrm{H}_{2}$, high-added value products (from oxygenates), $\mathrm{CO}_{2}$ hydrogenation (including methanation, reverse water-gas shift, alcohols synthesis, etc.), artificial photosynthesis, and Fischer-Tropsch conversion for renewable transportation fuels (power-to-liquids, PtL). 


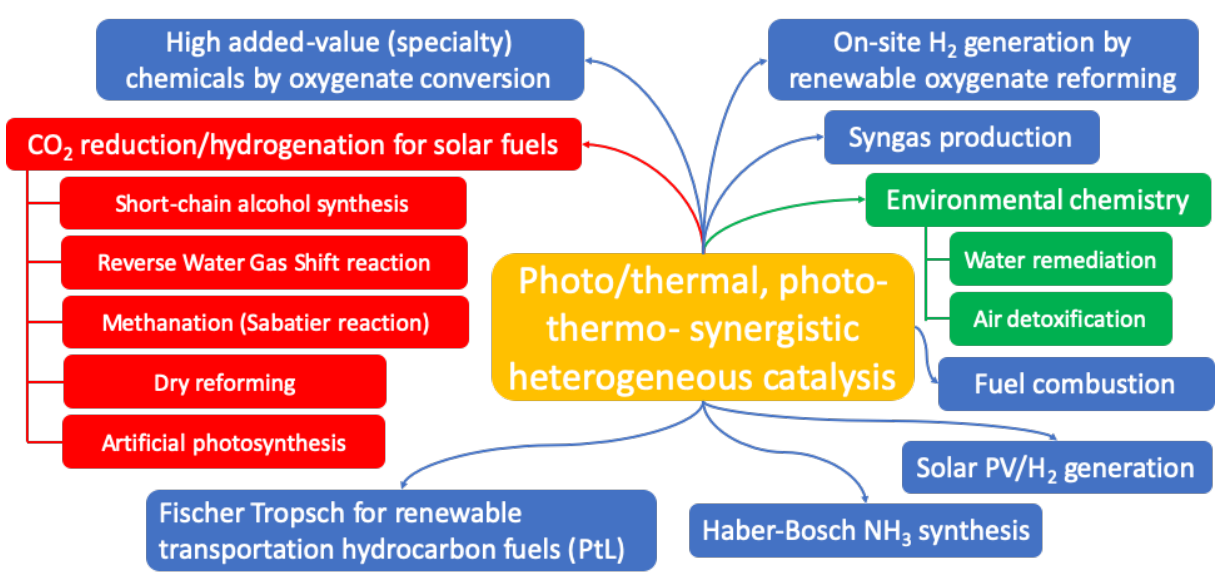

Figure 1. Illustration of the continuously-broadening and -diversifying span of novel applications in the field of Energy and Environment, from which examples of photo-thermo- catalysis are selected on the basis of their expected importance in future solar biorefineries centered on platform chemicals bio-ethanol and solar methanol, and presented in Section 7.

\section{Heterogeneous photo- and thermal catalysis}

Until recently, thermal and photo-excitation strategies were perceived as separate alternatives in overcoming (Arrhenius-type) activation energy barriers. Instead of raising temperature, a photocatalyst may offer a new route under ambient conditions to the same product(s) via a new transition state of lower potential energy, and with a saving in process energy demand. Nevertheless, the prospect of using both excitation modes simultaneously over a single catalyst to drive a process even more efficiently and/or selectively to the desired products logically follows from the same premise that inspires the scientist to seek a catalytic solution of any kind whatsoever, viz., to accelerate the slowest (rate-determining) step (rds) that governs overall reaction speed in the complex sequence of multiple elementary steps associated with all chemical change. A representative multiple-barrier Arrhenius diagram for an endergonic (energy-storing) process is shown in Figure 2. 


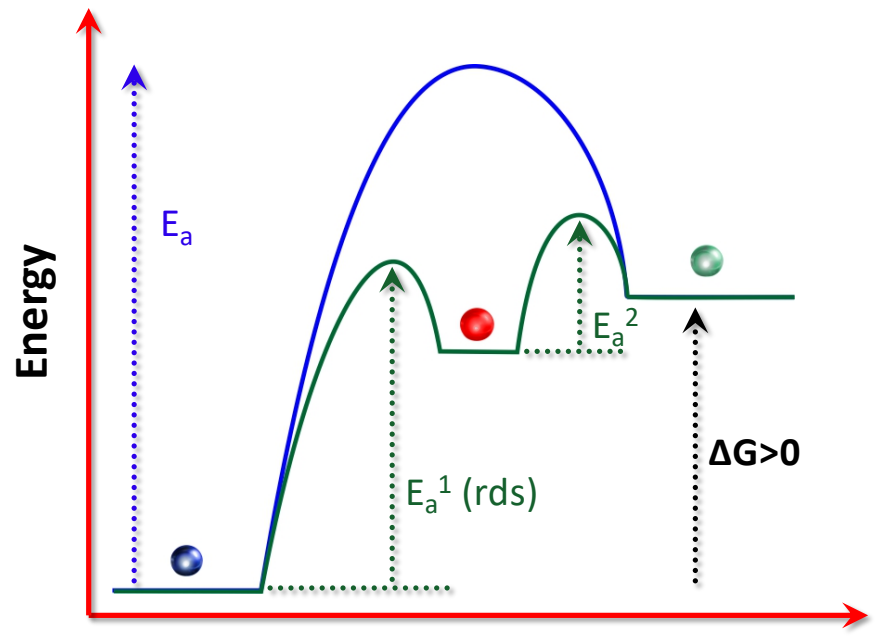

Reaction coordinate

Figure 2. Arrhenius diagram of a multiple (two-step, $\mathrm{E}_{\mathrm{a}}{ }^{1}$ and $\mathrm{E}_{\mathrm{a}}{ }^{2}$ ) activation energy barrier to an endergonic (uphill, energy-storing) process. rds : rate-determining step

Overcoming the rds by catalytic means, e.g., photo-excitation, leads to re-establishment of (admittedly faster) kinetics but now controlled by a new rds positioned elsewhere in the mechanistic sequence. If this is of the 'dark' type, there may still be a subsidiary but nevertheless important role for thermal activation in the photo-process. This simple concept serves to illustrate the potential complementarity of multiple excitation modes, while keeping in mind that 'a chain (reaction) is only as strong (fast) as its weakest (slowest) link'.

\subsection{Heterogeneous photocatalysis}

It is fair to say that photocatalysis is a recent discipline still some way from technical maturity. However, its capability to drive thermodynamically uphill reactions and to steer processes towards more energetic products, especially hydrogen, is self-evident and invaluable. It typically involves irradiation of a semi-conductor solid (as nanopowder or immobilized system) by a lamp or solar beam in liquid slurry or gas-phase (reactant) contact. Only photons of energies equal to or greater than the semi-conductor band-gap (mainly UV but extending into the visible region) are absorbed and can contribute to the photo-excitation process, with the promotion of an electron from the top of the valence band into the conduction band, leaving behind a photo-generated hole. Depending 
on the depth of (bulk) absorption, some of these photo-generated charges migrate to the surface and drive surface redox reactions of interest. Adsorbed electron acceptor molecules are reduced by electrons from the conduction band, while electron donor molecules are oxidized by holes from the valence band. The fundamentals of heterogeneous photocatalysis, focusing on reaction mechanisms and process engineering, and including the design of innovative photocatalytic materials, have been detailed and regularly updated in the last decades in exhaustive reviews and book chapters $[11-18]$.

Photocatalysis represents a greener alternative in synthesis or degradation reactions due its effectiveness in exploiting sustainable (solar) energy under mild conditions. Its key limitation is the maximum optical power available as a direct unfocused beam, which provides a natural (solar) insolation of $\sim 1 \mathrm{~kW} \mathrm{~m}^{-2}$. This corresponds to a photon flux (Einsteins $\mathrm{m}^{-2} \mathrm{~s}^{-1}$ ) in the millimolar range. Thus, intrinsic rates in unaided photocatalysis are still far from being practical in targeting industrial applications, where a high conversion at high selectivity and a realistic space velocity is mandatory. This highlights the importance of beam intensification and the essential role of solar concentrators in future photoreactor technology. Although process upscaling remains a sticking point, important progress has been achieved thanks to inputs from the field of material science and engineering and to the exploration of new materials, architectures and hybrid assemblies $[19,20]$. Major fundamental and technological advances, e.g., texturing on the nano-scale, improved charge separation efficiencies, extended lifetimes of photogenerated charge carriers, and sensitization into the visible region (constituting nearly half of total solar irradiance) have raised considerably the attainable efficiencies in photocatalysis.

\subsection{Thermal heterogeneous catalysis}

By contrast, thermal heterogeneous catalysis is well-established with a prior history of over a century of industrial development. By simply raising temperature, conversion rates have a high probability of reaching levels of technical relevance but, unfortunately, this is often at the price of 
lower process sustainability. It is also restricted to the acceleration of spontaneous or thermodynamically feasible reactions, i.e., those with negative change in the Gibbs free energy $(\Delta G)$, by lowering the activation energy barrier via a new pathway involving a surface-adsorbed transition state. The overall reaction consists of a succession of multiple elementary reaction steps that may present several potential barriers, each with an individual activation energy. The measured (apparent) activation energy is determined by the highest (potential) barrier in the overall sequence.

With rare exceptions, most industrial heterogeneous catalysts work under extreme conditions of temperature and pressure far removed from thermodynamic equilibrium for a variety of fundamental and technical reasons. This introduces undesirable side-reactions, e.g., coking, which often leads to loss of selectivity and deactivation on-stream. Associated process downtime for catalyst regeneration is an expensive business. As stated above, the primary motivation for coupling thermal and photo-excitation in a one-pot operation is to more closely approach ideal or reversible conditions by providing the optimum in "catalytic assistance".

\section{Definitions and concepts.}

Early studies of the temperature effect in photocatalysis back in the 1980's were reported as almost incidental curiosities and/or even due to adventitious heating from (optical absorption of) the probe beam itself [21-27]. The deliberate systematic evaluation of the combined effects of thermal and photo-excitation is a recent trend emerging in the last decade and rapidly intensifying. In consequence, neither a unique definition nor a 'standardised' terminology has been established to date. As such, a certain amount of confusion surrounds reports that appear to be describing the same phenomena when this is actually not the case. For example, the term photothermal used in two very recent reviews refers in one case to (synergies in) simultaneous illumination under heating (Ghoussoub et al.[28]), and in another to the localized heating effect resulting from light absorption and non-radiative relaxation (Wang et al.[29]). On the contrary, every source article introducing 
terms that fall generally under the 'photo-thermal' umbrella must be carefully scrutinised as to the specific methodologies or phenomena to which they refer.

From first principles, it should be possible to distinguish by kinetics experiments several cooperative (synergistic) effects that may operate under combined excitation:

- Type A. Photo-excitation drives a reaction through an alternative low-energy transition state, while thermal excitation acts on a new rds of the dark type in the same overall sequence. A lowering in apparent activation energy $\left(\mathrm{E}_{\mathrm{app}}\right)$ is expected.

- Type B. Photo-excitation alters favourably the steady-state balance in (active catalytic) surface coverage by intermediates. An increase in rate will be expected either via improved supply of the limiting reactant(s) and/or the suppression of accumulation or dispersal of catalyst poisons. Such a concentration effect may be accompanied by a change in reaction order. No change in $E_{\text {app }}$ is expected.

- Type C. Photo-excitation serves as a delivery mechanism of localized heat (via non-radiative relaxation) as an adjunct in a thermal process at an established base (bulk) temperature. No change in $E_{\text {app }}$ is expected.

To illustrate the disparate approach to this new terminology, Tang et al. used the term photothermal catalysis as a generic descriptor to include both the thermal acceleration of a photocatalytic reaction and the photo enhancement of thermocatalytic reactions [30]. In contrast, the Colmenares group (Nair et al.[31]) made a distinction and classification under the terms photo-thermo-catalysis and thermo-photo-catalysis, where the respective descriptors refer to a photo-effect on a thermal catalyst or to a thermal-effect on a photocatalyst. However, it should be recognized that whereas the thermo prefix is clearly adequate for a catalytic system driven by heat intensification (rise in temperature to overcome an activation energy barrier), the photo prefix is a more ambiguous term and strictly depends on the reaction mechanism involved, which is often unknown or ill-understood. Indeed, there has been a long debate on the definition of the term photocatalysis itself. At one extreme it could be taken as referring solely to redox processes in adsorbed species originating 
from optical (photonic) stimulation of electronic transitions in the bulk semiconductor particles (electron/hole creation), followed by surface migration, etc.

IUPAC recommends a broader and mainly phenomenological description - photocatalysis is (or involves) 'a change in the rate of a chemical reaction or its initiation under the action of $U V$, visible or IR radiation in the presence of a substance - the photocatalyst - that absorbs light and is involved in the chemical transformation of the reaction partners' [32]. The IUPAC definition is rather permissive and does not itemize any particular mode(s) of interaction between the photocatalyst and reactants. That the latter are presumed to be in the adsorbed state on the photocatalyst surface seems to be implicit. Consequently, in the context of a multi-mode (excitation) approach to catalysis the prefix 'photo'- may also connote light-assisted (or light-driven) thermal catalysis rather than a true photocatalytic reaction, i.e., one optically-driven via a new transition state of lower potential energy. We have to stress that the use of qualifiers such as 'photo-assisted' takes us back to the late $80 \mathrm{~s}$, when it was introduced by Wentworth et al. as an adjunct in the thermal decomposition of methanol and isopropanol in a fluidized bed reactor [33].

Nair et al. observed that the key significance of their approach (howsoever named) is the implementation or exploitation of a 'synergy between photocatalytic and (thermal) catalytic processes' [31]. This statement nicely posits the importance of dual co-excitation in utilitarian terms and should elicit a general consensus from specialists. However, while the light stimulus always consists in the 'external' irradiation of the catalyst through natural (sun) or artificial (lamp) photonic sources, alternatives exist as regards thermal energy generation. Beside the traditional external supply of heat to the catalyst as in conventional (thermal) operation, viz., indirectly from the reactor walls by conductive and convective transfer modes, illumination of a light-absorbing component in the catalyst offers direct 'optical heating' via yet another so-called photothermal effect, this one stemming from dissipation of the absorbed photon (electronic) energy into heat by nonradiative mechanisms.

One effective way to induce localised deposition of thermal energy by optical means is to irradiate into the strong surface plasmon resonance (SPR) absorption band of nanosize noble metal 
particles such as gold or silver, usually in supported form(s) [34]. The subsequent fast (non-radiative) relaxation of the exciton promptly converts the photon energy into heat, and results in considerable increase in the local temperature at the catalyst surface (type C). A similar mechanism, i.e., selected pyrolysis of localized tissues, underpins the efficacy of cancer phototherapy [35-38]. This strategy is referred to mostly by the identical term photothermal catalysis, but almost exclusively pertains to the sun as both (direct) light and (indirect) heat source, with the harvesting and the dissipation of visible or even near-infrared (NIR) light (according to the substrate optical absorption spectrum) to drive useful reaction $[39,40]$, like $\mathrm{CO}_{2}$ reduction/hydrogenation into solar fuels [41-44] or water splitting [45,46]. Although more expensive than traditional alternatives like carbon blacks, plasmonic metals are favoured absorbers in photothermal applications due to their greater versatility, offering a tunable range of spectral response and intensification of absorbing power.
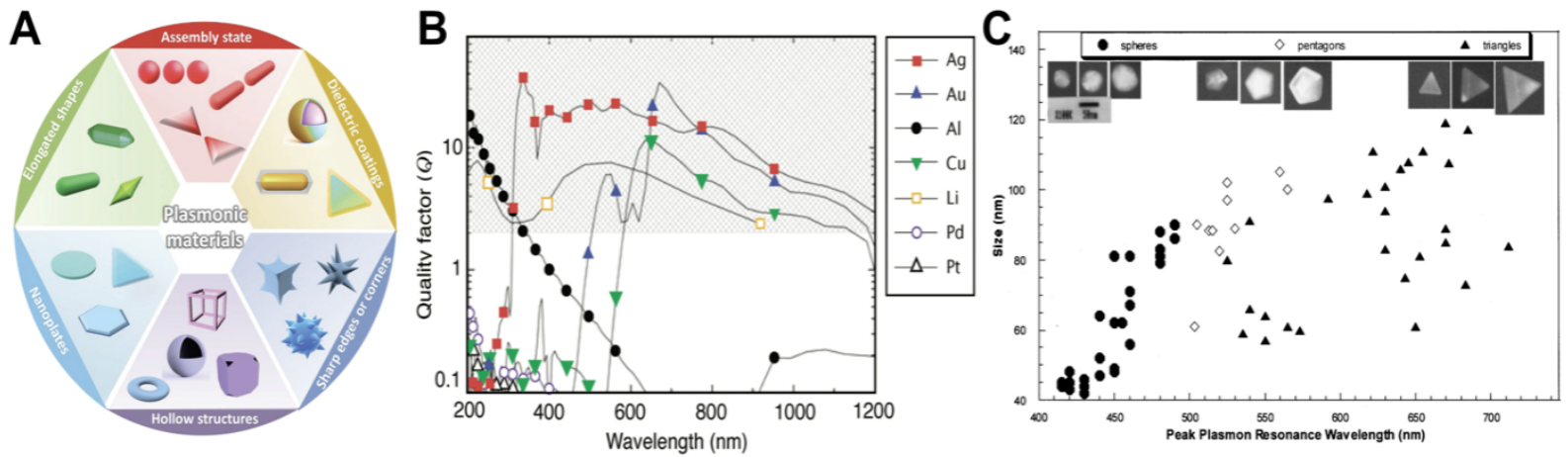

Figure 3. (A) Various strategies to enhance the optical absorption of plasmonic metals (reproduced from ref [47] with permission of Elsevier) ; (B) Quality factor Q of the LSPR for a metal/air interface, a higher Q factor denoting less damping and a stronger plasmon resonance. The shaded area depicts the region of interest for many plasmonic applications (reproduced from ref [48] with permission of ACS). (C) Influence of both the size of shape on the peak plasmon resonance wavelength for colloidal Ag nanoparticles (reproduced from ref [49] with permission of American Institute of Physics. 
The strong localized surface plasmon resonance effect (LSPR) is induced by tuning the incident photon frequency to the natural oscillation frequency of the surface-bound valence electrons, thereby establishing a collective resonance condition. This leads to strong electrical fields at the metal surface and to the generation of high densities of energetic charge carriers, so-called hot electrons and holes. While plasmonic metals are the most popular nanostructures, transition metal semiconductors or hybrid materials in various combinations are also reported to be of interest [50]. The intrinsically much lower LSPR responses of transition metal semiconductors (as compared to metals) may be increased by suitable band engineering and/or structural design, and is a topic of recent interest. For example, excitation in the valence band of the semiconductor (typically in the NIR region) can be sensitized by doping with extrinsic impurities or the creation of intrinsic defects. These result in both enhanced absorption and light-to-heat conversion efficiency due to a raised probability of non-radiative recombination [47].

\section{Photo-thermo- catalyst design strategies.}

The essential property of a so-called photo-thermo-catalyst is that at least one component must be sensitive to light, regardless of whether this is a semiconductor or not [41,51,52]. Any design strategy needs to integrate and fully exploit the impact of photonic excitation in tandem with conventional heating. This optimization will inevitably follow primarily an empirical approach given that the bulk photophysics and surface reaction mechanism are generally ill-defined and complex phenomena.

The first (and simplest) strategy is to use a photon flux as a novel 'direct' thermal energy source resulting from non-radiative (light-to-heat) relaxation after optical absorption (Type C). Under steady-state illumination, a heat gradient will be established at or close to the catalyst surface whose characteristics will depend on several factors amenable to experimental control. These include the optical power and dispersion of the light source (monochromatic, notch-filtered, bandpass, etc.), 
the range in extinction coefficient of the absorber (or 'instantaneous heat generator') across the incident wavelengths, its physical distribution, and the thermal (diffusive) properties of the catalyst and reactants. Such a localized heat deposition adds a new dimension to explore in thermal catalysis reaction engineering although its maximum working temperature will be constrained by limited optical (solar) power and/or the relative expense of high-power lamps in the Laboratory. Nonetheless, well-designed tubular reactors driven by very low-power $(\mathrm{x} 5-\mathrm{x} 10)$ solar concentrators can easily raise the flow medium (heat carrier/reactant) to $250^{\circ} \mathrm{C}$ [53]. Indeed, a recent advance in solar-thermal reactor design is to dispense with the external (absorber) coating and generate heat volumetrically throughout the thermal fluid by suspending 'nanofluid' absorbers, e.g., plasmonic metals like $\mathrm{Cu}$ or $\mathrm{Au}$, offering a more efficient direct optical heating mode [54].

To summarize, a first strategy lies in the use of light energy as thermal energy source by socalled light-to-heat conversion processes deriving from well-tuned illumination. In this case, the photo thermo catalyst is operating purely as a thermal catalyst, regardless of whether any external resistive heating is also applied to complement that internally provided by light. To ensure effective light-to-heat conversion, the utilization of plasmonic metal nanostructures remains till now the most popular option. It must be said that works have also been performed using suitably optimized semiconductor materials, e.g., by band gap engineering and irradiation into the LSPR in the valence band, usually found in the NIR region. This can be enhanced in intensity via the introduction of extrinsic impurities or the creation of intrinsic defects (see Zhu et al. for more details [47]).

The LSPR effect in a metallic nanostructure is correlated first and foremost to the identity of the metal [44]. However, as shown in Fig.3, a degree of spectral tunability is achievable by adjustment of several physical properties, e.g., the size, shape, assembly configuration and the dielectric environment $[29,34,47]$. The photo-generated hot electrons can further be involved in transient electronic excitation resulting in:

(i) bond activation by bringing additional vibrational energy to the reactant(s),

(ii) catalyzed intermediate conversion via electron transfer from the metal to unoccupied states in the adsorbate. 
In practice, localized optical heating will likely become popular as an adjunct to conventional electro-resistive heating (via inertial thermal equilibration) as it should alleviate the electrical power demand otherwise needed to raise the entire reactor body to process temperature. However, it is also a complicating factor in fundamental work because absorption of incident photons leads potentially to two different catalytic effects contemporaneously; optical - by inducing direct electronic transitions in the absorber, and thermal - via indirect local heating after non-radiative decay. This thermal component is even present to some degree in a hypothetical 'pure' photocatalytic process with unit quantum efficiency. Jablonski's rule dictates that instantaneous relaxation (to the ground vibrational level of the $1^{\text {st }}$ electronic excited state with heat release) follows after excitation by all and any photons with frequencies exceeding the energetic threshold for the electronic transition, e.g., super-band-gap photons generating 'hot' electrons in the case of a semiconductor absorber.

For this reason, there is always a degree of uncertainty as to the relative contribution of the thermal factor in any experimental work on photocatalysts and, thus, the reliability of measured quantum efficiencies in optically opaque systems typical of powdered solid beds. Historically, the level of any temperature rise at the photocatalyst surface under steady-state illumination, was seemingly a minor issue. Indeed, ad hoc numerical estimates based on incident optical power and assuming full heat generation (worst case from a fundamental viewpoint) in a sample of defined volume (optical depth at full extinction) and known (or assumed) heat flow characteristics predict expected temperature rises no greater than a few ${ }^{\circ} \mathrm{C}$ in typical Lab/lamp-based systems. However, as a deliberate target to be maximized in recent research strategies, claims of temperature excursions (induced by optical heating alone) of hundreds of degrees are steadily increasing (vide infra) due largely to reinforcing empirical factors, e.g., the pan-spectral absorption of newly-designed photo-thermo- catalysts and the exothermicity of some reactions [41]. The growing implementation of solar concentrators, as covered later in this review, will further exacerbate and delay resolution of this issue due to the higher optical power densities involved. It needs to be borne in mind that any photo-thermo'synergy', ideally measurable in quantitative terms, needs realistic estimates of 
catalytic rate parameters for each excitation mode (optical, thermal) independently in order to set working benchmarks.

A second strategy lies in the use of materials able to act simultaneously as both photo-catalyst and 'dark' (thermal) catalyst, or as an optically-responsive support in contact with a thermal catalyst. Several oxide semiconductor materials popular as photocatalysts serve as constituents in thermal catalyst formulations, albeit typically working under more extreme reaction conditions $[50,55]$ usually as supports since they can be prepared in high-surface-area form(s). Prime examples are $\mathrm{TiO}_{2}$ [52], $\mathrm{ZnO}$ or $\mathrm{CeO}_{2}$ semiconductors $\left(\mathrm{E}_{\mathrm{g}} \sim 3.2 \mathrm{eV}\right.$, surface area $\left.>50 \mathrm{~m}^{2} / \mathrm{g}\right)$. These may be activated under UV-A light to generate electron/hole pairs for photocatalysis, while they also serve as excellent supports in thermal catalysis, bearing and stabilizing noble metal nanoparticles like $\mathrm{Ru}$ [56], $\mathrm{Ag}$ [57], Pt [58], Pd and $\mathrm{Au}$ [59], as well as earth-abundant elements like Ni [60], $\mathrm{Co}, \mathrm{Cu}$ [61] or Fe. These metals often have dual roles, serving as active components in thermal catalysts and/or as co-catalysts for dark processes in photocatalysis. Thus, while the recent trend is away from supports like $\mathrm{TiO}_{2}$ (restricted to UV absorption only), towards pan-chromatic supports with a broad absorption across the visible into the near-IR region that absorb a wide fraction of the solar spectrum, historically they are logical candidates for studying any photo-/thermo synergy, although the requirement of strong optical absorption means that their metal loadings need to be high, making them expensive. In the long term, $\mathrm{M} / \mathrm{TiO}_{2}$ systems should be superseded in this research field.

However, an excellent metal-support model example is $\mathrm{Pt} / \mathrm{TiO}_{2}$, which is not only a photocatalysis benchmark but also manifests a striking synergy in thermal catalysis via the strong metal-support interaction (SMSI) effect [62]. Furthermore, by generating surface electron/hole pairs, illumination can be used to alter important chemical properties of the catalyst support, such as Lewis basicity and acidity, the steady-state density of surface oxygen vacancies, etc.

We have to stress that photon absorption by metal nanoparticles is not even restricted to the surface plasmon type. Many non-plasmonic metal nanoparticles can absorb light across the UV- 
visible depending on the interband transitions of bound electrons [52]. Thus, the traditional importance of wide band-gap semiconductors as key optical centres in photocatalysis may increasingly be moderated (and augmented) by contributions from abundant and cheap nano-dispersed metals. Dual-functional photo-thermo catalysts having the flexibility to incorporate significant levels of insulating support materials like $\mathrm{SiO}_{2}, \mathrm{Al}_{2} \mathrm{O}_{3}, \mathrm{MgO}, \mathrm{CaO}$, etc., conferring their unique surface chemical properties, will become an important direction in future nanocomposite design [63].

The strategy to be implemented for designing advanced photo-thermo catalysts necessarily relates to underlying mechanistic aspects. However, while the combination of both thermo- and photo-chemical contributions lays the foundations of the photo-thermo- catalysis (howsoever named), it clearly appears from recent studies that evidencing which pathway is predominantly driving the reaction remains a critically challenging task. It must be stressed that even in the case of a predominant mechanism, both kinds of mechanisms can occur simultaneously in a synergistic way. Therefore, mechanistic studies are only nowadays at their infancy, and new methodologies have to be developed to distinguish which reaction mechanisms are taking place depending on the (photo-thermo) catalyst nature.

Experimental methodologies are mainly based on the experimental determination of the influence of the light spectrum (intensity and wavelengths) on the (photo)catalytic rates. For instance, thermal reactions are reported to be characterized by an exponential relationship between the light intensity and the reaction rate, as a consequence of the linear dependence of the surface temperature increase of plasmonic nanoparticles with the photonic flux [51,64]. By contrast, an electron-driven reaction (e.g. for plasmonic reactions) is reported to follow in most of cases a linear dependence of the reaction rate with the intensity [51,65-67], although superlinear rate regimes are also observed on metal surfaces $[51,68,69]$. Those changes of rate regime have been proposed to depend directly on the reaction conditions, or to be linked to plasmonic hot electron-induced multiple excitations of the vibrational modes of the adsorbed species $[69,70]$. Other experimental approaches based on the variation of the light beam diameter or on isotopic labeling studies have also been reported $[51,71,72]$. Gascon and coll. also emphasize that the analysis of the reaction selectivity might be used for evidencing the predominating pathway [70], as thermal energy is provided to all freedom 
degrees (rotational, vibrational, translational) with as consequence the existence of a myriad of reaction pathways [73], while by contrast, selective injection of hot carriers into specific metaladsorbate bonds gives the ability to modulate and orientate the process selectivity in electrondriven reactions [69]. It must also be said that computational methods are expected to be of great help in elucidating the underlying mechanism(s), and recent results have been reported using the density functional theory framework for investigating on both the electronic structures and the electron transfer at the metal-semiconductor interfaces as well as on the interaction of hot carriers with adsorbed intermediates $[69,72]$. When appropriate, information is provided in the section 7 devoted to the recent advances in photo-thermo catalysis. For more details, the reader may consult the excellent summary of different experimental and computational methodologies implemented for helping in differentiating between thermal effects and hot carrier effects [70].

\section{Photo-thermo reactors.}

Historically, the design and engineering of catalytic reactors has been a strong function of the primary excitation mode, viz., photonic or thermal, with little or no consideration for secondary activation options. However, insofar as a photoreactor is under greater geometric design constraints, in terms of optimization of the power, spatial distribution, and delivery of the incident photon flux, assuring good access by reactants to optical excited states at the nano-dispersed absorber surfaces (high quantum yields), etc., such considerations will clearly play a determining role in any realistic approach to design of a photo-thermo reactor that can provide effective dual-mode excitation. No matter if the photons are considered as a (immaterial) reactant or not - an aspect that remains a matter of debate -, the absorption of photons must be scrupulously optimized inside any system where the observed events are activated by light [74].

Furthermore, the various options available to supply heat offer good flexibility in respect of incorporating the thermal component. These include external (resistive) heating in radial symmetry (as per conventional jacketed tubular thermal catalytic reactors), deposition of heat from external 
absorber coatings, as in traditional solar-thermal units, or direct heat dissipation at the surface of an absorber catalyst (or support) working in photo-thermal conversion mode. Additional design factors and ancillary equipment must also be integrated according to the experimental objectives, be these of fundamental (mechanistic) concern or of a more applied type.

\subsection{Solar thermal heating}

In the absence of any external resistive heating source, the primary objectives in reactor design for optical heating are optimization of the capture geometry for maximizing the incoming light flux along with rapid and highly efficient internal heat deposition. Solar thermal heating technologies use a light-absorber and associated infrastructure to selectively trap the heat resulting from the highest power components, i.e., the visible and IR components in the solar spectrum. The amplitude and spatial distribution of the localized temperature rise can be adjusted by suitable selection of light-absorber, receiver geometry and thermal (flow) characteristics.

When the sun is the only source of photons, the optical element responsible for the harvesting and efficient channeling of solar photons into a catalytic reactor is known as a 'solar collector'. Their typology and use are well-documented in extensive studies by Malato et al., although the group's work focuses on the engineering of photocatalytic reactors for waste-water treatment [75]. They fall into 3 main categories offering different ranges of operating temperature, depending on the concentration factor (C), and thence suitability for specific types of catalytic application [76]. The concentration degree of a solar collector is numerically equivalent to the ratio between the collector aperture area and absorber area. These are defined, respectively, as the area that intercepts the radiation and the area of the component that receives it. Solar collectors are usually classified into 3 main types:

(i) non-concentrating, low concentration or low temperature collectors $\left(\mathrm{T}<150^{\circ} \mathrm{C}\right)$. They are typically low-cost and simple to use. When non-concentrating, they are usually static, flat, facing the equator at fixed inclination and with no solar tracking. They can also be characterized by a low concentration degree $(\mathrm{C}<1.5)$, and in that case very 
common examples are the compound parabolic collectors (CPCs), given that these are ideal $[75,77]$.

(ii) medium-concentrating, or medium-temperature collectors $\left(\mathrm{T}=150-400^{\circ} \mathrm{C}\right)$. Concentration factors of 5-50 are typical and a single- or two-axis solar tracking system is necessary to maintain stable and high levels of integrated optical input. Examples are parabolic-trough collectors, linear Fresnel lenses and holographic collectors. CPCs have the advantage of collecting diffuse light in the visible/near infrared wavelength range, which can amount to over half the annual total of terrestrial insolation depending on latitude and humidity level [78].

(iii) high-concentrating, or high temperature collectors $\left(\mathrm{T}>400^{\circ} \mathrm{C}\right)$. These are based on a paraboloid with solar tracking, and require the use of high-precision/quality optical components and rugged receiver materials for stable operation under concentration degrees as high as 10,000. Examples include parabolic dishes, central receiver (tower) systems and solar furnaces [75,79].

Depending on the scale of application and the maximum working temperature, a typical layout for solar-thermal devices consists of a collector of suitable $\mathrm{C}$ value and a dimensionality compatible with that of the receiver. As shown in Fig. 4A (left), a popular selection is of the medium concentrating type (ii) combining a 2-dimensional parabolic trough and a tubular reactor receiver in annular configuration with the receiver positioned at the concentrator focus [80-82]. Effective lightto-heat conversion requires a "black" material that not only absorbs strongly across a wide range of the solar spectrum (ideally extending into the NIR), but also has high thermal diffusivity (to promote rapid and efficient heat transport to the central thermal fluid), and low thermal emissivity to minimize re-radiation losses. Well-designed tubular flow reactors heated by low-power (x5 $\mathrm{x} 10)$ solar concentrators can attain $240^{\circ} \mathrm{C}$ [53]. A recent advance in heat management has been to dispense with the conventional (external absorber layer) coating and generate heat volumetrically throughout the thermal fluid by suspending nanoparticle ('nanofluid') absorbers offering a more 
efficient direct optical heating mode. LSPR-type noble metals are preferred over nanocarbon blacks as the latter have high thermal emissivity [54].

A
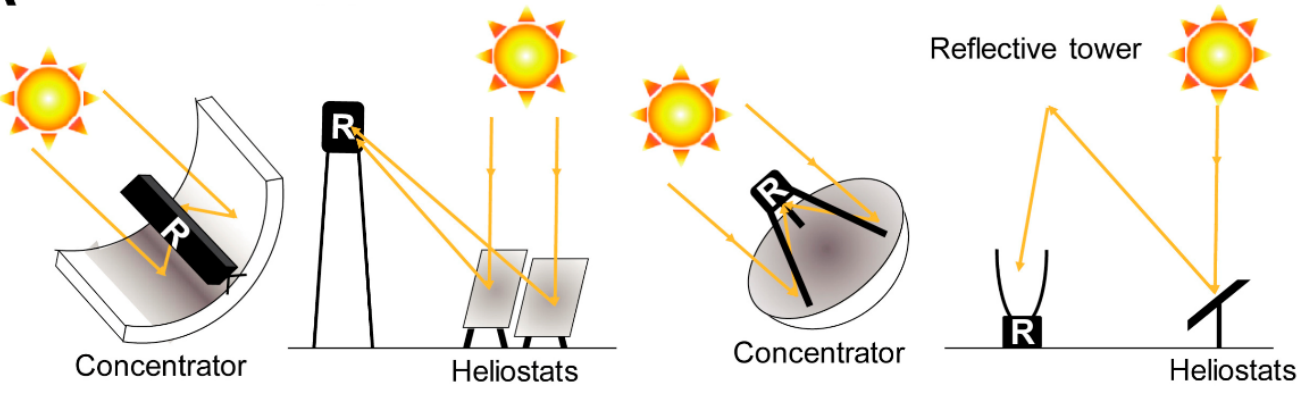

R - Receiver

B

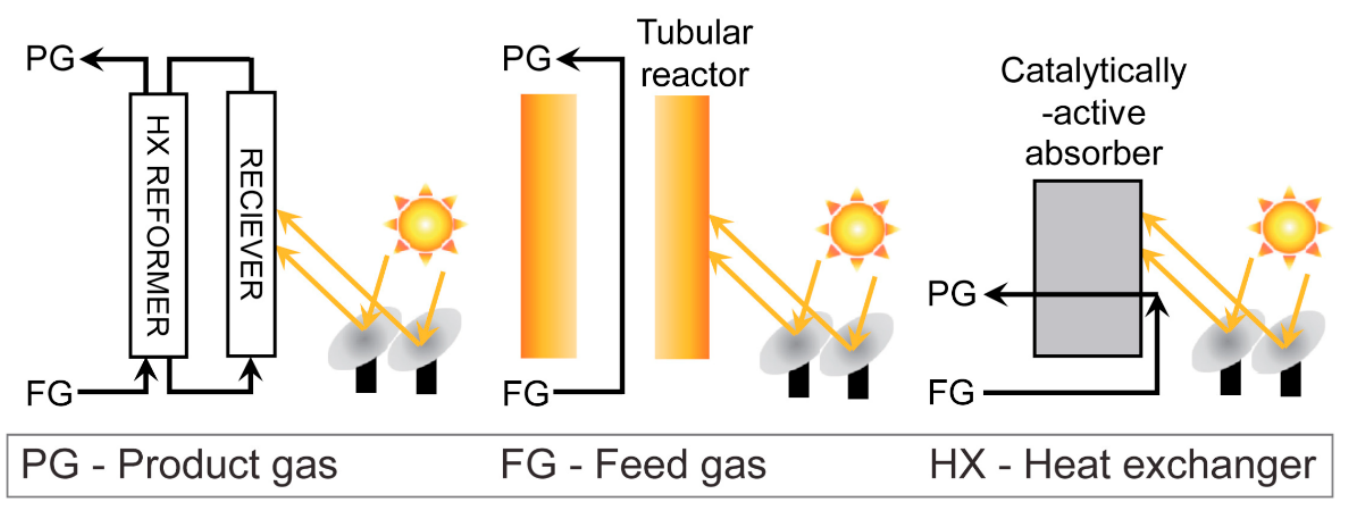

Figure 4. (A) Schematic depiction of medium- to high- solar concentrator types, itemized as (from left) parabolic trough, central power tower (heliostats), parabolic dish, and double concentration systems. Parabolic troughs and dishes offer concentration factors from 30-100 and attain temperatures of 500-700 K. Double-concentrators (right), consisting of a heliostat field, a reflective tower and a ground receiver, operate in the 5000-10000 concentration range and reach temperatures as high as $1500 \mathrm{~K}$, e.g., for thermochemical conversion processes involving stable molecules like $\mathrm{CO}_{2}$ and $\mathrm{H}_{2} \mathrm{O}$. (B) Different configurations for solar-thermal operations: (left)- reactor decoupled from solar receiver system; (middle)- integrated tubular reactor/receiver, and (right) - catalytically active solar absorber. (reproduced from ref [42] permission of Elsevier). 
Fig. 4B depicts various configurations for solar reactor systems, including layouts where the catalyst/reactor is physically remote, or decoupled, from the receiver (left), where the reactor/receiver is integrated but with opaque walls (middle), or where the catalyst itself is the exclusive or partial absorber undergoing direct illumination (right). The last case also offers prospects for photo/-thermal catalytic synergies depending on the likelihood of optical stimulation of electronic processes, which is a function of the type of absorber.

An example of sunlight-driven photo-thermo reactor of conventional tubular type working in the field is illustrated in Fig. 5. In a study of $\mathrm{SiO}_{2}$-encased plasmonic $\mathrm{Ag}$ with $\mathrm{TiO}_{2}$ composite nanoparticles in core/shell form, Gao et al.[80] constructed a simple and cheap prototype reactor, consisting of a quartz tube with thermal insulation except for the underside acting as window for illumination by a parabolic trough concentrator, as schematized in Fig .5(Foreground). A field test comparison (vs. Ag-free controls) under concentrated sunlight resulted in significantly enhanced rates in photo-dehydrogenation of oxygenates and desalination (steam distillation), attributed to localized heat generation due to broad-band absorption by Ag.
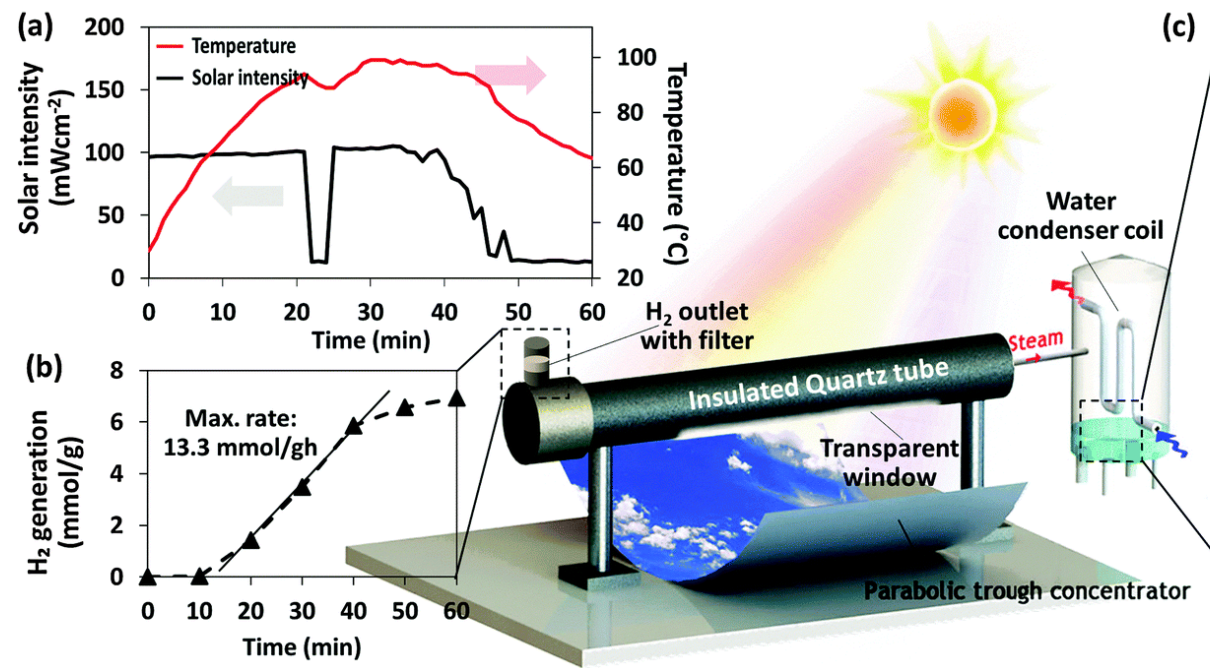

(c)

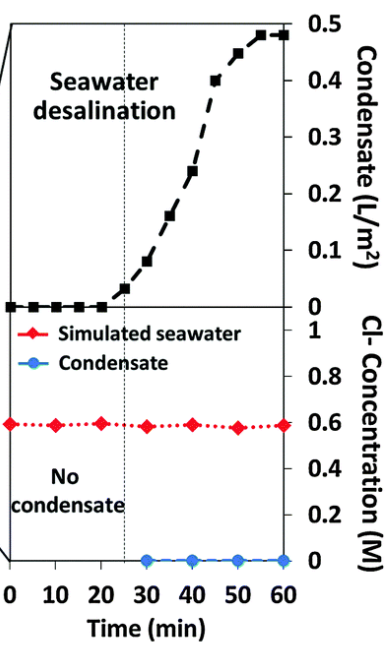

Figure 5. Foreground: - Schematic of a parabolic trough collector-based prototype reactor for sunlightdriven $\mathrm{H}_{2}$ production from seawater (and desalination). a) Outdoor time-evolution graphs of solar intensity 
and reactor temperature; b) $\mathrm{H}_{2}$ evolution rate; c) volume of the condensate (desalination), and invariant chloride level during irradiation of catalyst suspensions in simulated seawater (reproduced from ref [80] with permission of RSC).

\subsection{Photo-thermo microreactors}

In recent years, the advent of 3D printing technology has enabled flexibility in design and fast, cheap and reproducible manufacturing of structured reactors containing microchannel arrays on a sub-millimetre scale, thereby providing impetus to the development of process intensification. Compared to conventional ('macro'-) reactors, such miniaturization largely avoids issues linked to mass- and heat-transfer limitations, resulting in better energy efficiency, higher conversion rates and yields, improved safety (by easier handling of high-pressure conditions), more precise definition of reactor parameters, and amenability to process control [83]. For photocatalysts, such wide lateral dispersion and shallow depths serve to promote reactant/photon/catalyst encounters. A traditional problem in photo-reactor design is how to minimize or eliminate the unilluminated fraction of the catalyst, i.e., sub-surface and bulk nanoparticle layers positioned below 'infinite depth', the term for the condition of full extinction due to absorption and scattering. 

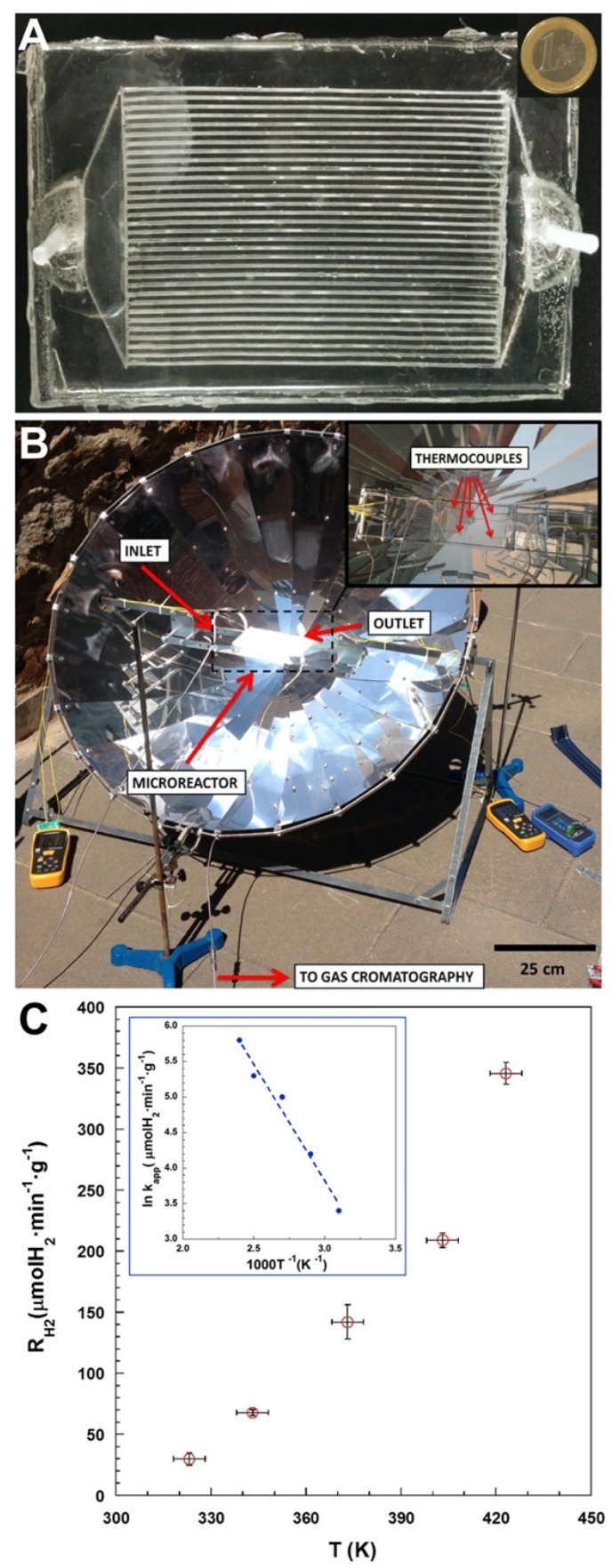

Figure 6. (A) Photograph of the 3D-printed silicone microreactor with 32 microchannels of $500 \mu \mathrm{m}$ (width) $\times 1 \mathrm{~mm}($ depth $) \times 117.5 \mathrm{~mm}$ (length) used in (B) outdoor experimental test setup for $\mathrm{H}_{2}$ production with the microreactor placed in the collector focus, irradiating the top cover with sunlight gathered by the parabolic mirror and the bottom of the reactor with direct sunlight (commercial parabolic $\mathrm{Al}$ solar reflector: $\mathrm{d}=1 \mathrm{~m}$, aperture area $=0.8 \mathrm{~m}^{2}$, AlSol K10, Spain). (C) Photocatalytic $\mathrm{H}_{2}$ generation rates obtained using the $(\mathrm{B} / \mathrm{C})$ experimental setup at different temperatures under sunlight irradiance (residence time $0.35 \mathrm{~s}$, 
GHSV $\left.=10200 \mathrm{~h}^{-1}, \mathrm{H}_{2} \mathrm{O}: \mathrm{EtOH}=9: 1 \mathrm{M}\right)$. The photocatalytic tests were carried out in Barcelona (41.38 $2.17^{\circ}$ ) with average solar and UV-A irradiance of $90 \pm 5 \mathrm{~mW} / \mathrm{cm}^{2}$ and $5.0 \pm 0.5 \mathrm{~mW} / \mathrm{cm}^{2}$, respectively. (reproduced from ref [84] with permission of Elsevier).

For typical indirect band-gap semiconductors like $\mathrm{TiO}_{2}$ infinite depth is established already in the top few microns, i.e., the dimensional regime of single particles or agglomerates of nanoparticles, albeit in porous form. Internally mounted light (LED) micro-sources coupled to optical fibres in annular or honeycomb configuration can dramatically improve illumination efficiency in a conventional (Laboratory) tubular or spheroidal reactor. If the catalyst is also applied as a micron-scale coating to a monolithic support, the mass-specific rates can be raised $\mathrm{x} 5$ as compared to a conventional liquid slurry reactor [85]. However, for applied work using external sunlight as source, either as a direct beam or re-directed and intensified by a concentrator, a planar rectangular microchannel array ('flatbed') can be just as effective. Micro-channel reactors provide a good framework for catalyst dispersion (shallow depths and narrow cross-sectional sub-division), and are proven to offer high efficiencies in solar synthesis applications [86].

Fig. 6 illustrates an example of a genuinely-structured sunlight-driven photo-thermo microreactor working in the field. Castedo et al. have exploited 3D printing to obtain broad-spectrum (UVVis-NIR) transparent silicone microreactors in both 9-channel and 32 channel ('scaled-out') versions, as shown in Fig. 6A $[83,84]$. These were compared in photo-dehydrogenation of flowing ethanol/water vapour mixtures over $\mathrm{Au} / \mathrm{TiO}_{2}$, in a laboratory set-up (inside an oven with LED lamp (UVA) irradiation), and in the field under concentrated sunlight from a parabolic dish (see Fig. 6B). Very respectable $\mathrm{H}_{2}$ evolution rates $\left(30-350 \mu \mathrm{mol}_{\text {. }} \mathrm{min}^{-1}\right.$ g.cat $\left.{ }^{-1}\right)$ were achieved over a range of temperatures from 323 to $423 \mathrm{~K}$ (the stability limit of the silicone) that resulted from optical heating in the solar concentrator system, as shown in Fig. 6C. Consistency in the apparent activation energies $\left(25 \pm 1 \mathrm{~kJ}^{\left.-\mathrm{mol}^{-1}\right)}\right.$ between the Lab-based and field systems (see Fig. 6C, insert) verified the operational rigour of the latter (large) assembly. Further consistency in the $\mathrm{H}_{2}$ evolution rates $(\sim 1$ 
mmol. $\mathrm{h}^{-1} \cdot \mathrm{cm}^{-2}$ ) between the 9- and 32-channel microreactors on an area-normalized irradiation basis was good evidence that a simple 'scaling-out' principle may apply to these modular devices.

\subsection{Photo-thermo reactors with resistive heating}

When external (resistive) heating is applied together with light irradiation, such a photo-thermo reactor in this type of configuration is typically insulated (opaque) so that the housing must incorporate a window of similar dimension and aspect ratio to those of the catalyst bed and the incident beam. It should preferably be made out of a strong thermal shock-resistant material like fused quartz. An example from the work of Han and Hu is shown in Fig. 7A, in which the catalyst is dispersed on a light-diffuse-reflection- $\mathrm{SiO}_{2}$ surface as substrate [87]. In another configuration from Ghuman et al., a borosilicate glass tubular reactor is heated by conduction using a copper block channel fastened within a custom-fabricated stainless steel brace, that enables reactor heating from the sides and below (Fig. 7B) [88].

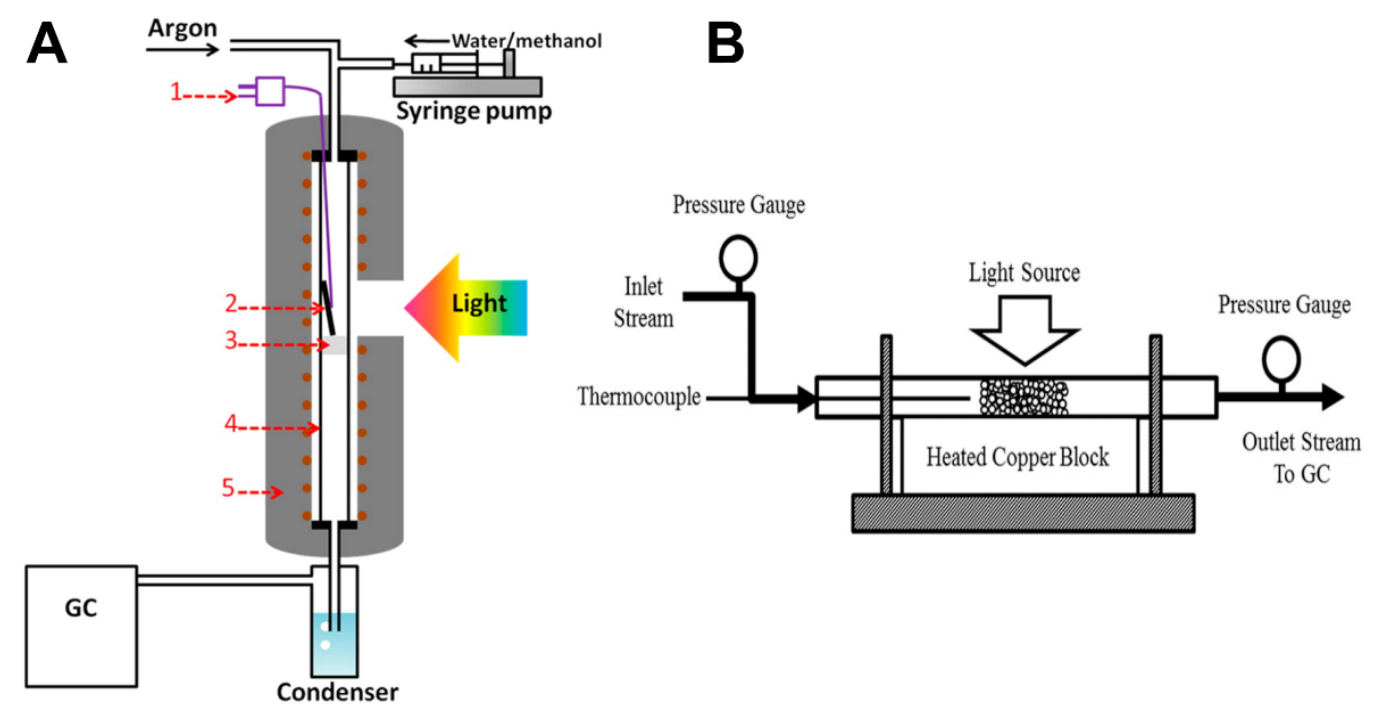

Figure 7. (A) Continuous flow annular thermo-photo reactor used for the temperature-induced photocatalytic $\mathrm{H}_{2}$ production from $\mathrm{H}_{2} \mathrm{O}$ with methanol as a sacrificial agent, with (1) thermocouple, (2) $\mathrm{Pt} / \mathrm{TiO}_{2}$ on $\mathrm{SiO}_{2}$ substrate (used as light diffuse-reflection-surface, (3) quartz wool, (4) quartz tube reactor, and (5) electrical tube furnace. (reproduced from ref [87] with permission of Elsevier). (B) Gas-phase thermo- 
photo catalytic packed bed flow reactor comprising a borosilicate tube ( $3 \mathrm{~mm}$ outer diameter and $2.5 \mathrm{~mm}$ inner diameter) packed with $1 \mathrm{~cm}$ length catalyst bed, with quartz wool as support at both ends. A heated copper block was used to heat the tubular reactor via conduction, while the top of the reactor was exposed to light irradiation from a Newport $300 \mathrm{~W}$ Xe lamp at a distance of $2 \mathrm{~cm}$, with a light intensity of 1000 $\mathrm{W} / \mathrm{m}^{2}$. (reproduced from ref [88] with permission of RSC).

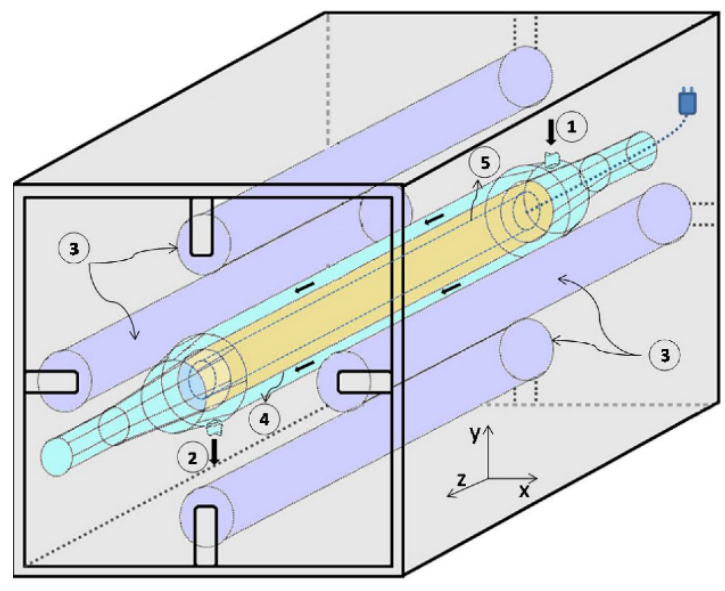

A

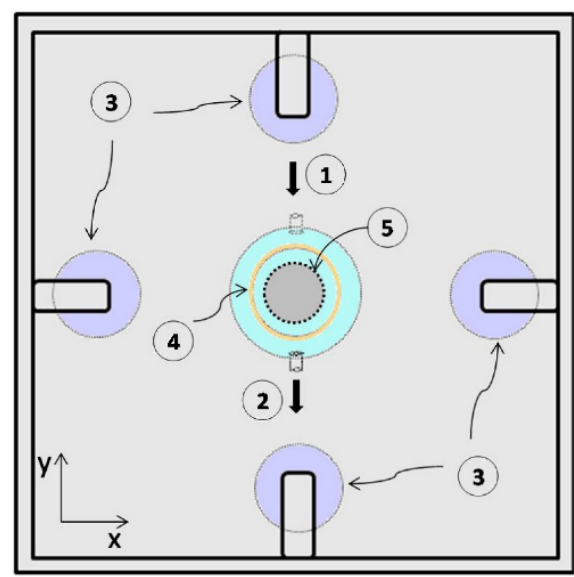

B

Figure 8. (A) Thermo-photo catalytic annular reactor proposed by the group of Fernandez, inside which the catalyst is deposited on the inner tube as a thin layer of controlled surface density. (B) Side section view. (1) Gas inlet, (2) gas outlet, (3) UV lamps symmetrically positioned outside the reactor, (4) catalyst sample as thin layer, (5) cartridge heater. (reproduced from refs [56,89] with permission of Elsevier).

Alternatively, a more holistic arrangement for light exposure is to make the reactor entirely out of a transparent material and incorporate narrow bands of heat element tracery. Unfortunately, quartz is a brittle material not so amenable to machining (shaping), and so Pyrex glass usually serves instead, despite having an optical (UV) absorption starting below $350 \mathrm{~nm}$. The group of Fernández-García developed a continuous flow annular Pyrex-glass thermo-photo-reactor using a centrally-positioned heater cartridge of extended length with a catalyst-coated inner wall $[56,89]$. As shown in Fig. 8, good illumination was achieved by 4 lamps symmetrically arrayed around the reactor. 
By contrast, thermo-photo reactors incorporating windows allow the main body to be fabricated from stainless steel, a tough and chemically inert material classically employed in thermal reactors, and suited particularly for high-pressure work, so that they can operate indifferently at atmospheric pressure or under pressure. The use of quartz windows also provides flexibility in regulating the optical properties (spectral range and intensity) of the incoming light, e.g., with interposition of monochromators, cold mirrors and/or various kinds of optical filters (long-pass, notch, cut-off, etc.).

\subsection{High Temperature (/pressure) reaction chambers}

Probably the most versatile and rugged commercial range of devices, originally designed for in-situ spectroscopic investigations of small powdered solid beds under extreme conditions, is the High-Temperature reaction chamber series available from Harrick Technology. When the sample

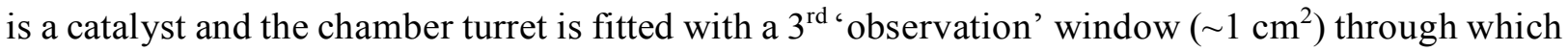
light may be directed (as from a lamp/filter/fibre optic combination) they serve admirably as microflow photo-thermo reactors. Built from stainless-steel alloy 316, models HVC-MRA-4 and -5 are the product of design evolution over 3 decades. By allowing operation in vacuo and/or up to 34.4 bar and $910^{\circ} \mathrm{C}$, they continue to prove invaluable in the hands of catalysis specialists, although it has to be stressed that at temperatures above $450^{\circ} \mathrm{C}$, the heater lifetime is significantly reduced, and they can only operate at the maximal temperatures under vacuum [69,90-92]. A snapshot of a typical plumbed-in Harrick device is shown in Fig. 9A. It is equipped with an external heating cartridge inserted underneath the sample holder in a vertical post arrangement, and with the option of a water-flow cooling system (to protect the window seals if necessary) and a K-type thermocouple in close contact with the catalyst bed for accurate temperature monitoring $\left( \pm 1^{\circ} \mathrm{C}\right)$. The prospect of conducting photo-thermo reactor testing along with in-situ or operando spectroscopic characterization (by Raman, FTIR, UV-Vis, etc.) of reaction mechanisms via intermediate(s) detection, reactant-induced surface (structural and/or electronic) changes, etc., is as exciting as it will be challenging. This is partly due to its easy integration into complex on-line flow analysis configurations 
allowing e.g., mass spectrometric (MS) detection of products at very low levels, as depicted in Fig. 9B.
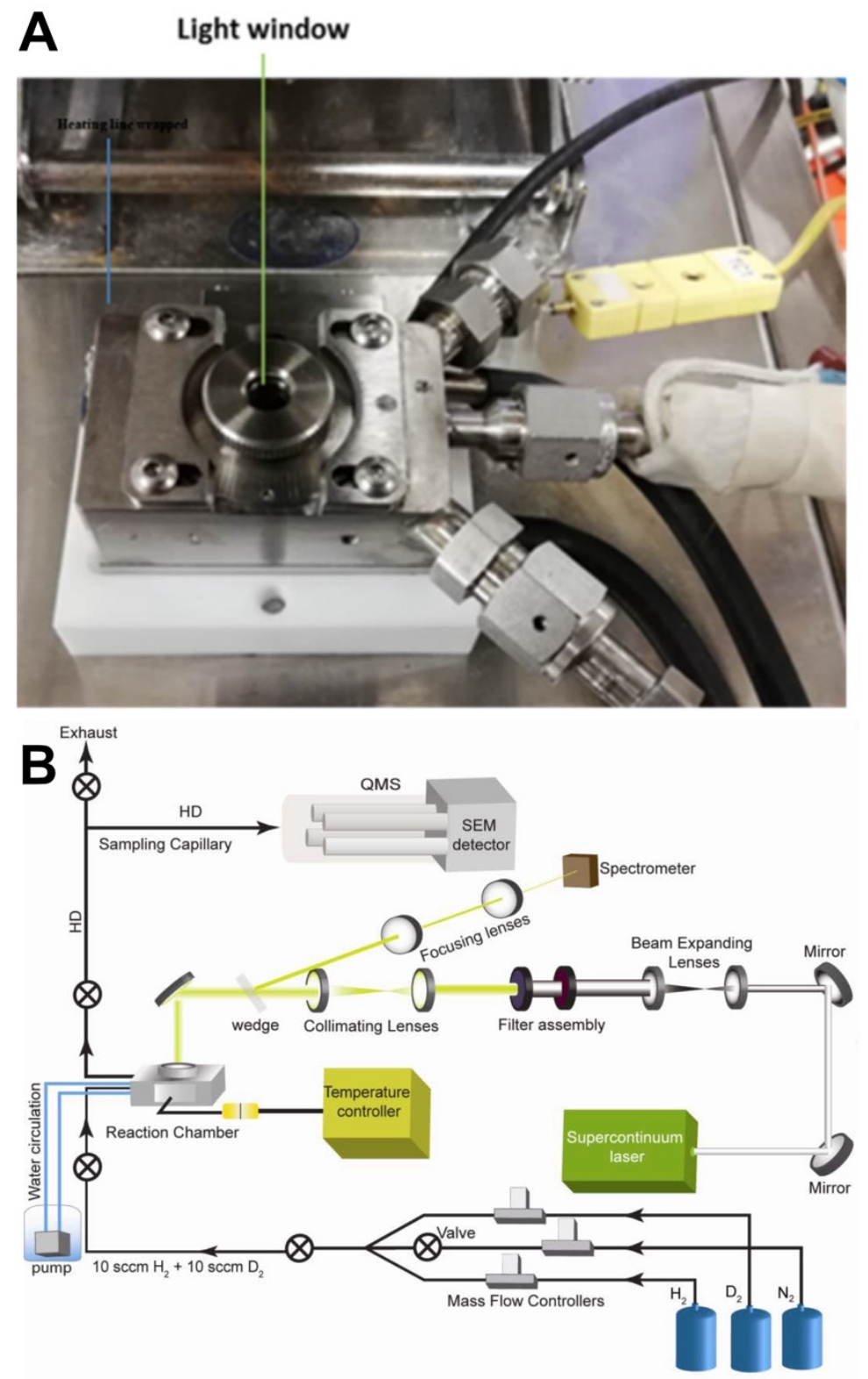

Figure 9. (A) Continuous flow high-pressure Harrick thermo-photo reactor (reproduced from ref [92]with permission of Nature Research). (B) Example of an overall experimental setup built around the flowthrough Harrick thermo-photo reactor, in which light intensity-dependent experiments are implemented using a set of neutral density filters, while wavelength dependence experiments are performed using different band-pass filters ranging from 500 to $800 \mathrm{~nm}$ in steps of $50 \mathrm{~nm}$ (reproduced from ref [93] with permission of ACS). 
(A)

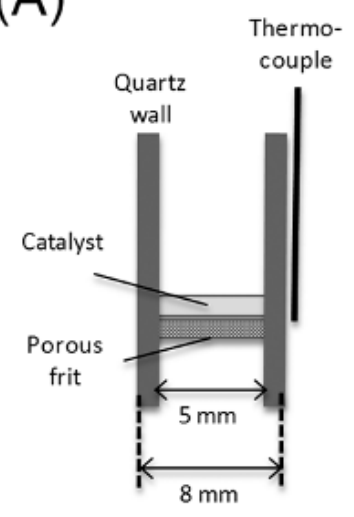

(C)

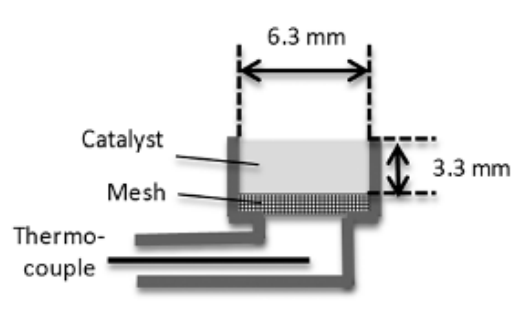

(B)

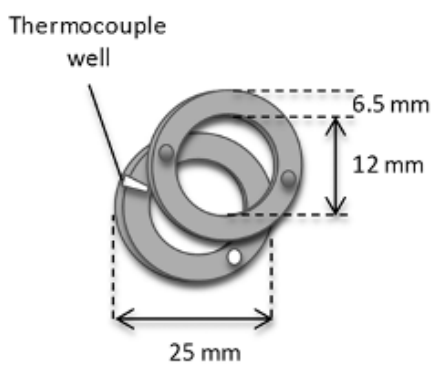

(D)

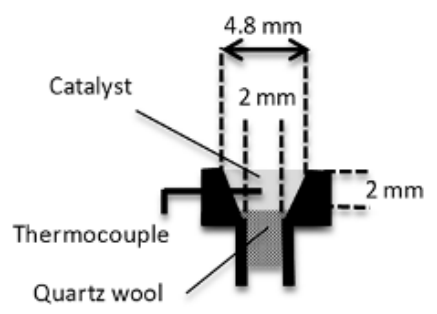

Figure 10. Schema of various catalyst bed configurations used by Li et al.: (A) in a conventional U-shaped quartz reactor, (B) in a "sandwich" transmission cell, (C) in the commercial Harrick DRIFTS cell and (D) in the commercial Spectra-Tech DRIFTS cell. (reproduced from ref [94] with permission of RSC).

However, as a caveat it must be pointed out that good temperature definition, i.e., lack of thermal gradients in the catalyst bed, for deriving accurate kinetic data is a serious challenge even having a well-positioned thermocouple in contact with the surface layer. The notoriously poor heat transport properties of powdered solids was the original motivation for implementing early solutions, such as the use of a continuous recycle reactor with a larger charge of catalyst in the loop having better temperature definition via tubular heating [95]. More recently, Li et al.[94] evaluated the temperature definition problem, and suggested effective correction methods, in studies on 3 different in-situ FTIR cells. These were of both diffuse reflectance (DRIFTS) and transmission 
modes, custom-built and supplied from commercial sources (Harrick and Spectra-Tech.). The geometric layout of the different configurations is shown schematically in Fig. 10. With the aid of an optical (IR) pyrometer, they revealed by surface emissivity measurements from the catalyst bed that these three IR cells showed a significantly lower temperature than that of the corresponding thermocouple located in or close to the sample bed. The discrepancy amounted to some 35 degrees $\left(\mathrm{T}_{\text {contr }}=280^{\circ} \mathrm{C}, \mathrm{T}_{\text {surf }}=245^{\circ} \mathrm{C}\right)$ in the Harrick cell, related mainly to the larger dimensions of its powdered bed (see Figs. 10C,D). The presence of significant thermal gradients, giving rise to variable effective mean reactor temperatures, were indicated by different methanation rates under identical (control) conditions. Fortunately, they also demonstrated that a systematic temperature correction was workable (e.g., $\mathrm{T}_{\text {eff }}=\mathrm{T}_{\text {contr }}-20^{\circ} \mathrm{C}$ for the Harrick cell) using calibration curves derived from rate measurements $\left(\mathrm{CO}\right.$ methanation over $\left.16 \mathrm{wt} \% \mathrm{Ni} / \mathrm{Al}_{2} \mathrm{O}_{3}\right)$ obtained in a traditional packed-bed tubular (non-spectroscopic) reactor having a well-defined temperature. However, more complex cases of competing reactions (selectivities $<100 \%$ ) having different activation energies are bound to result in indissolubly-mixed kinetics and unreliable data under such temperature gradients.

\section{Photothermal light-to-heat conversion-mechanisms and timescales}

The light-to-heat conversion processes involved in photothermal catalysis most popularly concerns plasmonic nanoparticles, and has its origin in the occurrence of non-radiative relaxation of plasmons, with the transfer of energy from photon-induced electronic excitations to lattice phonons. For a deeper understanding of the fundamental bases and underlying photophysics, the reader can consult the informative review of Ghoussoub et al.[28] in which the authors categorize the myriad processes involved as a function of their timescales, as depicted for a plasmonic oxidesupported metal in Fig. 11. These range from ultrafast processes $(<100 \mathrm{fs}$, mostly associated with light absorption and the resulting types of electronic excitation), fast processes (100 fs $-100 \mathrm{ps}$, charge separation/transfer phenomena, recombination, and certain types of non-radiative electronic 
relaxation) and slow processes ( $>100 \mathrm{ps,} \mathrm{heat} \mathrm{transfer} \mathrm{and} \mathrm{molecular} \mathrm{diffusion).} \mathrm{However,} \mathrm{it} \mathrm{should}$ be recognized that even these descriptions are only schemata of what is often a much more complex reality. Indeed, the reaction does not necessarily take place at the surface of the metal oxide support, but may also involve species that reside more selectively on the supported metal nanoparticles, e.g., $\mathrm{C}_{\mathrm{x}} \mathrm{H}_{\mathrm{y}} \mathrm{O}_{\mathrm{z}}$ intermediates that do not undergo "spillover", while the supported nanostructures even if in most cases are metallic - can also be semiconductors. 


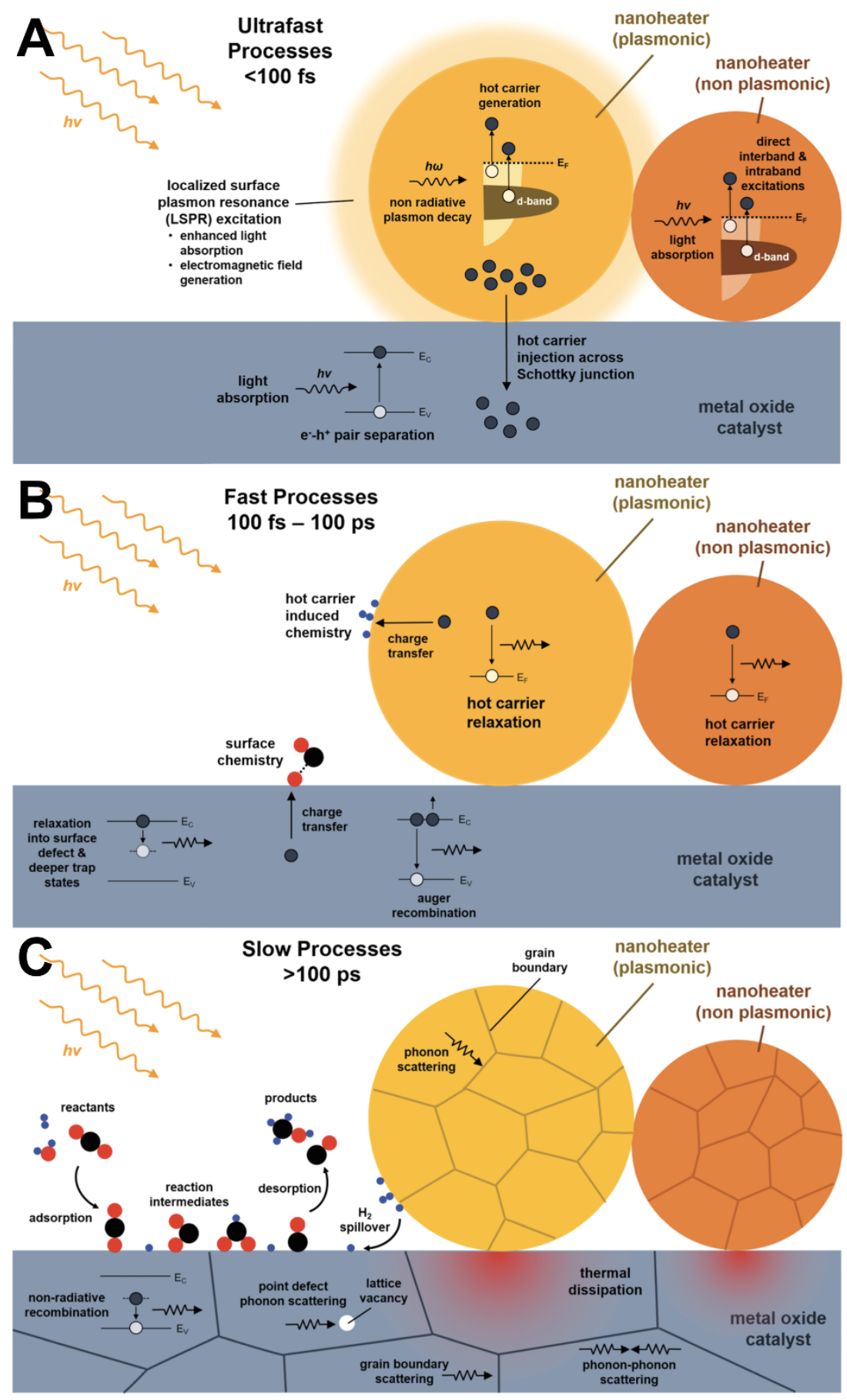

Figure 11. Scheme of the myriad photothermal processes occurring in a metal/metal oxide hetero-structured catalyst for $\mathrm{CO}_{2}$ hydrogenation under solar irradiation, categorized as (A) ultrafast ( $\left.<100 \mathrm{fs}\right)$, (B) fast $(100 \mathrm{fs}-100 \mathrm{ps})$ and $(\mathbf{C})$ slow $(>100 \mathrm{ps})$ processes. The metal nanoparticles are here denoted as "nanoheaters". The red, black and blue circles represent oxygen, carbon and hydrogen atoms, respectively, while the light-blue and navy colored circles represent holes and excited electrons within the nanoparticles (adapted and reproduced from ref [28] with permission of RSC). 
An alternative (complementary) scheme of the fundamental underpinning of the photothermal principle inherent in plasmonic nanoparticles is shown in Fig. 12. This details the sequence of events taking place at the nanoparticle level during light-to-heat conversion [96]. In a cascade-like mechanism, excitation of the metallic electron gas with photons at the resonance wavelength causes fast non-equilibrium heating, followed by sub-picosecond timescale relaxation through electronelectron scattering. This results in a fast increase in the surface temperature of the metal nanoparticle. Cooling to equilibrium subsequently occurs via energy exchange between lattice phonons and electrons. Within the first few hundred picoseconds following initial excitation, lattice cooling by means of phonon-phonon coupling allows the dissipation of heat into the surrounding environment. The light-to-heat conversion takes place therefore on the catalyst while the temperature of the reactant molecules is still lower than that of catalyst, making it different from that by furnace heating.

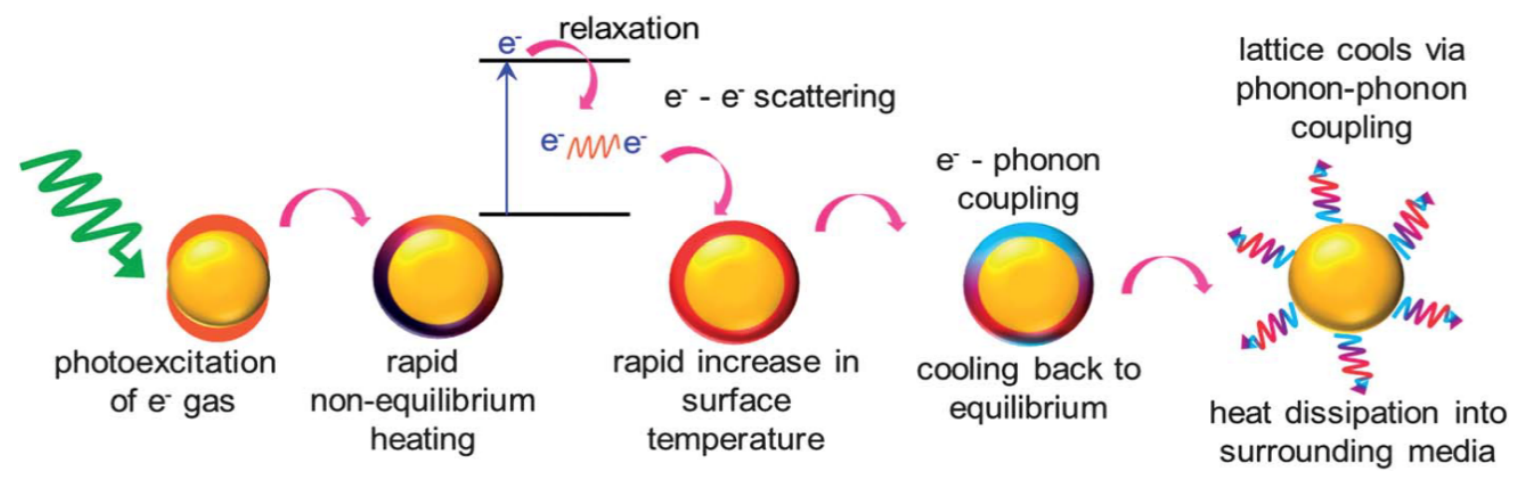

Figure 12. Schematized principle of the photothermal light-to-heat conversion with plasmonic nanoparticles (reproduced from ref [96] with permission of RSC).

A proper (quantitative) evaluation of thermal and non-thermal contributions in photo-thermo catalysis is of high importance, not only in fundamental terms by helping to unravel the reaction mechanism, but also as a practical guide in catalyst design, ultimately towards materials that perform well under milder and more sustainable conditions. The distinction (thermal vs. non-thermal) 
is not helped by inevitable confusion over the established terminology. So-called 'hot' electrons do not conform to Fermi-Dirac statistics (see Fig. 13) and introduce non-thermal effects by virtue of carrying excess electronic and vibrational energy not yet equilibrated (dissipated) into their surroundings.

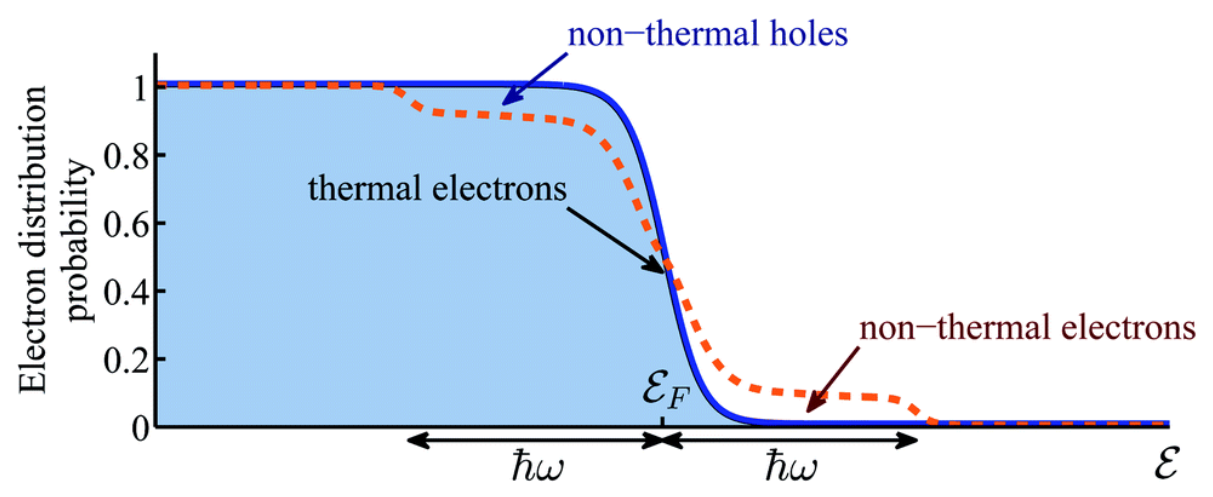

Figure 13. Schematic representation of the equilibrium (in the dark, blue line) and non-equilibrium (under illumination, dashed orange line) electron distribution. It is composed of thermal electrons near the Fermi energy which obey Fermi-Dirac Dirac statistics, and non-thermal ('hot') electrons in two ћ $\omega$-wide shoulders far from the Fermi energy which are not part of the Fermi-Dirac distribution. (reproduced from ref [97] with permission of RSC).

While many research articles claim that 'hot' electrons are the primary cause of catalytic bonddissociation over illuminated plasmonic metal nano-particles, this paradigm is coming increasingly under challenge. Following on from their earlier work, Dubi et al. have taken and re-evaluated the data from a number of seminal papers on plasmonic photocatalysis claiming to isolate the 'hot'electron contribution in some specific bond-dissociation reactions [97]. Apart from questioning the assumed (high) probabilities of hot electron generation in these works, they also found that refitting to a simple exponential (Arrhenius) form, i.e., attribution to a purely thermal effect, was quite convincing. Admittedly, this was with the proviso that the surface temperature was poorly measured, even by pyrometers, and actually underestimated by 5-10 degrees in some cases. This 
problem was exacerbated by the use of high-intensity irradiation selected to enhance any anticipated electronic (non-thermal) effects. Their argument has recently been moderated by Jain [98], showing that experimental data curves based on reasonable assumed values for either a thermal (Trise) or an electronic effect (lowering of the activation energy barrier) under illumination can be superimposable. Thus, ultimate resolution of this issue may need recourse to control experiments on strong non-plasmonic absorbers like carbon or metal blacks where only a thermal effect is expected. Selection of a highly temperature-sensitive model catalytic system to provide definitive evidence, e.g., via selectivity trends in parallel reactions of differing activation energies, will be of prime importance. In the interim, the existence and putative importance of "hot" electron effects in photocatalysis over plasmonic nanostructures remain open questions under debate [99-101].

We have to stress that the development of techniques allowing for accurate and precise surface temperature measurement remains a highly challenging objective. Work based on conventional thermocouples includes several reports of unexpectedly high ceiling temperatures attained under illumination (e.g., see Section 7.), so that nanoscale thermal measurements remain of huge importance in view of the discrimination between the thermo- and photo- chemical contributions to photo-thermo- catalysis. Recent advances towards this highly challenging objective have been made through the development of luminescent or highly advanced non-luminescent (indirect) methods (see e.g. Gascon and coll. [70]). For instance, scanning thermal microscopy with a nanoscale probe tip enabled surface temperature measurements with $10 \mathrm{~nm}$ spatial resolution and 10 $50 \mathrm{mK}$ accuracy $[102,103]$, while scanning transmission electron microscopy allows to obtain a resolution in the nanometre range by studying the influence of the temperature on the energy shift of plasmon peaks or the gain vs. loss phonon peaks in the electron energy spectrum $[104,105]$. Also, tip-enhanced Raman spectroscopy has been reported to enable mapping local temperature at a nanometre resolution by comparing Stokes and anti-Stokes Raman signals [106-109]. Targeting a more practical objective, an emerging alternative temperature sensor to consider is luminescence thermometry [110-112]. This non-invasive (remote) spatially-responsive optical probe of mean temperature across millimetre- thick (or micron- thick, depending on the distribution of rare-earth 
emitters) sample layer of finite area, ranging from the macroscopic $(\mathrm{cm})$ down to the nano-scale $(\mathrm{nm})$, is based on the reflection of light. Depending on the luminescence technique (e.g. thermoreflectance or optical interferometry), different temperature, spatial and temporal resolutions of local temperature can be obtained [113]. As such, it is less susceptible to anomalous readings at 'hot spots' that arise in reactor beds catalysing exothermic processes. Good thermal definition even allows for the exploitation of temperature gradients deliberately applied for beneficial aims, e.g., as in kinetic vs. thermodynamic control regulation in ammonia synthesis over a $\mathrm{Ru}-\mathrm{Cs} / \mathrm{MgO}$ catalyst [114].

\section{Photo-thermo- catalysis: a route towards improved industrial processing}

Here in the main section we present an overview of recent advances in photo-thermo catalysis, the default term we will use henceforth to describe simultaneous dual (photon- and heat) excitation of the catalyst and any synergies issuing from it. While many examples are taken from novel applications in the field of Energy and Environment, there is growing evidence that it will likely become standardized ultimately as the method of first choice (in catalyst screening) at the Discovery stage while providing impetus to $R \& D$ in the growing shift towards less energy-intensive and more sustainable ('greener') industrial processing. Synergies already reported can be quite unexpected in terms of a priori knowledge, e.g., thermo-photo enhanced Haber-Bosch ammonia synthesis $[115,116]$. There is insufficient scope in this review to cover its impact in applications focused on 'mainstream' environmental objectives such as air detoxification (e.g., mineralization of Volatile Organic Compounds like BTEX, aldehydes and alcohols; CO oxidation, etc.) or water remediation (with dye and phenol as refractory model substrates). For more detail on these, the reader may consult excellent recent reports by Colmenares et al. [31], Zeng et al. [43], Li et al. [117], Muñoz-Batista et al. [89], Fiorenza et al. [59], Hou et al. [55], Ma et al. [118], or Zhou et al.[119]. In this review, we focus instead on processes expected to be of strategic importance in the 
establishment of tomorrow's solar biorefineries, viz., on-site process hydrogen generation by oxygenate(s) reforming, high value-added (specialty) compounds by oxygenates conversion, $\mathrm{CO}_{2}$ reduction, and routes to renewable hydrocarbons (Fischer-Tropsch synthesis).

\subsection{Process $\mathrm{H}_{2}$ by Oxygenate Reforming}

A photocatalyst offers the unique ability to drive endergonic (thermodynamically uphill) processes that convert and store light energy in new chemical bonds. Reforming of oxygenates into hydrogen-rich mixtures are consequently good candidate reactions for taking advantage from any light assistance, as well as in a broader perspective any process involving a dehydrogenation component that are of interest for producing high value-added chemicals. For instance, ethanol steam reforming (ESR) and ethanol-to-1,3-butadiene (ETB) both proceed through the rate-determining preliminary step of dehydrogenation into acetaldehyde, itself a mildly endothermic reaction with good prospects for light-to chemical energy conversion.

Using methanol as low carbon-content oxygenate as $\mathrm{H}_{2}$ source, Highfield et al. demonstrated that mild heating $\left(\mathrm{T}<70^{\circ} \mathrm{C}\right)$ during the band-gap illumination of a photo-deposited $\mathrm{Pt}$ on $\mathrm{TiO}_{2}$ catalyst raised the quantum efficiency for photo-reforming of aqueous methanol vapor by a factor of $\sim 5$ to $\Phi=0.07$ [120]. They proposed a rationalization of the photo-/thermal synergy based mainly on in-situ DRIFTS studies. In the absence of any dark activity, illumination served to activate a new photo-mechanism but one in which the rate-determining step was of the 'dark' type. In this mechanism (an example of Type A), the initial photo-product, formaldehyde, underwent a sequence of dark processes, starting with the $\mathrm{TiO}_{2}$-promoted Cannizzaro disproportionation, yielding formate and methoxy species already at $40^{\circ} \mathrm{C}$. While methoxy was effectively cycled back to the initial photo-dehydrogenation stage, the slow step was identified as formate decomposition to $\mathrm{H}_{2}$ and $\mathrm{CO}_{2}$ (see Fig. 14A). The low value measured for the apparent activation energy $(40 \mathrm{~kJ} / \mathrm{mol})$ was taken as supporting evidence for 'water-assisted destabilization' of formate, i.e., a transition state that includes water coordinated with the adsorbed formate, as originally reported by Shido and Iwasawa [121,122]. 

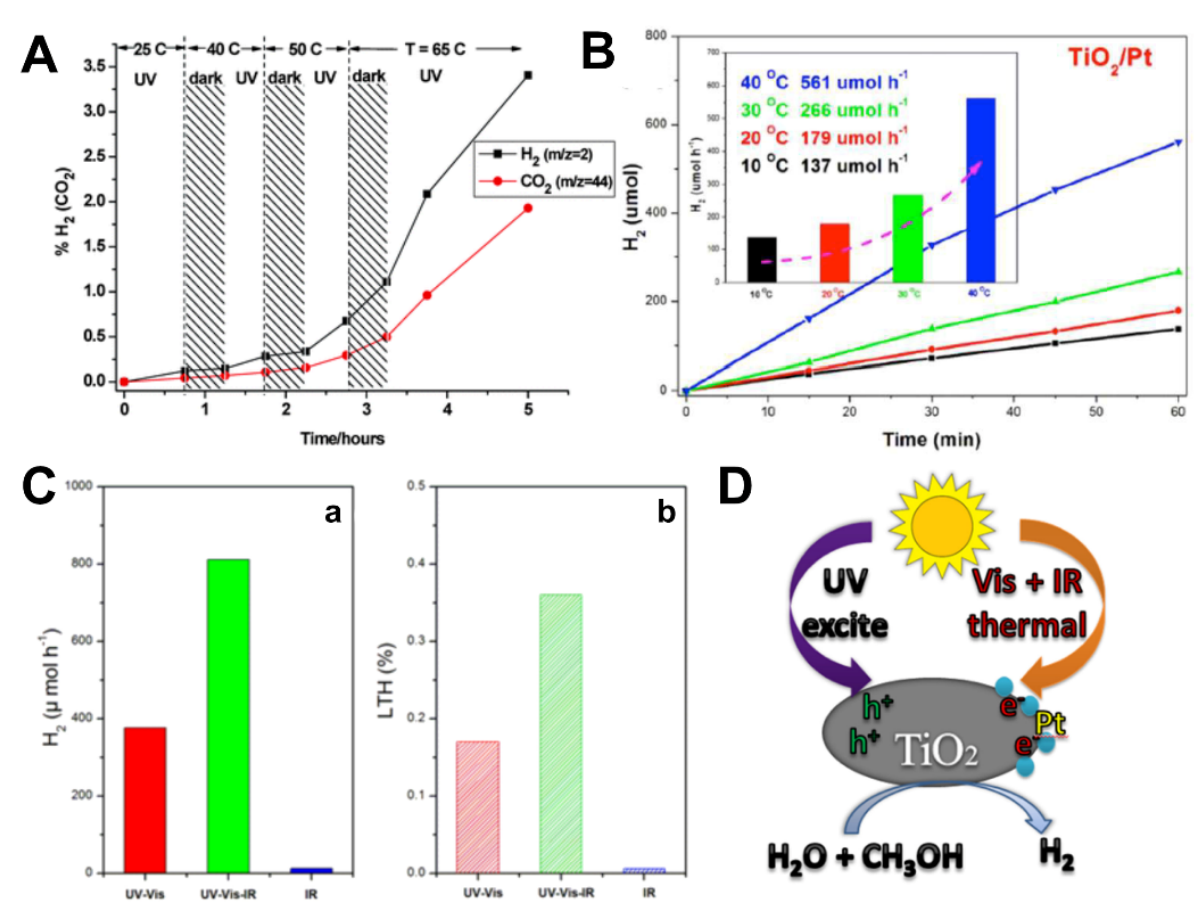

Figure 14. (A) Temperature effect on $\mathrm{H}_{2} / \mathrm{CO}_{2}$ evolution rates in photo-reforming of aqueous $\mathrm{CH}_{3} \mathrm{OH}$ over $\mathrm{Pt} / \mathrm{TiO}_{2}$ catalysts(reproduced from ref [120] with permission of RSC) ; (B) Influence of the temperature (external heating) in the $10-40^{\circ} \mathrm{C}$ range on the photocatalytic activity for $\mathrm{H}_{2}$ production from a methanolwater $(10 \% \mathrm{v} / \mathrm{v})$ solution upon UV-vis light $(320-800 \mathrm{~nm})$ over a $\mathrm{Pt}(1 \mathrm{wt} . \%) / \mathrm{TiO}_{2}$ catalyst (reproduced from ref [123] with permission of RSC) ; (C) Influence of the light spectrum (UV-Vis, UV-Vis-IR and IR) on the solar catalytic $\mathrm{H}_{2}$ generation from methanol-water solution over $\mathrm{Pt} / \mathrm{TiO}_{2}$ (in optimal amount of $50 \mathrm{mg}$ ) in terms of a) $\mathrm{H}_{2}$ production and b) light to hydrogen (LTH) conversion efficiency; (D) Associated $\mathrm{H}_{2}$ production mechanism upon UV-Vis-IR full spectrum irradiation (adapted and reproduced from ref [124] with permission of Elsevier).

This finding of a positive effect of heating in a photocatalytic process was soon corroborated by several new reports in the literature. Among them, Ye et al. nicely demonstrated that whereas photocatalytic activity in methanol reforming $\left(\mathrm{H}_{2}\right.$ generation $)$ over pristine $\mathrm{TiO}_{2}$ under $\mathrm{UV}$-vis light was low $\left(<2 \mu \mathrm{mol} . \mathrm{h}^{-1}\right)$ and actually decreased with rise in temperature from 10 to $40{ }^{\circ} \mathrm{C}$ (see Fig. 14B), loading of 1 wt. \% Pt onto $\mathrm{TiO}_{2}$ raised the activity one hundred-fold and established a positive 
(Arrhenius-type) thermal response over the same temperature range (Fig. 14C) [123]. They interpreted the synergism in light-heat co-induced $\mathrm{H}_{2}$ production by suggesting that $\mathrm{Pt}$ acted simultaneously as co-catalyst for the $\mathrm{TiO}_{2}$ photocatalyst (to enhance the photo-induced charge carrier separation efficiency upon UV illumination), and in its own right as thermal supported noble metal catalyst for (dark) methanol dehydrogenation. They surmised that the overall process efficiency should benefit from broad-band illumination by the entire solar spectrum, in which the short (UV) and longer (vis-IR) wavelength envelopes would in consequence also act in synergy, the second providing thermal enhancement of the catalytic $\mathrm{H}_{2}$ production by localized optical heating. In follow-up work [124], the same team demonstrated that optical heating, especially by inclusion of the infrared component, was powerful and efficient enough to render external resistive heating unnecessary. Full-spectrum (UV-vis-IR) irradiation raised the reactor temperature to $54^{\circ} \mathrm{C}$ (from $35^{\circ} \mathrm{C}$ under UV-vis light), thereby doubling the $\mathrm{H}_{2}$ production rate to $25 \mathrm{mmol}$.g.cat ${ }^{-1} \mathrm{~h}^{-1}$. Under panspectral excitation, they propose a fortuitous combination of photocatalysis (via electrons generated upon UV-A excitation of $\mathrm{TiO}_{2}$ being transferred to surface Pt particles to reduce protons), while only the dark process of methanol oxidation (proceeding independently and in parallel) is enhanced by the heat provided by the vis-IR light (Fig.14D). Readers must note that this interpretation (involving two parallel processes with different activation modes) is quite different to that attributed to the same reaction (a single sequence with coupled photo-/thermo activation - Type A) by Highfield et al. [120].

The use of the oxygenate methanol for producing $\mathrm{H}_{2}$ is naturally not limited to reactions in the liquid state. Even higher quantum efficiencies (and $\mathrm{H}_{2}$ evolution rates) have been reported in vapour-phase work up to $300^{\circ} \mathrm{C}$ by $\mathrm{Han}$ and $\mathrm{Hu}$ [87]. The authors claimed that their catalyst is based on 'black' $\mathrm{TiO}_{2}$, a surface disorder-engineered material obtained by high-pressure hydrogenation of $\mathrm{TiO}_{2}$ nanocrystals in temperature under $\mathrm{H}_{2}$, that caused a media stir upon discovery a decade ago [125], even though interest cooled thereafter and debate is still open on this subject. However, it must be stressed that the $\mathrm{H}_{2}$ treatment of their $\mathrm{Pt} / \mathrm{TiO}_{2}$ catalyst was not performed at high pressure. Over 1 wt $\% \mathrm{Pt} / \mathrm{TiO}_{2}$, the rate of $\mathrm{H}_{2}$ evolution reached $700 \mathrm{mmol} \cdot \mathrm{h}^{-1} \mathrm{~g}^{-1}$ at $280^{\circ} \mathrm{C}$ with an 
overall (AM 1.5) quantum efficiency $\Phi=0.78$, corresponding to a 5 -fold photo-enhancement of a dark process offering a viable rate by thermal activation alone. A detailed graphical summary is given in Figs. 15A-D.
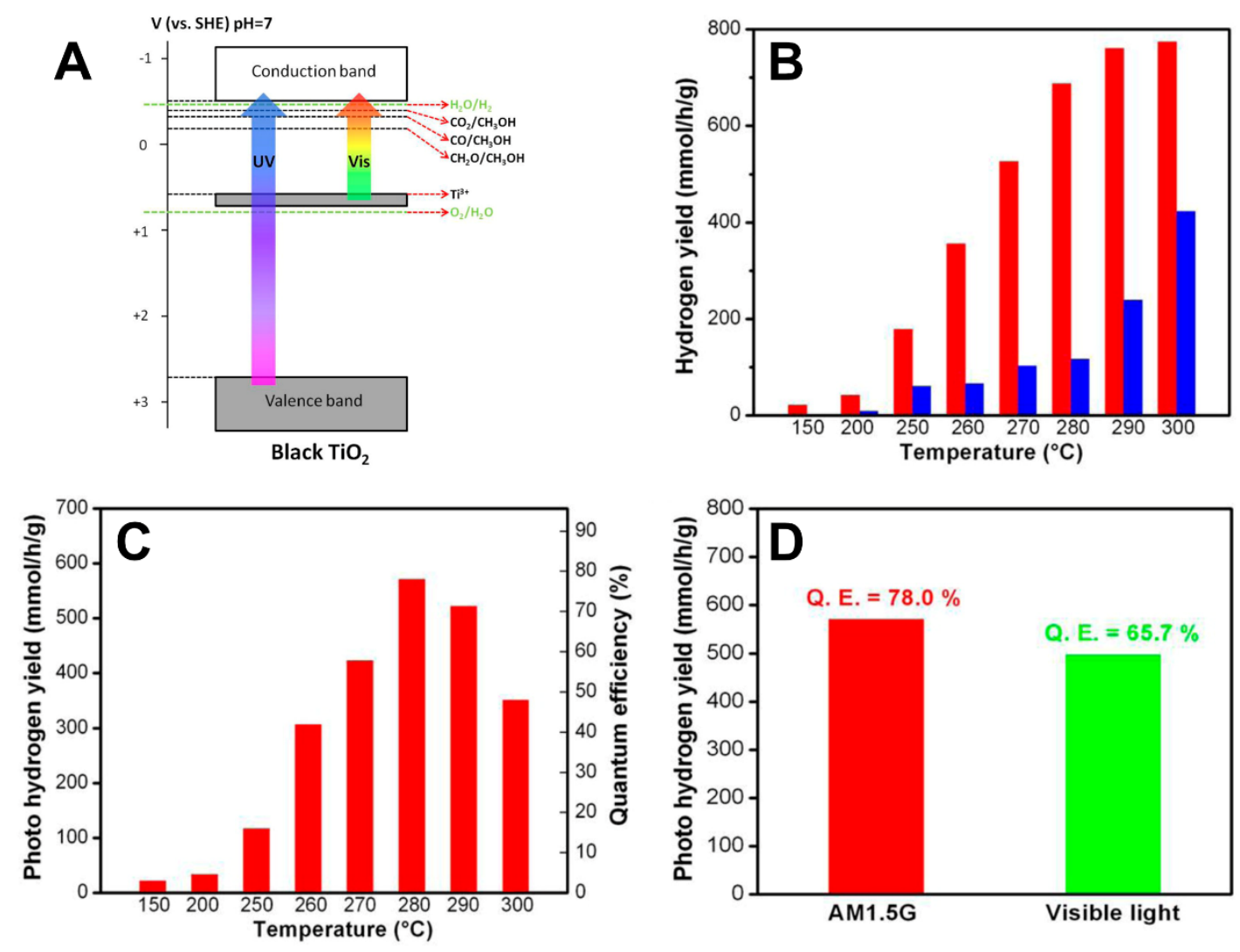

Figure 15. (A) Relationship between band structure of $\mathrm{H}_{2}$-treated $\mathrm{TiO}_{2}$ used in $\mathrm{Han}$ and $\mathrm{Hu}$ [87] and redox potentials of water splitting with methanol as a sacrificial agent.The absorption of UV generates the excitation of electrons from valence band $(\mathrm{VB})$ of $\mathrm{TiO}_{2}$ to its conduction band $(\mathrm{CB})$, whereas the absorption of visible light is associated with the excitation of electrons from the donor $\left(\mathrm{Ti}^{3+}\right)$ level to $\mathrm{TiO}_{2} \mathrm{CB}$. (B) Hydrogen yield $v s$ reaction temperature over $\mathrm{Pt} / \mathrm{TiO}_{2}$ catalyst without light illumination (blue bar) and with AM 1.5 global sunlight illumination (red bar) in the temperature-enhanced photocatalytic hydrogen production from $\mathrm{H}_{2} \mathrm{O}$ with a sacrificial agent (30\% methanol) ; (C) Photo hydrogen yield (equal to the difference of hydrogen yields with and without light irradiation) and apparent quantum efficiency $v s$ reaction 
temperature under AM 1.5 global sunlight illumination; (D) Photo hydrogen yields and apparent quantum efficiencies of visible light and AM 1.5 global sunlight at $280^{\circ} \mathrm{C}$. (adapted and taken from ref [87] with permission of ACS).

Photo-thermo-catalysis of steam reforming of methanol (SRM), targeting syngas $\left(\mathrm{CO} / \mathrm{H}_{2}\right)$ production, was explored over a $\mathrm{SrTiO}_{3}$ supported Pt catalyst by Han et al. (Fig. 16) [126]. Highly dispersed Pt at 1-3 wt.\% loading, acted as both co-catalyst and, due to its quasi-continuum absorption across the vis-NIR region, a thermal sensitizer, enabling the reactor temperature to reach $150^{\circ} \mathrm{C}$ in the absence of external heating under illumination from a $300 \mathrm{~W}$ Xe lamp at $530 \mathrm{~mW} / \mathrm{cm}^{2}$ ( $\sim 5$ suns). The use of bandpass filters showed that most of the heating effect was due to absorption of the NIR component beyond $800 \mathrm{~nm}$. Sustainable and high $\mathrm{H}_{2}$ evolution rates $\left(\sim 1 \mathrm{mmol} . \mathrm{h}^{-1}\right.$ over $100 \mathrm{mg}$ catalyst) at such a low temperature, roughly $3-4 \mathrm{x}$ higher than the analogous $\mathrm{SiO}_{2}$-supported Pt control, was clear evidence of substantial photo-assistance. In batch recirculation tests, a high methanol conversion of $95.5 \%$ was attained over $3 \% \mathrm{Pt} / \mathrm{SrTiO}_{3}$, with a peak (initial) selectivity of 94.4\% towards syngas. However, growing interference from parasitic reactions was evident, redirecting the product distribution towards $\mathrm{H}_{2} / \mathrm{CO}_{2} / \mathrm{CH}_{4}$, probably via the onset of Sabatier and Water Gas Shift reactions:

$\mathrm{CO}+3 \mathrm{H}_{2} \rightarrow \mathrm{CH}_{4}+\mathrm{H}_{2} \mathrm{O}$
$\mathrm{CO}+\mathrm{H}_{2} \mathrm{O} \rightarrow \mathrm{CO}_{2}+\mathrm{H}_{2}$

Despite this complication, the authors proposed that the degrading selectivity issue may be mitigated by conducting the photothermal SRM reaction within a flow-type reactor at low contact time rather than in a closed gas circulation system. 

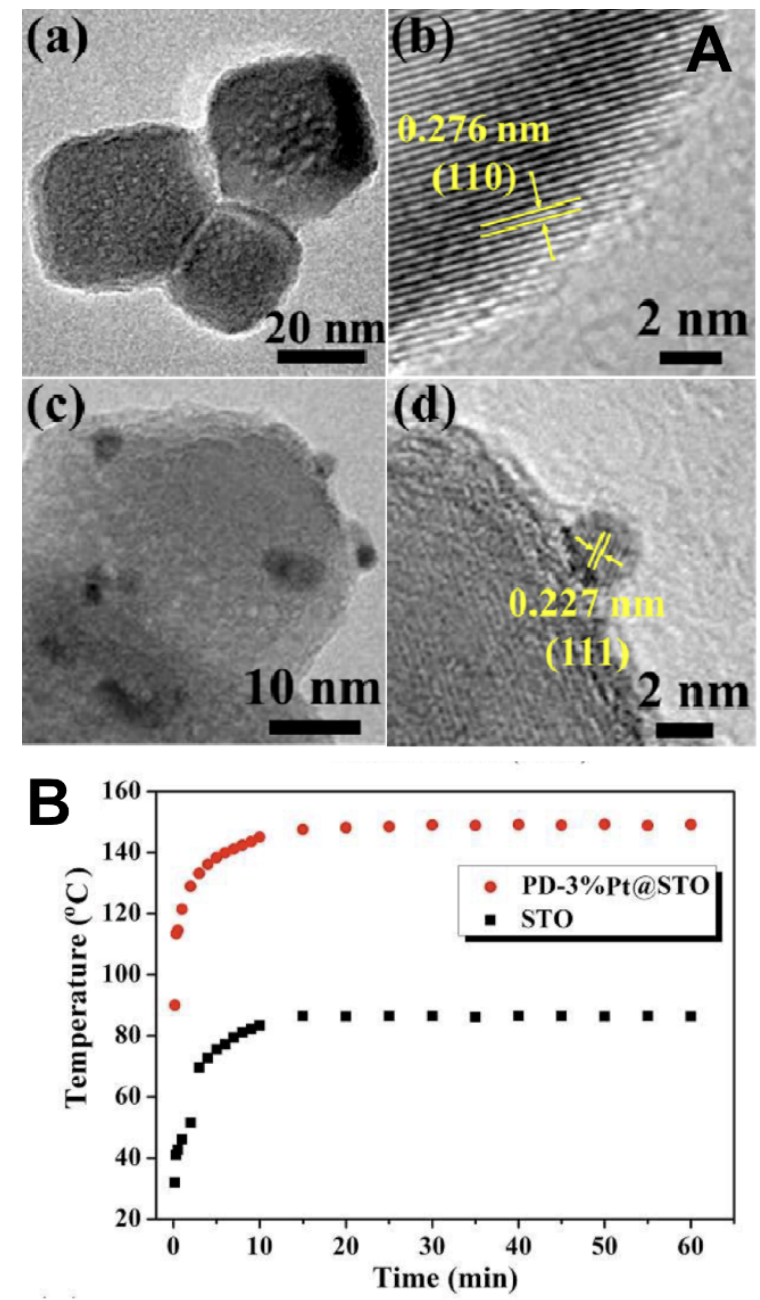

Figure 16. (A) Transmission electron microscope (TEM) images of the $\mathrm{SrTiO}_{3}$ semiconductor support $(\mathbf{a}, \mathbf{b})$ and of the $3 \% \mathrm{Pt} / \mathrm{SrTiO}_{3}$ photothermal catalysts prepared by the photodeposition method in anaerobic conditions using $\mathrm{H}_{2} \mathrm{PtCl}_{6}$ as metallic precursor in a mixed methanol/water solution (c,d). (B) Temperature monitoring over the bare $\mathrm{SrTiO}_{3}$ support (STO) and the $3 \% \mathrm{Pt} / \mathrm{SrTiO}_{3}$ photo-thermo- catalysts under light irradiation. Adapted and reproduced from ref [126] with permission of RSC)

Caudillo-Flores et al. recently used their 4-lamp array photoreactor (see section 4.3) to assess the photo-thermo synergy in reforming of aqueous methanol vapour over $\mathrm{Ru}$-supported anatase $\mathrm{TiO}_{2}$ catalysts $(1-10 \mathrm{wt} . \% \mathrm{Ru}$, mean size $=2.5 \mathrm{~nm})$ in continuous flow mode via combined $\mathrm{UV}-\mathrm{A}$ light and external (resistive) heating (Fig. 17) [56]. They quantitated any synergism on the basis of 'excess' values (rates and quantum efficiencies, QE), given by the difference between the number 
of hydrogen molecules per unit area per unit time as compared to the sum of individual rates from each activation mode applied separately. Although the performances obtained with their $\mathrm{Ru} / \mathrm{TiO}_{2}$ catalysts and notably the excess reaction rate resulting from the combined UV-A light/thermal excitation of the catalysts were by far lower than those reported by Han and $\mathrm{Hu}$ with a $\operatorname{Pt}\left(1 \mathrm{wt} . \% \% / \mathrm{TiO}_{2}\right)$ catalyst under solar light, nevertheless they identified a strong synergy in coexcitation where the excess values reached maxima at $240^{\circ} \mathrm{C}$, as shown in Figs. $17 \mathrm{C}$ and $17 \mathrm{D}$. Heating above $200^{\circ} \mathrm{C}$ enhanced the QE in photo-reforming (over ambient) by two orders of magnitude to $\Phi \approx 0.12$ (Fig. 17B), while addition of illumination increased the dark rate at $240^{\circ} \mathrm{C}$ by $40-50 \%$. They attributed the synergy to the promotion of individual steps in the same overall mechanism, as studied by DRIFTS, in which a progressive conversion of methanol to CO occurs via formaldehyde and formate-type surface species, followed by water-gas shift conversion to $\mathrm{H}_{2}$ and $\mathrm{CO}_{2}$
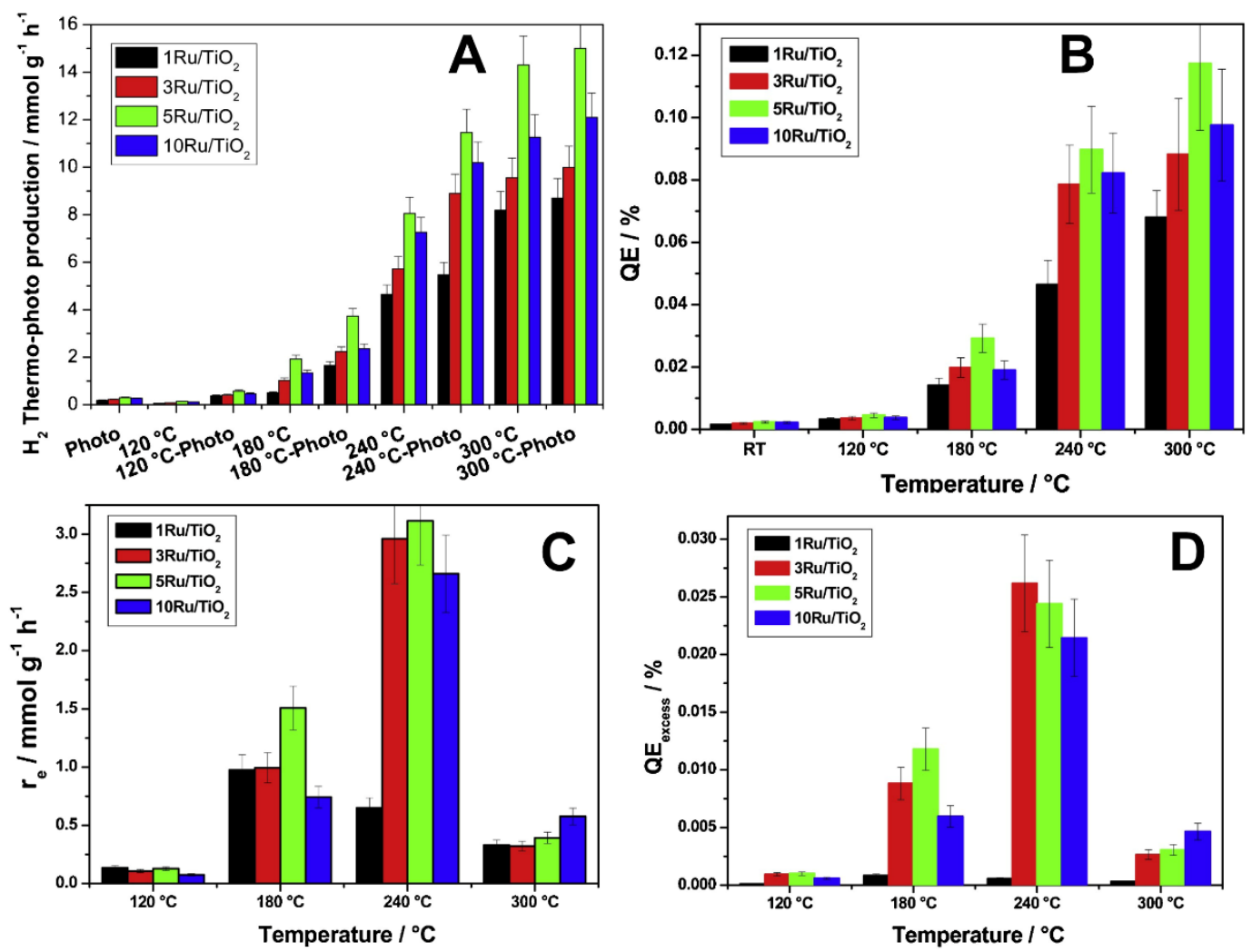
Figure 17. Influence of the reaction temperature (RT to $\left.300^{\circ} \mathrm{C}\right)$ on $(\mathbf{A})$ reaction rate; (B) Quantum Efficiency $(\mathrm{QE}) ;(\mathbf{C})$ excess reaction rate; and (D) excess Quantum Efficiency in the thermo-photo production of $\mathrm{H}_{2}$ from $\mathrm{CH}_{3} \mathrm{OH}: \mathrm{H}_{2} \mathrm{O}=3: 7(\mathrm{v} / \mathrm{v})$ over $\mathrm{Ru} / \mathrm{TiO}_{2}$ catalysts (reproduced from ref [56] with permission of Elsevier).

Interestingly, Fang et al. achieved a 1500 -fold enhancement in the $\mathrm{H}_{2}$ production rate obtained from methanol/water mixtures under visible light irradiation $(\lambda>420 \mathrm{~nm})$ when operating a $\mathrm{Rh}(1 \mathrm{wt} . \%) / \mathrm{TiO}_{2}$ (photo)catalyst at the temperature of $260^{\circ} \mathrm{C}$, in comparison to the corresponding rate measured at room temperature [127]. With the help of isotopic labelling experiments, they suggested that methanol used as sacrificial agent was the main provider of $\mathrm{H}_{2}$ at room temperature, while the coupling of thermal and photo energies resulted in the $\mathrm{H}_{2}$ production mainly from water. In addition to a change of reaction pathway of $\mathrm{H}_{2}$ production that would result from operating the catalyst above the water boiling point with in consequence a favored reduction of water instead of protons, the authors putted forward a double synergetic role of energies. First, the thermal (kinetic) energy introduced by elevating the reaction temperature could increase the oxidation driving force and thus improved the photocatalytic efficiency under visible light irradiation. Second, the authors suggested that the presence of light might influence the surface structure of the catalyst, and the photo energy in turn could accelerate thermal catalysis by reducing the naturallyoccurring oxidized layer at the surface of the Rh nanoparticles, and further enhancing the interaction between the $\mathrm{TiO}_{2}$ support and the $\mathrm{Rh}$ co-catalyst.

From the perspective of global resource sustainability, there is now an encouraging trend towards the use of cheaper, earth-abundant non-noble metals as viable co-catalysts for $\mathrm{H}_{2}$ production. In this frame, Fang et al. explored a low-cost $\mathrm{NiO}_{\mathrm{x}}$ (metal core/oxide shell) on $\mathrm{TiO}_{2}$ in the same photo-thermo-reforming reaction, using Aeroxide $\mathrm{TiO}_{2} \mathrm{P} 25$ as support, with a final reductive treatment at $500^{\circ} \mathrm{C}$ under $\mathrm{H}_{2}[60]$. The optimal catalyst contained 5 wt. $\% \mathrm{Ni}$, and achieved a $\mathrm{H}_{2}$ evolution rate of $54 \mathrm{mmol} / \mathrm{h} / \mathrm{g}$.cat under simulated $\mathrm{AM} 1.5 \mathrm{G}$ sunlight at $260{ }^{\circ} \mathrm{C}$, a factor of 2.5 greater than the dark rate. Apparent quantum efficiencies (AQE) were wavelength-dependent, ranging from $66 \%$ at $380 \mathrm{~nm}$ but falling to $15 \%$ at $500 \mathrm{~nm}$. Nonetheless, visible-light excitation still generated $\mathrm{H}_{2}$ at a rate $(27 \mathrm{mmol} / \mathrm{h} / \mathrm{g}$.cat $) 5$ orders of magnitude greater than at room temperature. In 
mechanistic investigations, isotope tracer experiments underlined that the enhancement of the $\mathrm{H}_{2}$ production upon light irradiation was mainly by H-atom abstraction from water rather than dehydrogenation or reforming of methanol. According to their proposed band energy scheme (Fig. 18A), heating increased the oxidation driving force of electrons responsive to visible light, i.e., those occupying shallow mid-gap states in their $\mathrm{TiO}_{2}$ support [125].

A similar noble metal-free Ti@ $\mathrm{TiO}_{2}$ core-shell catalyst, composed of 20-80 nm diameter quasispherical Ti particles coated by 5-15 nm crystals of defect-free anatase (with small amounts of rutile), was reported to exhibit a strong photo-response extending from the UV to the NIR region, seemingly as a result of broad-band absorption by the non-plasmonic metallic Ti core (Fig. 18B) [128]. Using isotopic studies with methanol- $\mathrm{D}_{2} \mathrm{O}$ solutions, Nikitenko et al. proposed a mechanism involving a Ti inter-band transition followed by charge transfer to the semiconducting $\mathrm{TiO}_{2}$ shell through the core/shell junction. The best catalytic performance in $\mathrm{H}_{2}$ evolution from water using methanol $(25 \%)$ as sacrificial reagent was observed under the joint effect of Vis/NIR light, at an incident irradiance of $0.5 \mathrm{~W} / \mathrm{cm}^{2}$ (absorbed power $=0.38 \mathrm{~W} / \mathrm{mL}$ ), with mild heating to $60{ }^{\circ} \mathrm{C}$. The low value estimated for the apparent activation energy $\left(17 \pm 4 \mathrm{~kJ} \mathrm{~mol}^{-1}\right)$ implied that the heating effect is possibly linked with a diffusional process (intermediate migration) as rate-limiting. However, since the oxidation (of methanol) was arrested at formic acid, the overall process appears as only partial reforming. 

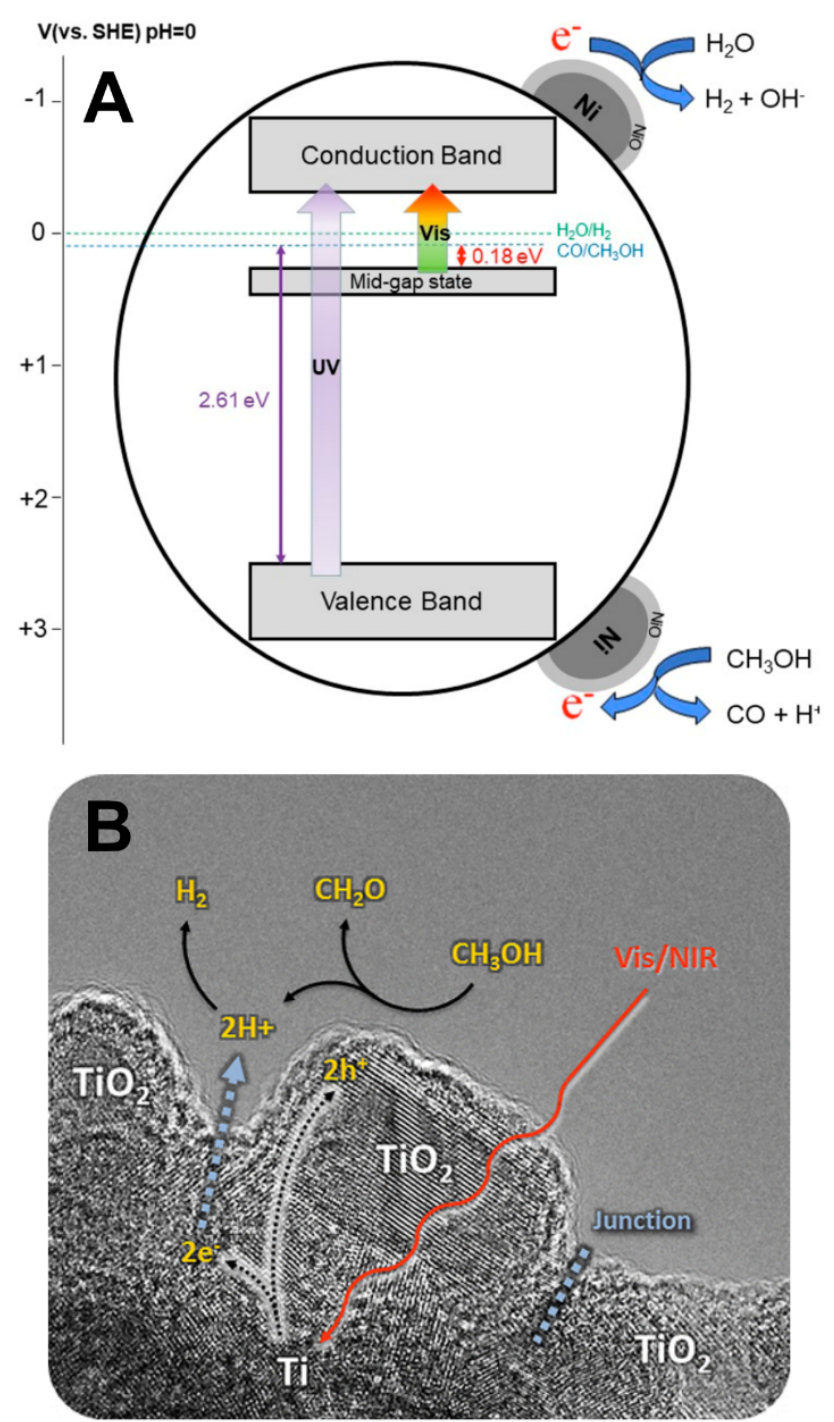

Figure 18. (A) Schematic reaction mechanism of thermo-photo catalysis on $\mathrm{NiO}_{\mathrm{x}} / \mathrm{TiO}_{2}$ catalyst using $\mathrm{CH}_{3} \mathrm{OH}: \mathrm{H}_{2} \mathrm{O}$ mixture (reproduced from ref [60] with permission of ACS) ; (B) Noble metal-free core-shell $\mathrm{Ti} @ \mathrm{TiO}_{2}$ junction photocatalyst prepared by the sono-hydrothermal crystallization in water of defect-free $\mathrm{TiO}_{2}$ nanocrystals at the surface of air-passivated metallic Ti nanopowders (reproduced from ref [128] with permission of ACS).

While photo-thermal synergies have been found to operate in ethanol oxidation, notably in studies by Amal and co-workers [42], enhancement of its potential as a H-source, e.g., as in ethanol steam reforming (ESR - eqn.3) along with other sustainable bio-oxygenates, has not been reported to date. 


$$
\mathrm{C}_{2} \mathrm{H}_{5} \mathrm{OH}_{(\mathrm{g})}+3 \mathrm{H}_{2} \mathrm{O}_{(\mathrm{g})} \rightarrow 2 \mathrm{CO}_{2}+6 \mathrm{H}_{2} \quad\left[\Delta \mathrm{H}^{0}=+174 \mathrm{~kJ} / \mathrm{mol}\right]
$$

In the case of ethanol, this is somewhat surprising as any advances may potentially have high impact due to activity/selectivity issues restricting progress in state-of-the-art thermal catalysis. Reforming typically operates more than $200^{\circ} \mathrm{C}$ above the thermodynamic threshold temperature, i.e., $>400{ }^{\circ} \mathrm{C}\left(\Delta \mathrm{G}^{0} \approx 0\right.$ at $\left.210^{\circ} \mathrm{C}\right)$ and the Co-based catalysts inevitably suffer from rapid deactivation by coking [129]. However, the first step in the ESR mechanism is dehydrogenation of ethanol to acetaldehyde:

$$
\mathrm{C}_{2} \mathrm{H}_{5} \mathrm{OH}_{(\mathrm{liq})} \rightarrow \mathrm{CH}_{3} \mathrm{CHO}+\mathrm{H}_{2} \quad\left[\Delta \mathrm{H}^{0}=+85 \mathrm{~kJ} / \mathrm{mol}\right]
$$

This is a mildy endothermic reaction offering good prospects for light-to-chemical energy storage by exploiting photonic excitation. Such studies appear especially opportune as a high energy barrier is associated with the dark process [130]. While their earlier photocatalytic studies at ambient temperature were conducted over anatase-supported $\mathrm{Au},[131]$ recent investigations by Nadeem and Idriss [132] have focused on the effect of heating on UV- irradiated nanosized $(<10$ nm) Ag at 3 wt $\%$ loading on the bi-phasic $\mathrm{P} 25 \mathrm{TiO}_{2}$ (88\% anatase, 12\% rutile). As shown in Fig. 19A, under UV illumination over a range of set temperatures up to $355^{\circ} \mathrm{C}$, ethanol pre-dosed samples evolved a clearly increasing level of product $\mathrm{H}_{2}$ and $\mathrm{CH}_{3} \mathrm{CHO}$ along with $\mathrm{CH}_{3}$ radicals, probably linked to undesirable decarbonylation of the aldehyde. Interestingly, visible ( $>400 \mathrm{~nm})$ illumination into the plasmon resonance edge and extended absorption tail of the Ag component had no effect, showing that both metal and support need to be optically co-excited. A superior photothermo dehydrogenation rate for $\mathrm{Ag} / \mathrm{TiO}_{2}$ was observed at all temperatures, but reached maximum thermal enhancement $\left(\mathrm{x} 4\right.$ vs. $\mathrm{TiO}_{2}$ ) at $\sim 180^{\circ} \mathrm{C}$. Arrhenius plots were rather complex with both the catalyst and P25 control showing similar $\mathrm{E}_{\text {app }}$ values (26 vs. $29 \mathrm{~kJ}^{\mathrm{mol}}{ }^{-1}$, respectively) but only above a threshold temperature of $\sim 180^{\circ} \mathrm{C}$ (see Fig. 19B). These apparent activation energies are 
strikingly lower than those typically obtained in pure thermal (dark) conditions, e.g., $150 \mathrm{~kJ} . \mathrm{mol}^{-}$ ${ }^{1},[133]$ and may also help to explain the virtual non-existence of dark activity in this work.

A similar study of solar-driven ethanol dehydrogenation over Ni-promoted $\mathrm{Cu} / \mathrm{SiO}_{2}$ at high activity and selectivity (absence of ethylene, the dehydration product) has just been reported by Luo et al.[134] One key difference with the work of Nadeem and Idriss [132] is the significant activity even in the dark state. For example, the dark conversion rate over supported $\mathrm{Cu}$ reached $\sim 30$ mmol.gcat ${ }^{-1} \mathrm{~h}^{-1}$ and an accurate activation energy determination $\left(E_{\text {app }}=92.4 \mathrm{~kJ} \cdot \mathrm{mol}^{-1}\right)$ was obtained over the range $170-210{ }^{\circ} \mathrm{C}$. Low-level $\mathrm{Ni}$ addition (0.04 at.\%) raised the dark $\mathrm{H}_{2}$ production rate to $71.5 \mathrm{mmol}$.gcat ${ }^{-1} \mathrm{~h}^{-1}$ at $210{ }^{\circ} \mathrm{C}$ and lowered notably the apparent activation energy $\left(\mathrm{E}_{\text {app }}=67.4\right.$ $\left.\mathrm{kJ} . \mathrm{mol}^{-1}\right)$. Visible irradiation $(5.7 \mathrm{suns})$ of $\mathrm{Ni}_{0.04} \mathrm{Cu}$ induced self-sustaining reaction via optical heating, further lowered $\mathrm{E}_{\text {app }}\left(41.5 \mathrm{~kJ} \cdot \mathrm{mol}^{-1}\right)$, and raised the $\mathrm{H}_{2}$ production rate to $176.6 \mathrm{mmol} . \mathrm{gcat}^{-1} \mathrm{~h}^{-1}$, corresponding to a solar-to- $\mathrm{H}_{2}$ efficiency of $\eta_{\mathrm{STH}}=3.8 \%$. A scheme of the putative importance of atomically-dispersed $\mathrm{Ni}$ in promoting solar-driven ethanol dehydrogenation is shown in Fig. 20 below. The high activity, selectivity, and observed trends in activation energies upon alloying gain support from related publications on non-oxidative dark conversion of ethanol over $\mathrm{Pd} / \mathrm{Au}$ [135], $\mathrm{Cu} /(\mathrm{Ni}, \mathrm{Pd}, \mathrm{Pt})[136]$, and $\mathrm{Pd} / \mathrm{ZnO}[137]$. 

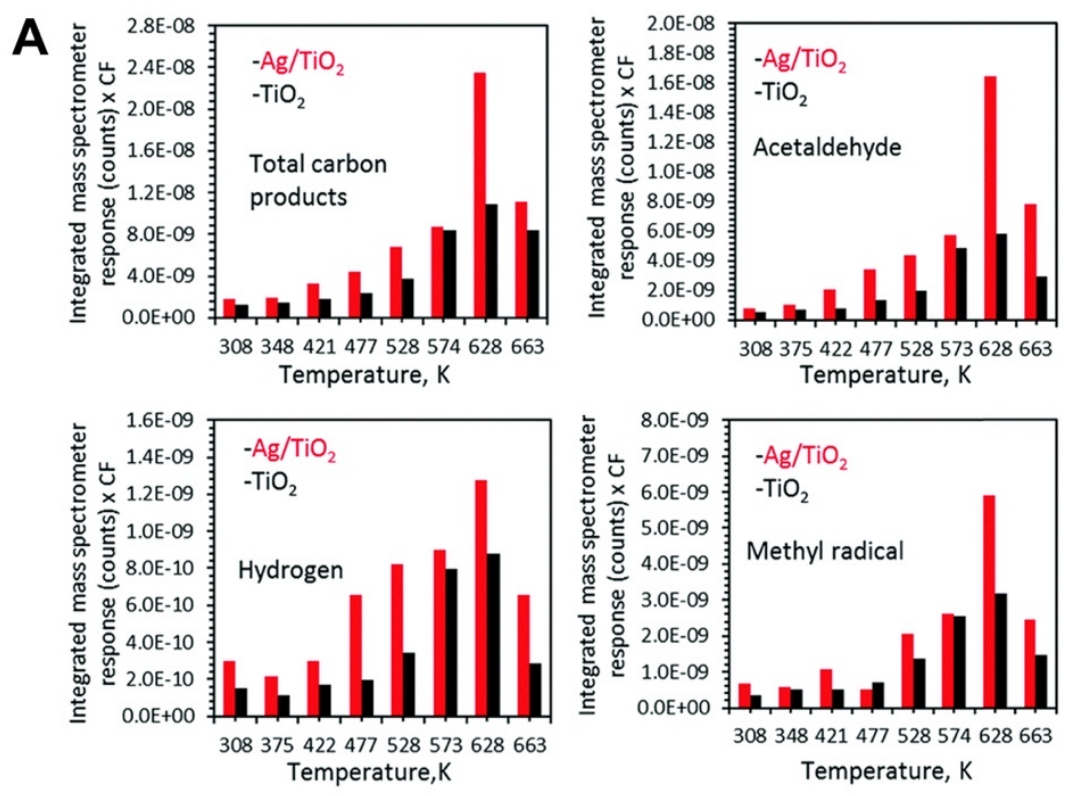

B

$1 / \mathrm{T}\left(\mathrm{K}^{-1}\right)$

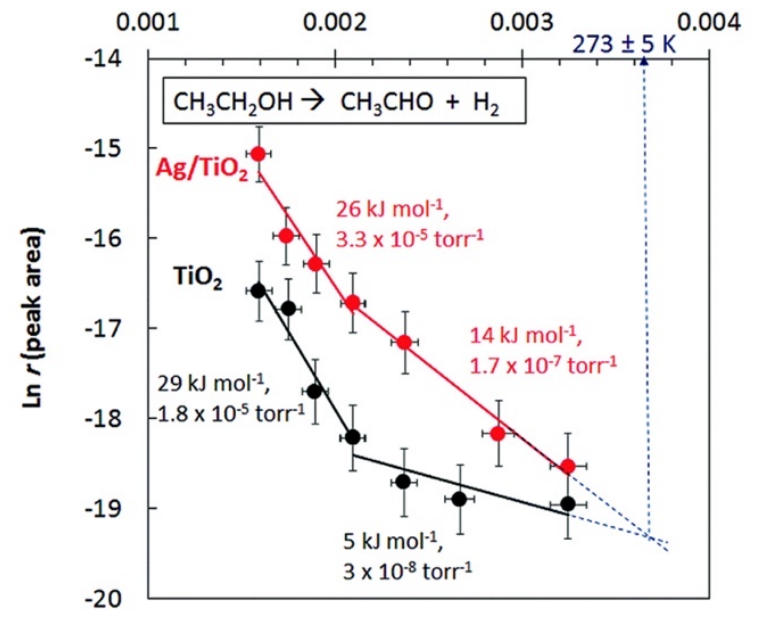

Figure 19. A. UV-stimulated evolution of reaction products from ethanol pre-dosed $\mathrm{Ag} / \mathrm{TiO}_{2}$ (vs. $\mathrm{P} 25 \mathrm{TiO}_{2}$ control) at increasing temperatures. B. Arrhenius plots for ethanol photo-thermo dehydrogenation over the range $25-360{ }^{\circ} \mathrm{C}$. Apart from a $\mathrm{x} 4$ higher rate over the sample (vs. control) and significant difference in $\mathrm{E}_{\text {app }}\left(14\right.$ vs. $\left.5 \mathrm{~kJ} \mathrm{~mol}^{-1}\right)$ at low temperature, both plots show a discontinuity at $180{ }^{\circ} \mathrm{C}$, above which $\mathrm{E}_{\mathrm{pp}}$ values were closely similar at $26 \& 29 \mathrm{~kJ} \mathrm{~mol}^{-1}$.(reproduced from Ref [132] with permission from RSC). 


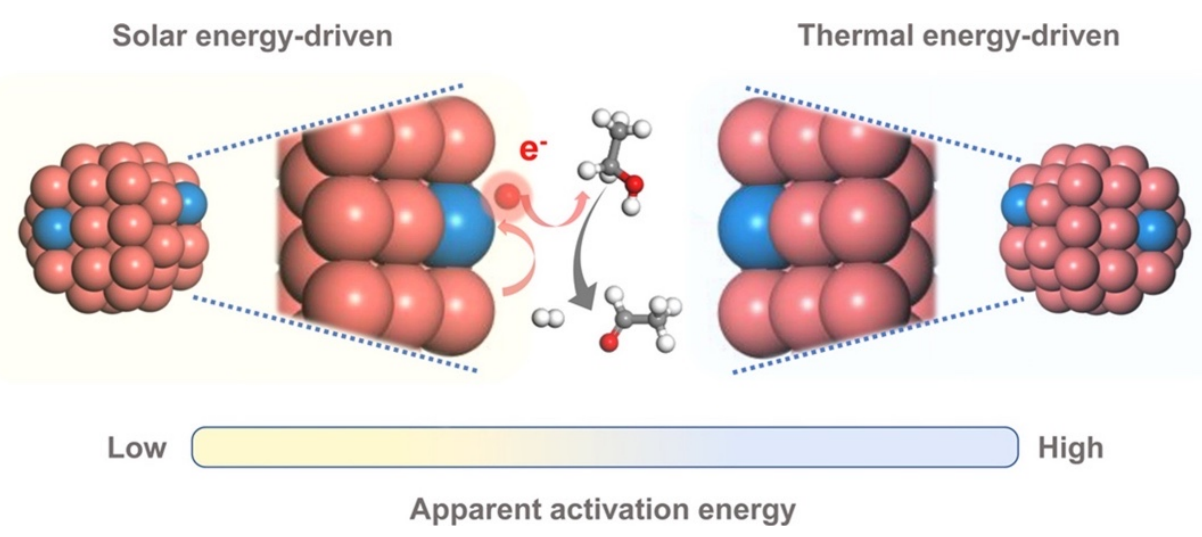

Figure 20. Schematic representation of solar-driven dehydrogenation of ethanol over atomically-dispersed $\mathrm{Ni0} .0_{4} \mathrm{Cu}$ on $\mathrm{SiO}_{2}$ (taken from ref. [134] with permission from Elsevier).

\subsection{High value-added compounds by oxygenate(s) conversion}

The synthesis of high value-added compounds by oxygenate(s) conversion is a highly challenging field due to the importance of the products targeted. These include, e.g., aromatic aldehydes and their derivatives, used as raw substrates for synthesizing pharmaceuticals or fine (specialty) chemicals, via selective oxidation of the corresponding alcohols. Also, many valuable compounds can be obtained through the hydrogenation of unsaturated oxygenate platform molecules derived from lignocellulosic biomass or its downstream intermediates. This application field appears under-investigated till now in respect of a number of crucial issues, such as control of selectivity and of the potential benefits of combined thermal/photonic activation.

A photocatalytic approach to selective oxidation (dehydrogenation) is generally preferred on the basis of more selective conversion (to the desired product) by virtue of lower temperature operation. However, in the benzyl alcohol-to-benzaldehyde reaction, the high oxidation power of $\mathrm{TiO}_{2}$ compromises the selectivity by its tendency to attack and degrade the aromatic ring. J. Zhang et al. circumvented this issue by application of a visible light-responsive $\mathrm{Zn}_{3} \operatorname{In}_{2} \mathrm{~S}_{6} @ \mathrm{ZnO}$ binary composite with a lower bandgap $\left(\mathrm{E}_{\mathrm{g}} \approx 2.88 \mathrm{eV}\right)$ and more reducing band edges than $\mathrm{TiO}_{2}$, positioned at $\mathrm{E}_{\mathrm{CB}}=-0.9 \mathrm{eV}$ and $\mathrm{E}_{\mathrm{VB}}=1.9 \mathrm{eV} .[138]$ Under visible light $(\lambda>420 \mathrm{~nm})$ irradiation in an oxygenated liquid benzotrifluoride solvent, the composite with $10 \% \mathrm{ZnO}$ raised the alcohol conversion 
and yield after $2 \mathrm{~h}$ at $50^{\circ} \mathrm{C}$ from $61.7 \%$ and $58.3 \%$ for pure $\mathrm{Zn}_{3} \mathrm{In}_{2} \mathrm{~S}_{6}$ to $91.3 \%$ and $88.6 \%$, respectively (selectivity $>95 \%$ ). Mild heating raised the yield to nearly $100 \%$ by $70^{\circ} \mathrm{C}$. The photo-thermo catalyst was stable in repeated test runs. Similar performance and analogous trends were observed in a range of para-substituted benzyl alcohols, and evidence was found for involvement of the superoxide radical anion $\left(\mathrm{O}_{2}{ }^{-}\right)$.

Elsewhere, Y. Zhang et al. showed that reduced graphene oxide supported gold ( $\mathrm{Au} / \mathrm{RGO})$ may be considered as an alternative visible-responsive photo-thermo- catalyst for the same reaction, viz., selective oxidation of a large range of benzylic alcohols [139]. Under broad-band visible light irradiation with the temperature fixed externally at $75^{\circ} \mathrm{C}$, over $90 \%$ conversion was attained in $4 \mathrm{~h}$. The control values under photo-activation at $25^{\circ} \mathrm{C}$, or in the dark at $75^{\circ} \mathrm{C}$, were similar but significantly lower at $30-35 \%$. Curiously, tests with narrow bandpass filters showed that dual excitation performed better at higher temperature due to an enhanced activity around $500 \mathrm{~nm}$ where the Au plasmon resonance peak occurs in colloidal form. This may be due to a genuine temperature-dependent alteration of the photo-action spectrum, but is more likely due to interference from optical heating, that raised the local surface temperature significantly above the bulk (control) value.

Yang et al. have reported a photo-enhancement, under both full-solar and visible-only illumination, in hydrogenation of various cyclic and linear alkenes and ascribed it to a purely thermal effect driven by quasi-continuum (plasmonic) absorption of Pd nanocubes $(\sim 17 \mathrm{~nm})$ acting as local 'nanoheaters' with high light-to-heat conversion efficiency [140]. The support was a metal-organic framework (MOF) consisting of $\mathrm{Zn}(2$-methylimidazole)2, also known as ZIF-8. While the control experiment in the dark at room temperature in 1-hexene hydrogenation reached a yield of $27 \%$ after $30 \mathrm{~min}$, this was nearly doubled either by resistive heating to $50^{\circ} \mathrm{C}$, broad-band (full-solar spectrum) irradiation at $60 \mathrm{~mW} . \mathrm{cm}^{-2}$, or visible-only irradiation at $100 \mathrm{~mW} . \mathrm{cm}^{-2}$ (see Fig. 21). Even though this concept was not applied to the hydrogenation of oxygenates but to alkenes, its extension might be of interest, although MOFs are known to suffer from stability issues in comparison to more established catalyst and support materials. 

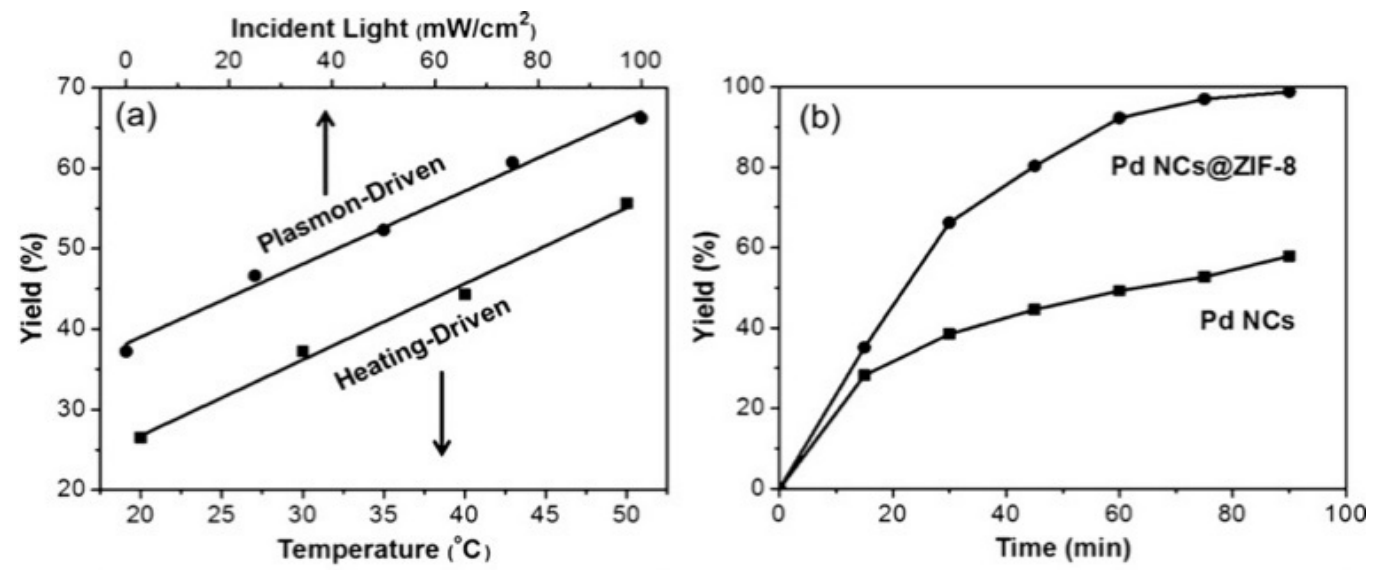

Figure 21. (a). Systematic increase in hexane yield (from 1-hexene hydrogenation) over Pd NCs @ZIF-8 driven by broadband optical power or resistive heating. (b) Yield vs. time under full-solar illumination $\left(100 \mathrm{~mW} . \mathrm{cm}^{-2}\right)$ showing the benefit of the ZIF-8 support, possibly acting as a local reservoir for hydrogen. (reproduced from ref. [128] with permission of Wiley-VCH).

This core-shell approach to plasmonic (strong optical) heating was quickly followed up by Wang et al.,[141] who used laser excitation into the NIR plasmon absorption of hierarchical $\mathrm{Cu}_{7} \mathrm{~S}_{4}$ hollow microspheres inside the same porous ZIF-8 support for cyclo-condensation reactions of oxygenates. $\mathrm{Yb}(\mathrm{III})$-based quantitative luminescent sensors deposited directly on the catalyst allowed an estimate of $\sim 30 \%$ for the photo-thermal transduction factor (light-to-heat conversion efficiency) and indicated linear rises in surface and bulk temperature under high-power laser irradiation $\left(100-700 \mathrm{~mW} . \mathrm{cm}^{-2} ; \lambda=1450 \mathrm{~nm}\right)$, driving excursions of over $120^{\circ} \mathrm{C}$ and $20^{\circ} \mathrm{C}$, respectively, in just a few minutes. Dark control experiments at the same bulk temperatures obtained by resistive heating showed that rates were enhanced via the optical heating method by a factor of $5 \mathrm{x}$. Yields close to $100 \%$ were attained after $6 \mathrm{~h}$ under a monochromatic laser power of $500 \mathrm{~mW} . \mathrm{cm}^{-2}$, or in broad-band terms the equivalent of 5 suns.

\section{3. $\mathrm{CO}_{2}$ conversion}

Investigation of photo-thermal synergies, potentially using only the sun as combined light/heat energy source, has recently been extended to the catalytic reduction of $\mathrm{CO}_{2}$ to hydrocarbon fuels. 
This area is attracting considerable interest as sustainable carbon cycling will be pivotal in the success of any future zero-emission renewable energy system. $\mathrm{CO}_{2}$ is converted by reaction with $\mathrm{H}_{2}, \mathrm{CH}_{4}$ and $\mathrm{H}_{2} \mathrm{O}$ as primary reductants, so that the corresponding reactions are hydrogenation, dry reforming, and artificial photosynthesis [29,142].

\subsubsection{Methanation}

The photo-methanation of carbon dioxide has a long history and aroused controversy when it was first propounded in 1987, claiming evidence for photoactivity already near room temperature [143]. While further investigations verified the exceptional dark activity of the $\mathrm{Ru} / \mathrm{TiO}_{2}$ catalyst [95], photo-enhancement was re-interpreted as an 'optical heating' effect [144]. However, recent and more concrete examples of photo-thermo-catalytic synergies (vide infra) are mounting evidence of its reality. The Sabatier reaction (eqn.5) is a spontaneous exothermic reaction that converts $\mathrm{CO}_{2}$ into the valuable gaseous fuel SNG (synthetic natural gas) albeit at the expense of a high consumption of renewable $\mathrm{H}_{2}$ [145].

$\mathrm{CO}_{2}+4 \mathrm{H}_{2} \rightarrow \mathrm{CH}_{4}+2 \mathrm{H}_{2} \mathrm{O} \quad\left[\Delta \mathrm{G}^{0}=-113 \mathrm{~kJ} \cdot \mathrm{mol}^{-1}\right]$

It typically proceeds in the dark but only above $250^{\circ} \mathrm{C}$. A key development in modern photo(thermo) catalysts is the trend towards improved matching of their optical absorption properties to the solar spectrum. In semiconductors, this means an increasingly narrow bandgap resulting in substantial photo-response across the visible and well into the NIR, responsible for over $90 \%$ of solar radiant power. There is also an increasing trend towards plasmonic (noble) metals and black or 'full spectrum' nano-metallic absorbers based on inter/intra-band transitions, e.g., in group VIII elements like $\mathrm{Ni}, \mathrm{Co}$, and $\mathrm{Ru}$.

Precursor works by the group of J. Ye proposed photothermal methanation of $\mathrm{CO}_{2}$ by $\mathrm{H}_{2}$ over Group VIII (nano)catalysts as a simple and viable alternative for solar fuel production [41]. Alt- 
hough it is thermodynamically downhill, it circumvents the many drawbacks associated with 'artificial photosynthesis' (AP - see section 7.3.5). AP effects the simultaneous photo-driven reduction of $\mathrm{CO}_{2}$ and water oxidation at the conduction and the valence band edges of the semiconductor, respectively [146,147], but is dogged by low efficiencies linked to the kinetic limitations of multiple charge transfer and the poor ability of semiconductors to activate $\mathrm{CO}_{2}$ [148]. The authors claim that the high conversion efficiency to methane (in the $\mathrm{mmol} / \mathrm{h} / \mathrm{g}$ range and with a low CO selectivity)results from several attractive features of the group VIII metals (among which Ru was the most promising at a $2.4 \mathrm{wt} . \%$ level), namely:

(i) they promote more effective energy utilization over the whole range of the solar spectrum due to much stronger photo-absorptive power than conventional semiconductor photocatalysts;

(ii) they impart the so-called photothermal effect- allowing the surface temperature of $\mathrm{Al}_{2} \mathrm{O}_{3}$ supported group VIII catalysts to exceed by $200^{\circ} \mathrm{C}$ that achievable over the bare $\mathrm{Al}_{2} \mathrm{O}_{3}$ supporting the absence of external heating; and

(iii) they are powerful catalysts in $\mathrm{CO}_{2}$ activation per se.

The authors considered that their findings might pave the way for performing photothermal $\mathrm{CO}_{2}$ methanation (or generating in the same way useful chemical feedstocks) using $\mathrm{H}_{2}$ produced via light-driven water splitting. However, we have to stress that $\mathrm{CO}_{2}$ methanation requires a lot of process energy from renewable $\mathrm{H}_{2}$, thus compromising process sustainability.

Major growth in applied photo-thermo catalysis is also driving a reorientation in catalytic/optical materials design and preparation. Traditional wide-gap semiconductors(primarily responsive to UV light) are becoming increasingly absent or redundant components although transparent insulating (thermally stable) oxide supports remain important $[40,42,149]$. A notable exception is a report of $\mathrm{Ru}$ on black Si nanowires $(\mathrm{Ru} / \mathrm{SiNW})$ [150]. A photo-enhancement of the $\mathrm{CO}_{2}$ methanation rate to $\sim 1 \mathrm{mmol} \cdot \mathrm{h}^{-1}$ g.cat ${ }^{-1}$ at $150^{\circ} \mathrm{C}$, roughly double the activity of the dark control, was investigated in more detail with no resistive heating but thermal equilibration over $3 \mathrm{~h}$ under illumination instead. Under increasing optical power $\left(5-15\right.$ suns, $\left.50-120^{\circ} \mathrm{C}\right)$, the photo-enhancement over the 
dark case was more pronounced (x5 - x6) even though the apparent activation energy remained the same at $\sim 54 \mathrm{~kJ}^{\mathrm{mol}}{ }^{-1}$ (see Fig. 22). They went on to show that only irradiation with super bandgap photons, i.e., those absorbable by $\mathrm{Si}$ at $\lambda<1000 \mathrm{~nm}$, contributed to the rate enhancement whereas continuum absorption by the $\mathrm{Ru}$ across the visible-NIR had no effect. The semiconductor photo-effect was attributed to heterolytic photo-activation of molecular $\mathrm{H}_{2}$, and ensuing $\mathrm{Ru}-\mathrm{H}$ surface bond enrichment, by charge carrier migration from the Si nanowires to the metal. The ratedetermining step in the dark mechanism is believed to involve homolytic cleavage of $\mathrm{H}_{2}$ directly on $\mathrm{Ru}$ and multi-step $\mathrm{H}$-transfer to the active carbide $\mathrm{Ru}-\mathrm{C}_{\mathrm{x}}$, itself obtained from successive dissociation of $\mathrm{CO}_{2}$ and $\mathrm{CO}$. The implied favourable alteration in the balance of steady-state (competitive) occupancy by $\mathrm{Ru}-\mathrm{H}$ and $\mathrm{Ru}-\mathrm{C}_{\mathrm{x}}$ intermediates due to illumination should be verified by kinetic studies on the pressure exponents. This will allow proper categorization of what is likely a ‘Type B' photo-thermo synergy [see also Section 7.3.2. Reverse water gas-shift reaction].

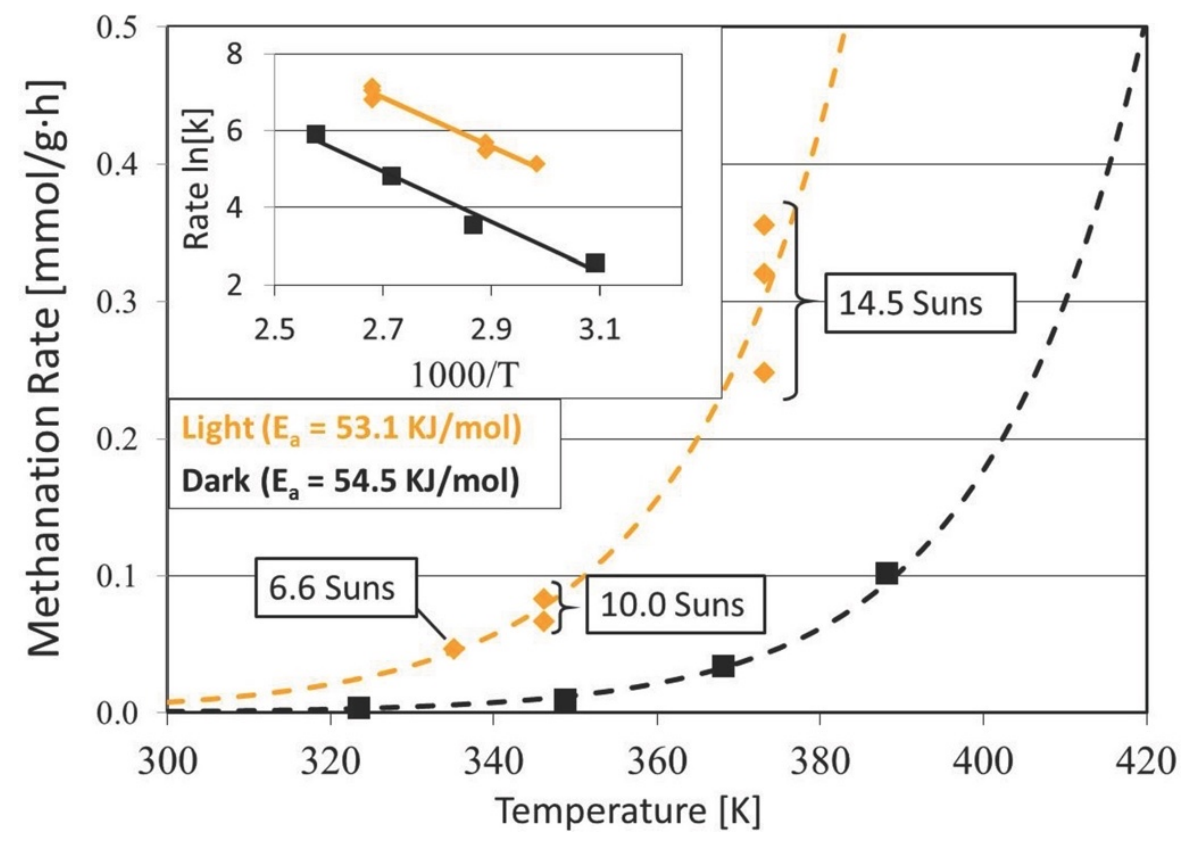

Figure 22. Normalized methanation rates over $\mathrm{Ru} / \mathrm{SiNW}$ under solar-simulator at irradiation equilibrium temperatures obtained via optical heating (dashed yellow curve) vs. dark control experiments at matching temperatures obtained by resistive heating (dashed black curve). Inset: solid-yellow - apparent activation 
energy ( $\left.E_{\text {app }}\right)$ of methanation under irradiation; solid black - apparent activation energy ( $\left.E_{\text {app }}\right)$ for methanation in the dark. (reproduced from ref [150] with permission of Wiley-VCH).

In stark contrast, Sastre et al. have reported an extremely high photo-thermo- activity in $\mathrm{CO}_{2}$ methanation over a similar catalyst, consisting of polydispersed Ru nanorods (aspect ratio $\approx 10 / 1$ ) on $\gamma-\mathrm{Al}_{2} \mathrm{O}_{3}$, and attributed it to shape-dependent visible-NIR plasmon optical absorption in $\mathrm{Ru}$ [151]. Under 1 sun irradiation at $150{ }^{\circ} \mathrm{C}$ the photo-enhancement was a factor of two, but on top of a very high dark conversion rate of $\sim 50 \mathrm{mmol} \cdot \mathrm{h}^{-1}$.g.cat ${ }^{-1}$. This was ascribed mainly to optical heating, whereas at higher intensities up to 8.5 suns (leading to temperatures above $200{ }^{\circ} \mathrm{C}$ in combined heating mode) a genuine photo-thermo synergy became evident, producing rates $3 \mathrm{x}$ higher than estimates for dark controls. The photon-to-methane conversion efficiency was high and temperature-dependent, ranging from $22.3 \%, 25.0 \%$, to $54.8 \%$ at catalyst temperatures of $212^{\circ} \mathrm{C}, 221^{\circ} \mathrm{C}$, and $231^{\circ} \mathrm{C}$, respectively.

A similar photo-enhancement was observed by Wang et al. on $\mathrm{Ru} / \mathrm{TiO}_{2}$ catalysts upon $\mathrm{AM} 1.5$ sunlight illumination ( 1 sun) in the $150-300^{\circ} \mathrm{C}$ temperature range, with a strong increase in $\mathrm{CH}_{4}$ yield and the ability of the thermo-photo catalyst to produce $\mathrm{CH}_{4}$ at the low temperature of $150^{\circ} \mathrm{C}$ while no $\mathrm{CH}_{4}$ was formed in the dark (Fig. 23) [152]. The semi-conductor nature of the $\mathrm{TiO}_{2}$ support was proposed to play a role, as no photo-enhancement was observed on a $\mathrm{Ru} / \mathrm{Al}_{2} \mathrm{O}_{3}$ catalyst with large $(>8 \mathrm{eV})$ band bap within an analogous temperature range. The results were explained in terms of thermodynamics and kinetics. The authors proposed that the insufficient driving forces for $\mathrm{H}_{2}$ oxidation might be the main cause of the negligible activity obtained at room temperature for $\mathrm{CO}_{2}$ hydrogenation. They further suggested that the introduction of thermal energy (via elevating the reaction temperature) can enhance the kinetic energy of the reactants, thus increasing the overall driving and giving rise to substantially higher activities of $\mathrm{CO}_{2}$ reduction in photo-thermo process mode above $150^{\circ} \mathrm{C}$. 

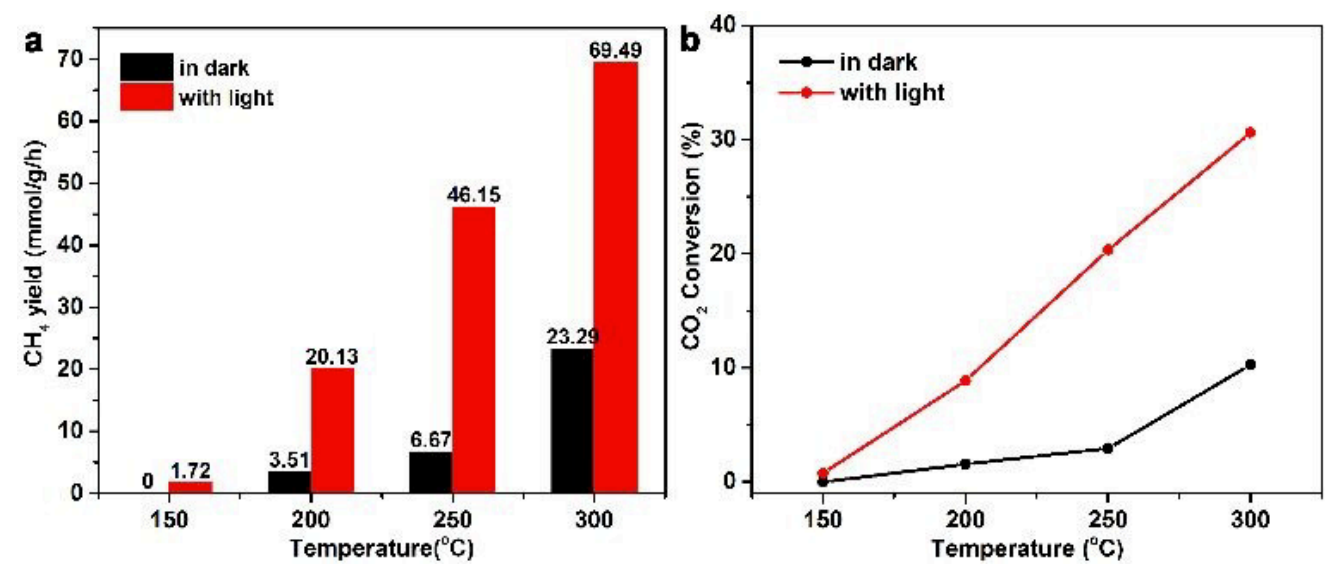

Figure 23. Thermo-catalytic (black bar) and thermo-photo catalytic (red bar) $\mathrm{CO}_{2}$ methanation over $\mathrm{Ru} / \mathrm{TiO}_{2}$ catalysts at temperatures in the $150-300^{\circ} \mathrm{C}$ range. Reaction conditions: $\mathrm{H}_{2} / \mathrm{CO}_{2}(3: 1)$ mixture gas, GHSV $=20000 \mathrm{ml} \cdot \mathrm{gcat}^{-1} \mathrm{~h}^{-1}, 1 \mathrm{~atm}$, illumination of $1 \mathrm{Sun}\left(100 \mathrm{~mW} / \mathrm{cm}^{2}\right)$ simulated by $500 \mathrm{~W}$ solar simulator. The catalyst is deposited on $\mathrm{SiO}_{2}$ disk as diffuse-reflection-surface substrate. (reproduced from $\mathrm{Ref}$ [152] with permission of RSC).

\subsubsection{Reverse water gas-shift reaction}

The partial reduction of $\mathrm{CO}_{2}$ into $\mathrm{CO}$ via the Reverse Water Gas-Shift (RWGS) reaction has been less investigated in the field of photonic/thermal dual activation. This is despite the fact that, mechanistically, $\mathrm{CO}$ is a key component in industrial syngas and its presence (along with $\mathrm{CO}_{2}$ and $\mathrm{H}_{2}$ ) facilitates downstream processing to methanol or higher hydrocarbons via Fischer-Tropsch (FT) processing, and with enhanced selectivity (vide infra). Renewable variants of these liquid fuels and platform chemicals will be of growing importance in sustainable biorefinery processing $[153,154]$

The Ozin group has developed hydroxylated indium oxide nanostructures, $\operatorname{In}_{2} \mathrm{O}_{3-\mathrm{x}}(\mathrm{OH})_{\mathrm{y}}$, by the thermal dehydration of $5 \mathrm{~nm}$-size $\operatorname{In}(\mathrm{OH})_{3}$ nanoparticles (Fig. 24).[88] They achieved photochemical $\mathrm{CO}_{2}$ reduction at a rate of $153 \mu \mathrm{mol} \cdot \mathrm{h}^{-1} \cdot \mathrm{g}_{\mathrm{cat}}{ }^{-1}$ at $190{ }^{\circ} \mathrm{C}$ as shown in Fig. $24 \mathrm{~B}$, i.e., $4 \mathrm{x}$ better than the dark (thermochemical) rate, and proposed a reaction mechanism whereby the surface exposes Lewis base (hydroxide) and Lewis acid sites (Indium ions adjacent to an oxygen vacancy), as 
shown in Fig. 24A. These sites act in a cooperative and concerted manner by assisting in the adsorption and heterolytic dissociation of $\mathrm{H}_{2}$. H-coordinated intermediate species subsequently activate $\mathrm{CO}_{2}$ to yield $\mathrm{CO}$ and $\mathrm{H}_{2} \mathrm{O}$ as final products. The proposed reaction mechanism is believed to involve an adsorptive analogue of a molecular frustrated Lewis pair (FLP) interaction. The photoeffect was rationalized on the basis that electrons and holes enhance heterolytic dissociation of $\mathrm{H}_{2}$. Arrhenius plots showed that illumination lowered the apparent activation energy from 107 to 86 kJ. mol ${ }^{-1}$ (see Fig. 24C). In more recent advances from the same group, porous 1D defect-rich $\mathrm{In}_{2} \mathrm{O}_{3-\mathrm{x}}(\mathrm{OH})_{\mathrm{y}}$ nanorods designed and prepared in high aspect ratio further raised activities in both RWGS and methanol synthesis (see below) by prolonging the lifetime of the photogenerated charge carriers [155]. 

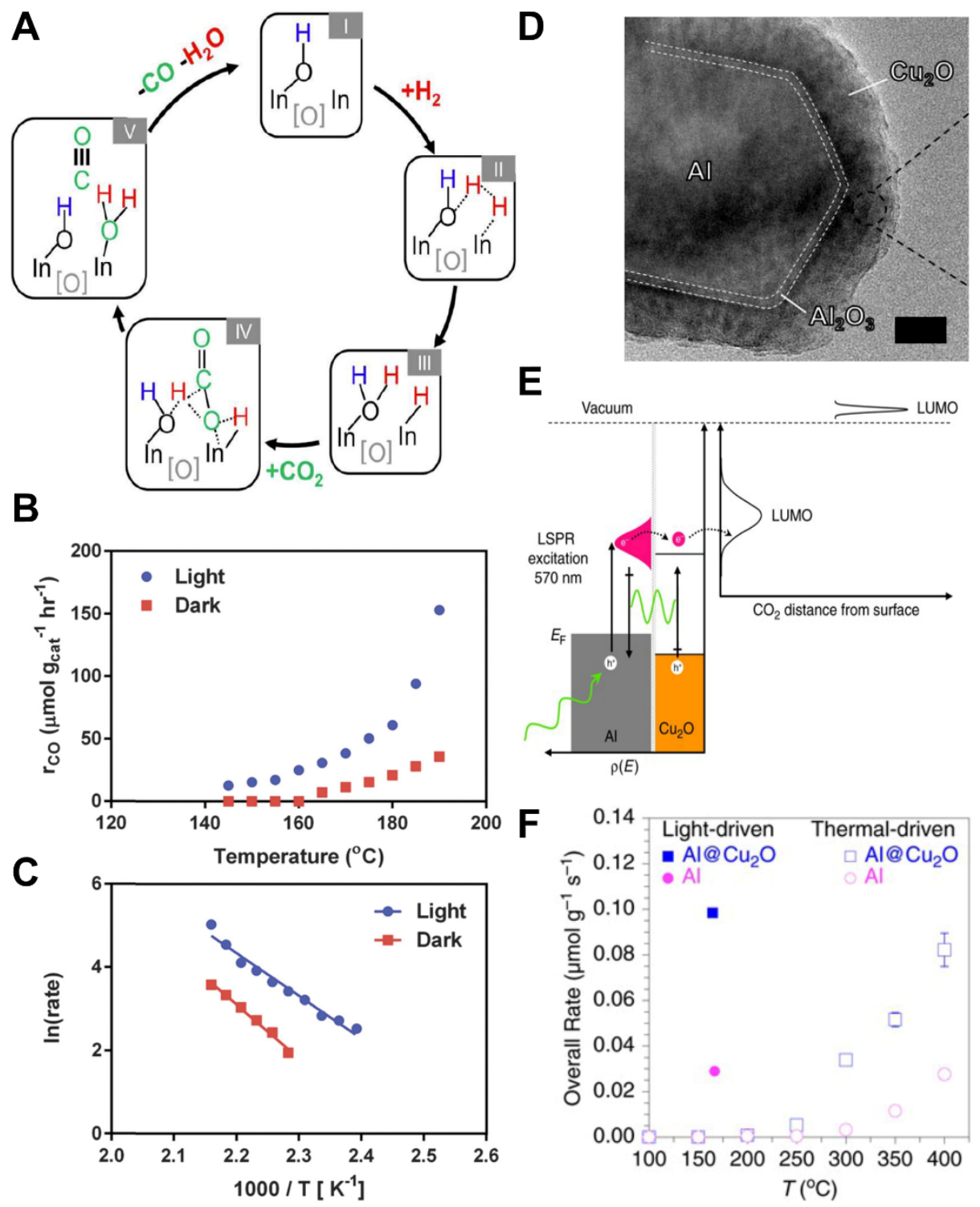

Figure 24. (A) Proposed (concerted) mechanism for RWGS over $\operatorname{In}_{2} \mathrm{O}_{3-\mathrm{x}}(\mathrm{OH})_{\mathrm{y}}$ photo-thermo catalyst; (B) the temperature dependence of $\mathrm{CO}$ production, and (C) the pseudo-Arrhenius plots under dark and light conditions. (all adapted from ref [88] with permission of Springer); (D) High resolution TEM images of the core/shell $\mathrm{Al} @ \mathrm{Cu}_{2} \mathrm{O}$ nanoparticles with a 2-4 nm thick amorphous, native $\mathrm{Al}_{2} \mathrm{O}_{3}$ interfacial layer. E) Energy band diagram of the $\mathrm{Al} @ \mathrm{Cu}_{2} \mathrm{O}$ catalyst for the light-induced plasmon-mediated carrier generation for injection into unoccupied states of $\mathrm{CO}_{2}$ for $\mathrm{C}=\mathrm{O}$ bond activation. (F) Overall RWGS rates vs. temperature in purely thermal-driven (light off) conditions for $\mathrm{Al}$ nanocrystals and $\mathrm{Al} @ \mathrm{Cu}_{2} \mathrm{O}$ catalysts (unfilled data points), and $570 \mathrm{~nm}$ light-induced reaction rate obtained at $10 \mathrm{~W} / \mathrm{cm}^{2}$ (filled data points). 
The test temperature $\left(175^{\circ} \mathrm{C}\right)$ was obtained by localized optical heating only. (all reproduced from ref [156] with permission of Elsevier).

In terms of advancing long-term sustainability in materials resources, plasmonic catalysts are needed that are not based on expensive rare metals. As shown in Fig. 24D, a core/shell photothermo catalyst composed of earth-abundant elements $\left(\mathrm{Al} @ \mathrm{Cu}_{2} \mathrm{O}\right)$ has been developed by Halas and colleagues for operation as 'antenna-reactor' nanostructures in which the light harvesting (Al) and catalysis $\left(\mathrm{Cu}_{2} \mathrm{O}\right)$ components are separated but act in synergy [156]. As shown in Fig. 24F, whereas dark activity was only detectable above $250^{\circ} \mathrm{C}$, visible light irradiation from a supercontinuum fibre laser at $10 \mathrm{~W} / \mathrm{cm}^{2}(100$ suns $)$ into the $\mathrm{Al}$ plasmon band at $570 \mathrm{~nm}$ increased the surface temperature up to $175^{\circ} \mathrm{C}$ by localized optical heating and resulted in $\mathrm{CO}$ production at a rate of $\sim 0.1 \mu \mathrm{mol} . \mathrm{s}^{-1}$ g.cat ${ }^{-1}$, with an external quantum efficiency of $0.3 \%$. After $\mathrm{CO}_{2}$ adsorption at coordinatively unsaturated $\mathrm{Cu}(\mathrm{I})$, the purported activation mechanism for $\mathrm{C}=\mathrm{O}$ bond dissociation is believed to involve injection of plasmon-induced hot carriers into unoccupied states in $\mathrm{CO}_{2}$, as depicted in the energy diagram in Fig. 24E. By the same token, the ultra-high selectivity towards CO $(>99.3 \%)$ is attributed to carrier-stimulated non-thermal desorption of excited $\mathrm{CO}^{*}$. The authors stress that the abundant generation of hot carriers might result either from LSPR damping in the Al core or from near-field excitation in the $\mathrm{Cu}_{2} \mathrm{O}$ shell, in both cases as a result of the $\mathrm{Al} / \mathrm{Cu}_{2} \mathrm{O}$ energy band alignment.

Zhang et al. designed a core/shell Fe@C thermo-photo catalyst, consisting in Fe nanoparticles $(<10 \mathrm{~nm})$ encapsulated by ultrathin carbon C (1-3 layers) [157]. The authors attributed the positive effect of light irradiation in terms of $\mathrm{CO}$ production rate to a photothermal effect, as well as to the implication of UV-light-excited hot electrons on the plasmonic Fe nanoparticles (LSPR effect) that facilitate the $\mathrm{CO}_{2}$ activation via its partial polarization. The enhanced activity correlated well with both the intensity and the wavelength of the incident UV light.

Lu et al. have recently made an interesting study of the RWGS reaction over $\mathrm{Au} / \mathrm{CeO}_{2}$ and with a unique finding (Fig. 22) [158]. We believe it is the first reported case of a Type B effect, in which 
a strong photo-enhancement appears to correlate with the favourable perturbation of a pressure term in the rate equation. As shown in Fig. $25 \mathrm{~A}, \mathrm{CO}_{2}$ conversion in the dark was quite low, reaching just $3.2 \%$ at $400^{\circ} \mathrm{C}$. Under illumination the conversion across the same temperature range (360$400^{\circ} \mathrm{C}$ ) was over an order of magnitude higher, ultimately exceeding $40 \%$ at $400^{\circ} \mathrm{C}$. However, unlike the previous report of Ghuman et al. (Fig 24C) [88], there was no discernible change in $E_{\text {app }}$ but instead a strong perturbation of the rate dependence on partial pressure of $\mathrm{H}_{2}$. The exponent in $\mathrm{P}^{\mathrm{n}}{ }_{\mathrm{H} 2}$ rose from $\mathrm{n}=0.63$ in the dark to $\mathrm{n}=1.52$ under illumination (Fig. 25D). Such a dramatic effect is clear evidence that the dark process is H-supply-restricted, and that photo-excitation circumvents this limitation, possibly by promoting the growth of surface $\mathrm{Au}-\mathrm{H}$ bonds as observed by in-situ DRIFTS. By analogy with the proposal of O'Brien et al. in $\mathrm{CO}_{2}$ methanation [150], photogenerated charge carriers may open up a new route to key $\mathrm{M}-\mathrm{H}$ intermediates by promoting heterolytic dissociation of $\mathrm{H}_{2}$. Reconciling the conflicting but equally-convincing findings of Ghuman et al.[88] and Lu et al.[158] in the RWGS reaction lead to the remarkable and encouraging conclusion that a photo-thermo synergy can enhance the same reaction via different mechanisms (type A [88] and/or type B [158]), possibly catalyst-dependent. Our view is that recognition of this fact constitutes a clear advance in the field. 

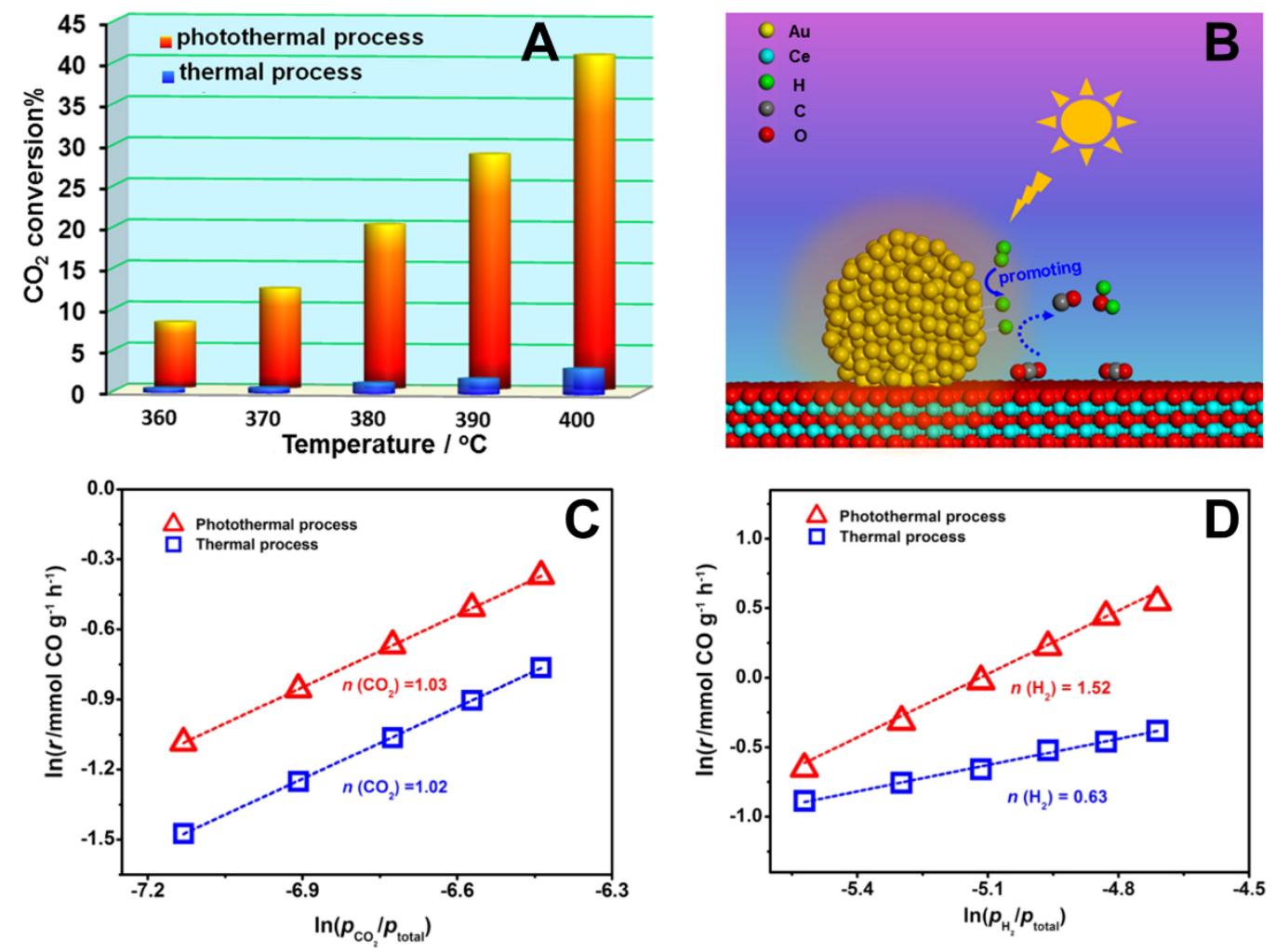

Figure 25. A. Plots of $\mathrm{CO}_{2}$ conversion in RWGS reaction over 0.9 at. $\% \mathrm{Au} / \mathrm{CeO}_{2}$ from $360-400^{\circ} \mathrm{C}$ in the dark (blue) and under illumination (red), showing a strong photo-enhancement. B. Mechanistic scheme showing the promotion of $\mathrm{H}_{2}$ dissociation over Au nanoparticles. C. Plot of CO production rate dependence on partial pressure of $\mathrm{CO}_{2}$ in the dark and under illumination. D. Plot of $\mathrm{CO}$ production rate dependence on partial pressure of $\mathrm{H}_{2}$ in the dark and under illumination (reproduced from ref. [158] with permission of Elsevier).

\subsubsection{Hydrogenation in short-chain alcohol synthesis}

Reports on combined photonic/thermal activation applied in the synthesis of short-chain alcohols such as methanol and ethanol remain till now quite scarce, although these products carry remarkable added value as liquid fuel or carbon feedstocks in comparison to gaseous $\mathrm{CH}_{4}$ and $\mathrm{CO}$.

Following their work on the RWGS reaction described in section 7.3.2. [88], the group of Ozin found that their rod-like defect-laden $\operatorname{In}_{2} \mathrm{O}_{3-\mathrm{x}}(\mathrm{OH})_{\text {y }}$ photo-thermo- catalyst was also capable of achieving a steady production of methanol even at 1 bar, albeit at $\sim 50 \%$ selectivity (vs. CO from 
the RWGS reaction). Irradiation from an unfiltered $130 \mathrm{~W}$ Xe lamp at $250{ }^{\circ} \mathrm{C}$, the optimum temperature for the thermochemical (dark) process, roughly doubled the activity from 54.1 to 97.3 $\mu \mathrm{mol.s} \mathrm{s}^{-1}$ g.cat ${ }^{-1}$ but at the price of a slight decrease in methanol selectivity $[155,159]$. The photoenhancement was also most pronounced at $250^{\circ} \mathrm{C}$ with both light and dark rates dropping significantly upon heating to $300^{\circ} \mathrm{C}$ due to a corresponding loss in selectivity. In this temperature range, the thermodynamics already favour CO production over methanol synthesis. However, since both reactions share elementary mechanistic steps in their early stages the photo-thermo- synergy in methanol synthesis was attributed to the same function as in RWGS, i.e., heterolytic dissociation of $\mathrm{H}_{2}$ (see section 7.3.2) [88].

Wang et al. recently followed up on the work by the Ozin group (reported above) in a similar study at ambient pressure but over $\mathrm{Cu} / \mathrm{ZnO}$, the classical industrial methanol synthesis catalyst, by exploiting the plasmonic properties of nanosized metallic copper (Fig. 26) [160]. The methanol production rate was modestly enhanced by a factor 1.5 at $220{ }^{\circ} \mathrm{C}$ upon visible light irradiation, due almost entirely to a substantial lowering of $E_{\text {app }}$ from 82.4 to $49.4 \mathrm{~kJ} \mathrm{~mol}^{-1}$ (see Fig. 26C). They proposed a LSPR-enhanced mechanism combining the photoexcitation of hot electrons on the $\mathrm{Cu}$ nanoparticles and electron transfer through the adjacent $\mathrm{Cu}-\mathrm{ZnO}$ interfaces, with a synergetic activation of reaction intermediates allowing the reaction barrier to be lowered (see Fig. 26A). Enhanced electric fields were visualized on the surface of plasmonic $\mathrm{Cu}$ nanoparticles, which would excite abundant hot electrons (Fig. 26B). The activation of *HCOO species upon light irradiation was proposed to alleviate the surface poisoning of the $\mathrm{Cu} / \mathrm{ZnO}$ catalyst caused by the accumulation of such species $[161,162]$. 

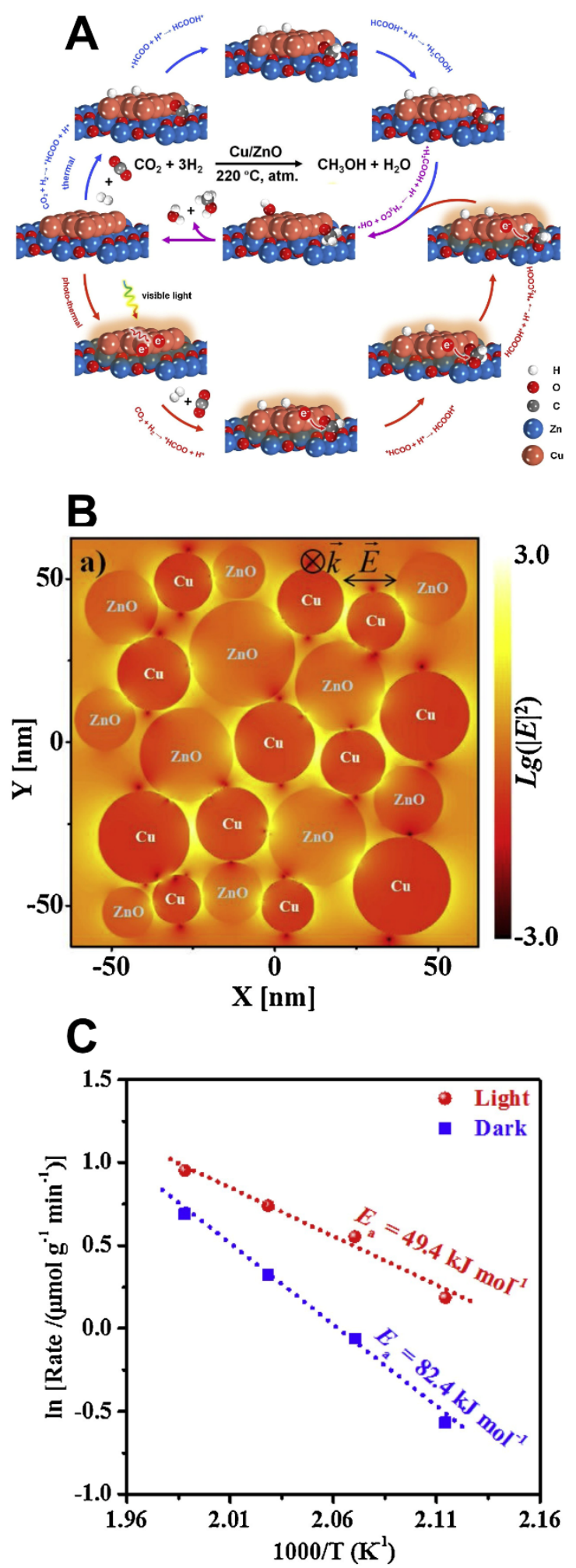

Figure 26. (A) Mechanism proposed by Wang et al. [160] for the visible-light enhancement of methanol synthesis on a $\mathrm{Cu} / \mathrm{ZnO}$ thermo-photo catalyst. It follows a similar formate pathway as in the thermochemical route, involving $* \mathrm{HCOO},{ }^{*} \mathrm{HCOOH},{ }^{*} \mathrm{H}_{2} \mathrm{COOH}$ and ${ }^{*} \mathrm{CH}_{3} \mathrm{O}$ intermediates, with the hydrogenation of * $\mathrm{HCOOH}$ as the rate-limiting step. The photo-excited hot electrons on the $\mathrm{Cu}$ nanoparticles and adjacent 
to the $\mathrm{Cu}-\mathrm{ZnO}$ interfaces synergistically promote the activation of reaction intermediates, which lowers the reaction barrier and enhances the methanol production rate. (B) Spatial distribution of electromagnetic fields upon $580 \mathrm{~nm}$ irradiation as simulated by the finite difference time domain (FDTD) method. The enhanced electric fields on the surface of plasmonic $\mathrm{Cu}$ nanoparticles may result in excitation of abundant hot electrons. (C) Arrhenius plots under dark and light conditions. (reproduced from ref [160] with permission of Elsevier).

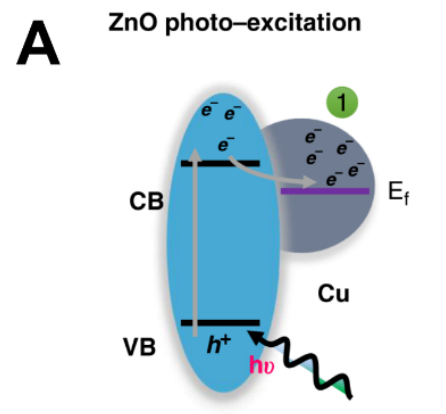

Zno

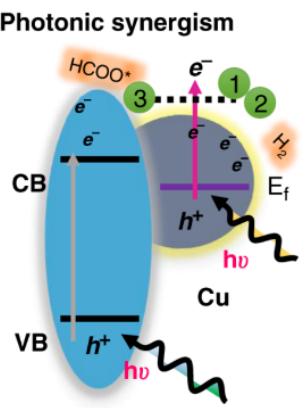

Zno

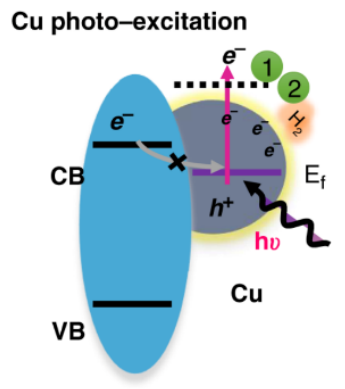

ZnO

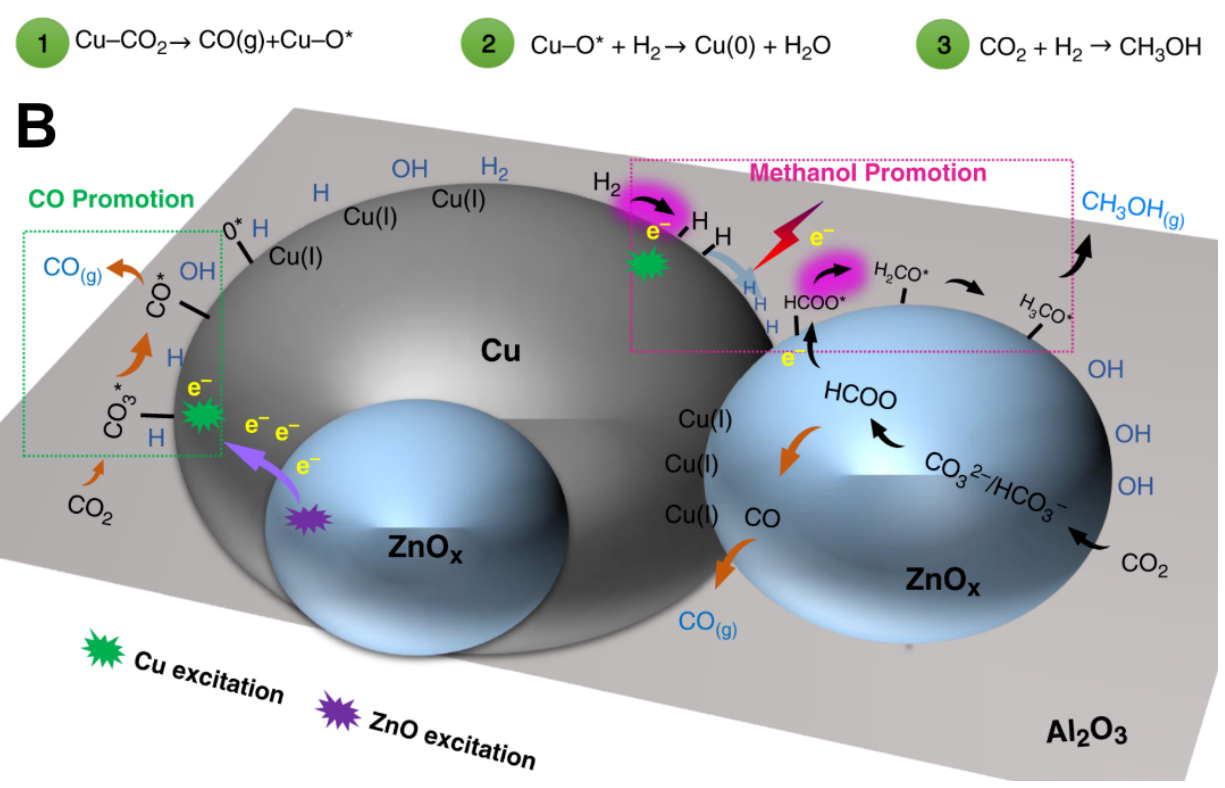

Figure 27. (A) Electron excitation in $\mathrm{Cu}$ and $\mathrm{ZnO}$ and subsequent electron transfer between both phases upon irradiation by different light spectral ranges. The equations below the schematics indicate the potential reactions which could be enhanced when interacting with certain light-generated electrons. The potential electron acceptors are highlighted. (B) Light-assisted $\mathrm{CO}_{2}$ hydrogenation reaction on the industrially- 
relevant $\mathrm{Cu} / \mathrm{ZnO} / \mathrm{Al}_{2} \mathrm{O}_{3}$ catalyst. Pathways for $\mathrm{CO}$ (chemisorbed $\mathrm{CO}_{2}$ dissociation or $\mathrm{ZnO}-\mathrm{HCOO} *$ decomposition) and methanol production $(\mathrm{Cu}-\mathrm{ZnO}$ interface-mediated processes) are illustrated with black and orange arrows, respectively. Green dotted rectangle: $\mathrm{CO}_{2}$ dissociation to $\mathrm{CO}$ promoted by the electrons transferred to $\mathrm{Cu}$ surface; Red dotted rectangle: the light-mediated methanol production is attributed to the promoted $\mathrm{H}^{*}$-supply and $\mathrm{HCOO}^{*}$-hydrogenation (glowing dark arrow) at the $\mathrm{Cu}-\mathrm{ZnO}$ interface perimeter under dual excitation of $\mathrm{Cu}$ and $\mathrm{ZnO}$. (reproduced from ref [92] with permission of Springer).

Most recently, Xie et al. have made a mechanistic breakthrough and provided insights into the key elementary processes at the surface of the industrially-relevant $\mathrm{Cu} / \mathrm{ZnO} / \mathrm{Al}_{2} \mathrm{O}_{3}$ catalyst under light-heat dual activation (Fig. 27) [92]. They report on the effect of electronic excitations of the catalyst on $\mathrm{CO}_{2}$ hydrogenation and exploration of light-triggered surface reactions through ex-situ and in-situ spectroscopies. Working at a pressure of 21 bar, irradiation with the UV-visible component (350-800 nm) of a Xe lamp at $0.6 \mathrm{~W} / \mathrm{cm}^{2}$ enabled a lowering of the operating temperature by $50^{\circ} \mathrm{C}$ (to $225^{\circ} \mathrm{C}$ from the optimum dark temperature of $275^{\circ} \mathrm{C}$ ) with no loss in methanol yield $\left(\sim 245 \mathrm{~g} \cdot \mathrm{h}^{-1} \cdot \mathrm{kg} \cdot \mathrm{cat}^{-1}\right)$. This easing of process severity was due primarily to a favourable increase in selectivity at lower temperature. Interestingly, studies with bandpass filters and cold mirrors showed that only simultaneous irradiation into both the ZnO bandgap (UV, $\lambda<400 \mathrm{~nm}$ ) and $\mathrm{Cu} / \mathrm{CuO}_{\mathrm{x}} \mathrm{LSPR} /$ bandgap (visible, $\lambda=420-800 \mathrm{~nm}$ ) gave a photo-enhancement in methanol synthesis. On the contrary, individual excitation with UV or visible bands favoured the formation of CO instead (see Fig. 25A). In-situ DRIFTS provided evidence in support of the view that lowtemperature synthesis of methanol proceeds at the $\mathrm{Cu}-\mathrm{Zn}$ oxide interfacial perimeter of the catalyst with the two main phases acting cooperatively; the metal supplying $\mathrm{H}$-atoms to the adjacent oxide in a defective state (with O-vacancies), which in turn anchors $\mathrm{CO}_{2}$ and partially hydrogenated intermediates during stepwise reduction (via H-spillover) (Fig. 27B).

This dual cooperative functionality appears essential to the synthesis mechanism such that only broad-band photo-excitation, resulting in less directional flow of charge carriers from/to any single component, yields the best results. From other works summarized in this review, a clear pattern is 
emerging that photon absorption of various kinds readily drives dissociation of molecular $\mathrm{H}_{2}$, usually over metals $(\mathrm{Cu}$ in this case) but also over certain semiconductors. Establishment of a definitive mechanism, e.g., homolytic vs. heterolytic, needs further investigation. The implication in this $\mathrm{CO}_{2}$-to-methanol work is that photons also assist (via generation of charge carriers, hot electrons, etc.) in the activation of key surface adsorbates, e.g., formate, dioxomethylene, etc., directly on $\mathrm{ZnO}$.

While the foregoing commentary shows that photo-thermo synergies in enhancing methanol synthesis are growing rapidly, evidence for their influence in higher alcohols synthesis, especially in improving selectivity [163], would also be of great impact. $2^{\text {nd }}$ generation solar biorefineries would gain major operational benefits by coupling the principal biofuel and platform chemical cellulosic ethanol with renewable (solar) methanol (RM) in an industrial symbiosis, as illustrated in Fig. 28. These include a reduction in carbon footprint by 50\%, a major increase in carbon (atom) efficiency in biomass utilization from $55 \%$ to $73 \%$, and a rise in thermal efficiency from $66 \%$ to over $80 \%$ [164].

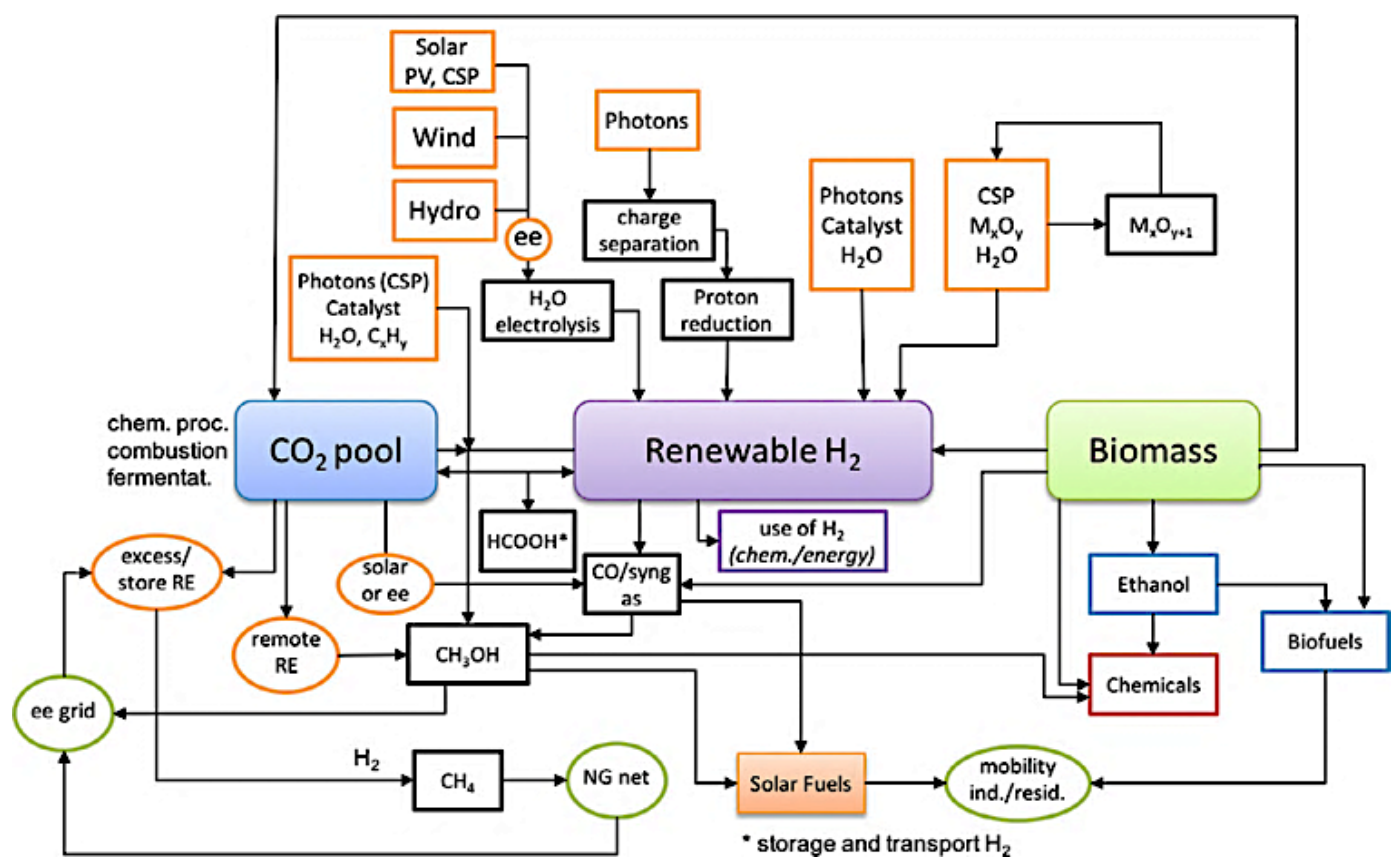


Figure 28. The solar-biorefinery concept for energy storage as fuels and platform chemicals, modified from the original by Schlögl [165] (reproduced from ref. [164] with permission from Elsevier).

Recently, the Garcia/Corma group in Valencia have reported exciting advances in $\mathrm{CO}_{2}$ hydrogenation using simulated sunlight to promote selectivity towards $\mathrm{C}_{2}+$ hydrocarbons and ethanol over a core/shell-structured catalyst made from earth-abundant materials (Fig. 29) [166]. This $\mathrm{Co@C} \mathrm{nanocomposite} \mathrm{thermal} \mathrm{catalyst} \mathrm{consisted} \mathrm{of} \mathrm{metallic} \mathrm{Co} \mathrm{decorated} \mathrm{with} \mathrm{CoO}_{\mathrm{x}}$ and a $\mathrm{Na}$ promoter, surrounded by thin carbon layers. While $\mathrm{CH}_{4}$ was the main product in the dark $\left(235^{\circ} \mathrm{C}\right.$, 2.8 bar), irradiation from a $1000 \mathrm{~W}$ Xe lamp with AM1.5 filter at $24 \mathrm{~kW} / \mathrm{m}^{2}$ (24 suns) under otherwise identical conditions raised the selectivity towards $\mathrm{C}_{2+}$ hydrocarbons to $50 \%$, and ethanol to $6.5 \%$ but only at modest $(<50 \%) \mathrm{CO}_{2}$ conversion. Although the possible origin of photo-sensitivity was not discussed, it was ascribed to mainly the UV component and considered a genuine electronic effect (not an artifact of optical heating) because the selectivity shifted back to $\mathrm{CH}_{4}$ in dark control tests at higher temperature. A mechanism was proposed based on studies of cobalt carbide intermediates using ambient pressure XPS and operando Raman spectroscopy. Re-direction of the product distribution by light irradiation was attributed to stabilization of $\mathrm{CO}$ intermediates at the surface, promoting higher selectivity towards ethanol via a $\mathrm{CO}$ insertion mechanism. For further clarification, the reader is referred to the detailed mechanistic summary located in the legend of Fig. 29 overleaf. 

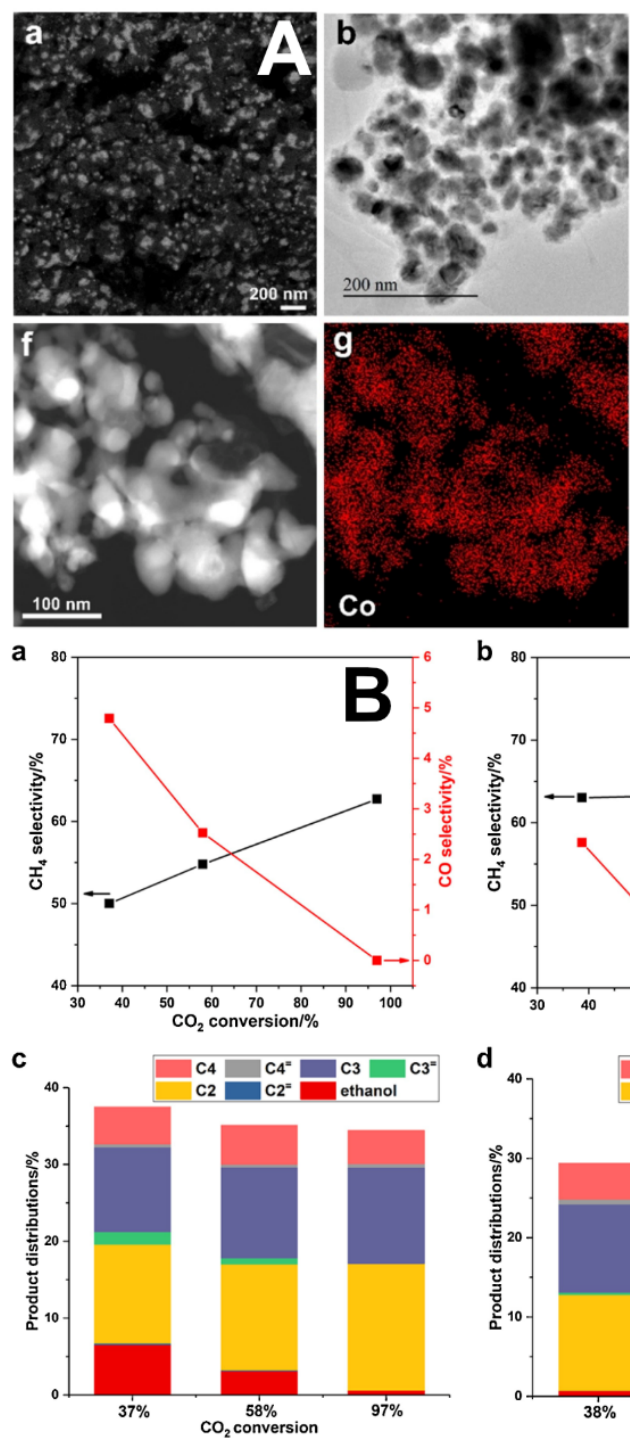
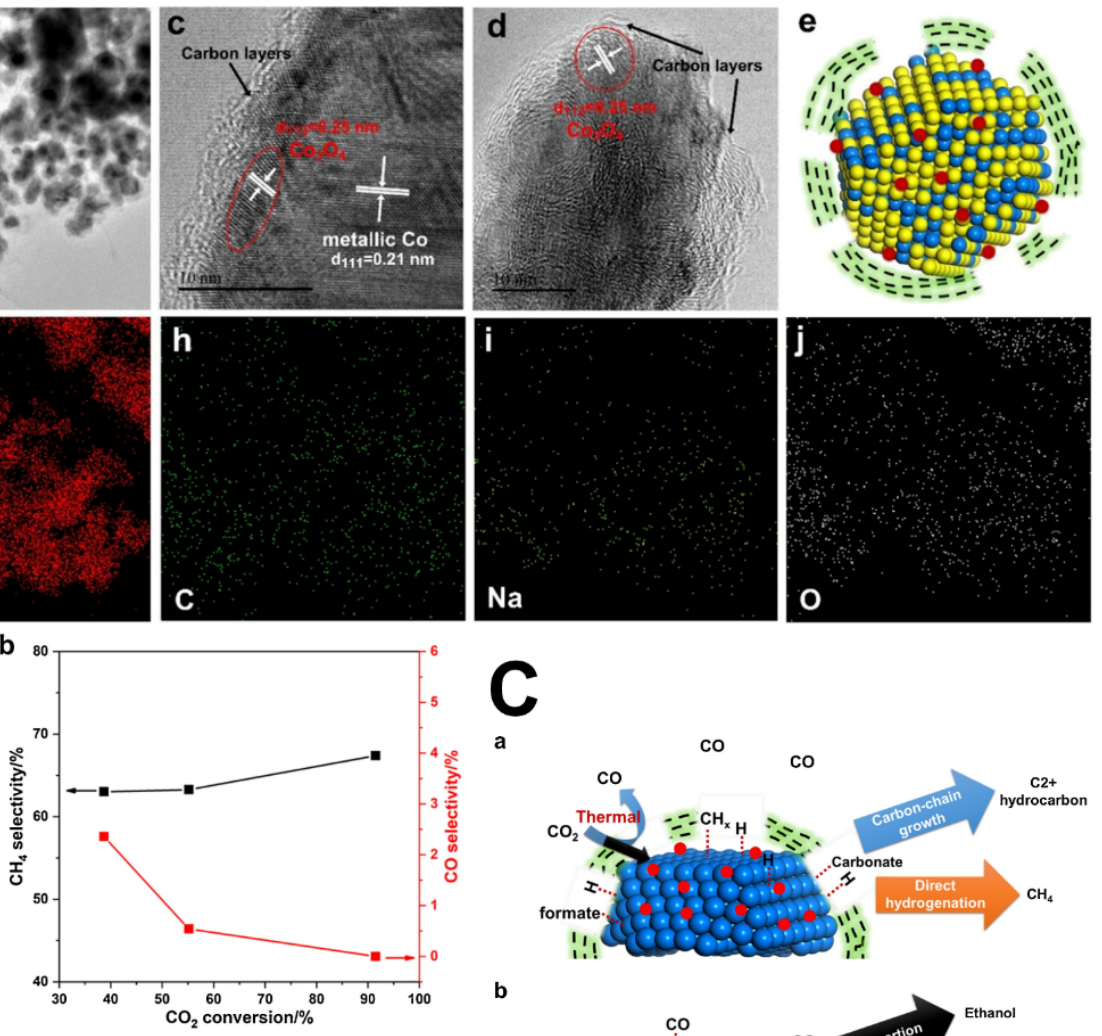

a co
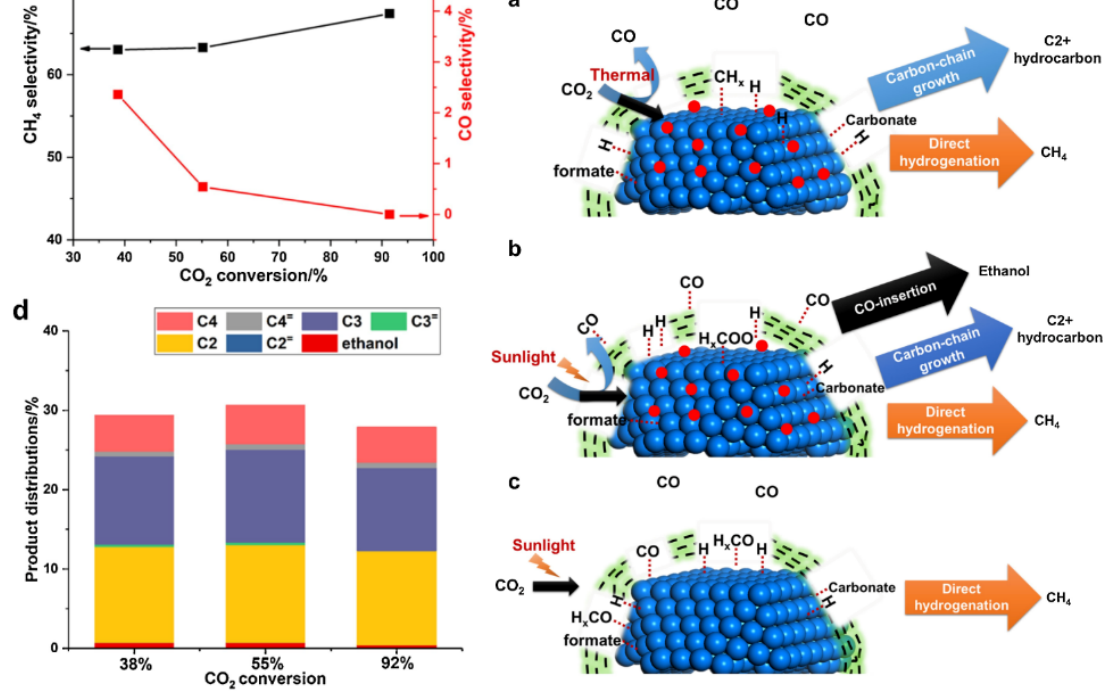

Figure 29. (A) Structural characterization of Na-Co@C catalysts developed by the group of Corma/Garcia [166] (a) Field-emission scanning electron microscopy (FESEM) image, (b) transmission electron microscopy (TEM) images, and (c, d) high-resolution transmission electron microscopy (HRTEM) images of Na$\mathrm{Co} @ \mathrm{C}$ sample, (e) schematic illustration of one $\mathrm{Na}-\mathrm{Co} @ \mathrm{C}$ nanoparticle. $\mathrm{Co}, \mathrm{CoO}_{x}$ and $\mathrm{Na}$ are represented by yellow, blue and red balls, respectively, while the carbon layers are represented as shaded dashed lines. (f) Scanning transmission electron microscopy (STEM) image and (g-j) corresponding elemental mapping of different elements in the Na-Co@C sample; (B) Evolution of the products during $\mathrm{CO}_{2}$ hydrogenation at different conversion levels with Na-Co@C under photothermal and thermal conditions. (a) Selectivity to $\mathrm{CH}_{4}$ and $\mathrm{CO}$ under photothermal conditions. (b) Selectivity to $\mathrm{CH}_{4}$ and $\mathrm{CO}$ under thermal conditions. (c) 
Selectivity to $\mathrm{C}_{2+}$ hydrocarbons and ethanol under photothermal conditions, (d) Selectivity to $\mathrm{C}_{2+}$ hydrocarbons and ethanol under thermal conditions. Reaction conditions: $100 \mathrm{kPa}, 235^{\circ} \mathrm{C}$, and irradiations using a solar simulator equipped with a 1000W Xe lamp coupled with an AM1.5 filter, corresponding to an irradiance at the catalyst surface of $24 \mathrm{~kW} \mathrm{~m}^{-2}$; (C) Schematic illustration of the hydrogenation mechanism under thermal and photothermal conditions ( $\mathrm{Na}$ is shown with red circles): (a) under thermal conditions, Na-Co@C catalyst mainly produce $\mathrm{CH}_{4}$ and $\mathrm{C}_{2+}$ hydrocarbons, (b) under photothermal conditions, ethanol is also produced on the $\mathrm{Na}-\mathrm{Co} @ \mathrm{C}$ catalyst as well as $\mathrm{C}_{2+}$ hydrocarbon and $\mathrm{CH}_{4}$, (c) under photothermal conditions, the enol species seem to be stabilized on the Co@C catalyst (ie. in the absence of sodium), and the $\mathrm{C}-\mathrm{OH}$ scission favors the formation of $\mathrm{CH}_{4}$ as the predominant product, due to the fast hydrogenation of the intermediates instead of $\mathrm{C}-\mathrm{C}$ coupling reaction (reproduced from ref. [166] with permission from Elsevier).

\subsubsection{Dry reforming reaction}

While the RWGS reaction is a way to obtain $\mathrm{CO}$ from $\mathrm{CO}_{2}$ hydrogenation for operating downstream syngas process, $\mathrm{CO}_{2}$ ('dry') reforming of methane is a way to directly convert two high impact greenhouse gases into syngas for Fischer-Tropsch synthesis and other downstream reactions (eqn.6) [167-169].

$\mathrm{CO}_{2}+\mathrm{CH}_{4} \rightarrow 2 \mathrm{H}_{2}+2 \mathrm{CO}$

The search for photo-thermo dry reforming catalysts based on noble metals ( $\mathrm{Rh}, \mathrm{Pd}, \mathrm{Pt})$ as well as transition $(\mathrm{Ni}, \mathrm{Co})$ metals is driven by the need to overcome the main drawbacks of hydrocarbon(s) thermal reforming, viz., the elevated temperatures necessary to drive such endothermic reactions, and related catalyst deactivation due to metal sintering and/or carbon deposition. However, it must be said that, although combining light and heat allows the working temperature of the catalysts to be significantly reduced, this latter remains quite elevated. 
Photo-thermo bimetallic dry reforming catalysts are reported to employ a plasmonic promoter for enhancing the performance of noble metal catalysts. Remarkable results were reported using $\mathrm{Au}$, and the strong activity enhancement observed with the bimetallic Rh-Au/SBA-15 catalyst upon visible light illumination $\left(420-800 \mathrm{~nm}\right.$, at $\left.500^{\circ} \mathrm{C}\right)$ was demonstrated to result from the LSPR effect from the Au promoter, with the implication that excited (hot) electrons facilitate the activation of the adsorbed reactants and intermediates by polarizing both reactant $\left(\mathrm{CO}_{2}\right.$ and $\left.\mathrm{CH}_{4}\right)$ molecules (Fig. 30A,B) [170].
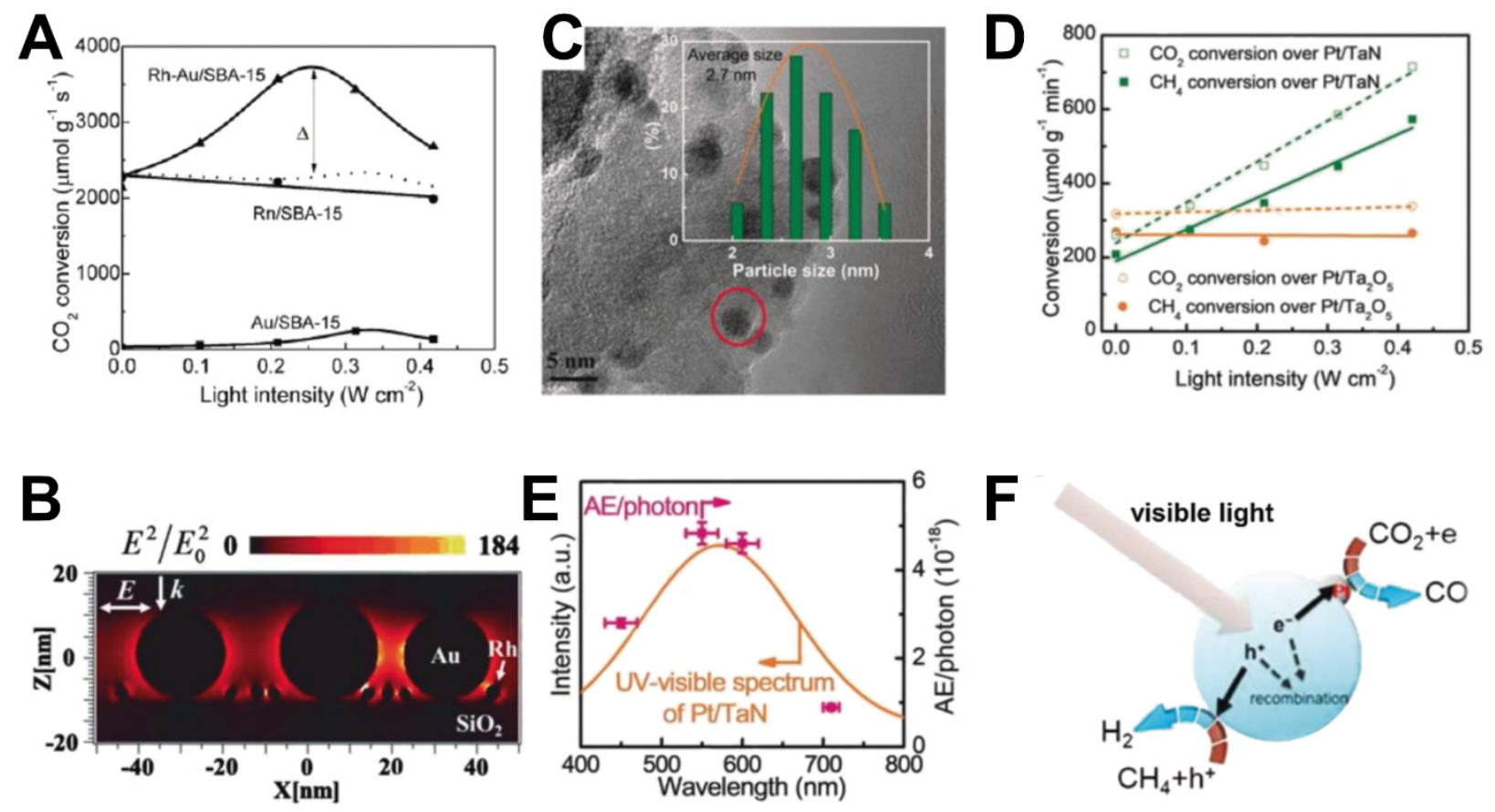

Figure 30. Photo-thermo dry reforming reaction over the Rh-Au/SBA-15 catalyst with (A) the evolution of the reforming activity as a function of the light intensity $\left(420-800 \mathrm{~nm}, 500^{\circ} \mathrm{C}\right)$ and $(\mathbf{B})$ the spatial distribution of the electromagnetic fields ; Photo-thermo dry reforming reaction over the $\mathrm{Pt} / \mathrm{TaN}$ catalyst with (C) HR-TEM image of the catalyst, (D) the evolution of the reforming activity as a function of the light intensity $\left(500^{\circ} \mathrm{C}\right),(\mathbf{E})$ the correlation between the UV-vis spectra and the Activity Enhancement induced by one photon (AE/photon) and (F) the proposed reaction mechanism. (adapted from ref [29] with permission of Wiley-VCH). 
By contrast, both alloy structure and plasmonic properties were proposed to explain the great improvement of the stability of the $\mathrm{Pd}_{1-\mathrm{x}} \mathrm{Au}_{\mathrm{x}} / \mathrm{Al}_{2} \mathrm{O}_{3}$ catalysts (notably for $\mathrm{x}=0.1$ ) under visible light [171], while associating plasmonic Auto $\mathrm{Pt}$ on a $\mathrm{SiO}_{2}$ support allowed to extend the activation wavelength range thanks to the combination of both Au and Pt LSPR effects and in consequence to apply a broad-band solar energy source $\left(300-800 \mathrm{~nm}\right.$ at $\left.0.6 \mathrm{~W} / \mathrm{cm}^{2}\right)[44]$.

Kinetic measurements showed a significant reduction of the activation energy upon illumination, with consequently the obtention of enhanced $\mathrm{CO}_{2}$ conversion rates compared to the dark conditions, and the use of lower reaction temperatures $\left(350-500^{\circ} \mathrm{C}\right)$ in addition to an increased stability for some of the catalysts. Interestingly, a non-expected mechanistic insight was reported by Liu et al. by studying $\mathrm{Ni} / \mathrm{SiO}_{2}$ catalysts over a large $\mathrm{Ni}$ size range. They revealed the structure-sensitive nature of the photo-thermo dry reforming reaction, with metallic interband transitions dominating in large Ni particles while the LSPR effect was predominant in small particles [172].

Beside the key-role of both the plasmonic promoter and the reforming metal catalyst, the important role of the support was also underlined, and the use of Si-modified $\mathrm{CeO}_{2}$, black $\mathrm{TiO}_{2}$ and TaN as supported has also been reported [173-175]. In this frame, it is worth putting forward the beneficial optical properties of the TaN support, which polarity was reported to facilitate the photogenerated charge under irradiation for allowing the $\mathrm{CO}_{2}$ reduction and the $\mathrm{CH}_{4}$ oxidation to be driven separately by the electrons and the holes during the photo-thermo dry reforming (Fig. 30F) [29]. The results obtained at the (high) temperature of $500^{\circ} \mathrm{C}$ on the $\mathrm{Pt} / \mathrm{TaN}$ catalyst with a wellcontrolled nanoparticle size for the metallic co-catalyst revealed the linear dependence of both $\mathrm{CO}_{2}$ and $\mathrm{CH}_{4}$ conversions with the incident light intensity (Fig. 30C,D), while the authors correlated the absorption optical properties of the Pt/TaN catalyst with the activity enhancement induced by one photon, measured to be maximum at the wavelength of ca. $570 \mathrm{~nm}$ (Fig. 30E).

\subsubsection{Artificial photosynthesis}

The process of natural photosynthesis converts solar energy into chemical bond energy stored in organic biopolymers, the building blocks of all living organisms and, over millions of years of 
geochemical processing, also the source of fossil hydrocarbons (oil, gas and coal) [176-178]. Artificial photosynthesis refers to the re-direction or mimicking of the natural process to yield endproducts of greater value and versatility in chemical industrial processing. It is discussed here as a special case of $\mathrm{CO}_{2}$ hydrogenation in which the reductants $(\mathrm{H}$ atoms) are derived from water by solar (visible) photonic excitation. In principle, it is an ideal process for light-to-chemical energy conversion and storage based on unlimited natural resources, $\mathrm{CO}_{2}$ and $\mathrm{H}_{2} \mathrm{O}$. However, the highly endergonic process of water splitting implicitly involved in the overall mechanism represents a major technical hurdle to advancement. Thus, the energetics in the synthesis of a valuable solar fuel like methanol (eqn.7, $\Delta \mathrm{G}^{0}=+702 \mathrm{~kJ} . \mathrm{mol}^{-1}$ ) are completely dominated by the electrochemical half-cell for water splitting $\left(\mathrm{O}_{2}\right.$ evolution, eqn.8), although admittedly such a $6 \mathrm{e}^{-}$process can be driven, at least in principle, by visible photons $(\lambda \leq 620 \mathrm{~nm})$.

$$
\begin{array}{ll}
\mathrm{CO}_{2}+2 \mathrm{H}_{2} \mathrm{O} \rightarrow \mathrm{CH}_{3} \mathrm{OH}+3 / 2 \mathrm{O}_{2} & {\left[\mathrm{E}^{0}=+1.21 \mathrm{~V}\right]} \\
3 \mathrm{H}_{2} \mathrm{O} \rightarrow 6 \mathrm{H}^{+}+6 \mathrm{e}^{-}+3 / 2 \mathrm{O}_{2} & {\left[\mathrm{E}^{0}=+1.23 \mathrm{~V}\right]} \\
\mathrm{CO}_{2}+6 \mathrm{H}^{+}+6 \mathrm{e}^{-} \rightarrow \mathrm{CH}_{3} \mathrm{OH}+\mathrm{H}_{2} \mathrm{O} & {\left[\mathrm{E}^{0}=-0.02 \mathrm{~V}\right]}
\end{array}
$$

However, we have to stress that this section deals mainly with conventional photocatalysts exposed to gas phase $\mathrm{CO}_{2} / \mathrm{H}_{2} \mathrm{O}$ at relatively high temperatures $\left(\mathrm{T}>100^{\circ} \mathrm{C}\right)$ to benefit from any photo-/thermo synergy. Indeed in a photoelectrode setup, most systems operate in aqueous liquid electrolyte, so that, although thermal enhancement of photoelectrochemical current is known, there are clear practical limitations for tests above $100^{\circ} \mathrm{C}$. Deconstruction of eqn. 7 into two half-cell reactions (eqns. $8 \& 9$ ) is therefore only indicated for clarification of the redox energetics, while it may also have mechanistic significance. It cannot be coincidental that metallic $\mathrm{Cu}$ (or semiconducting $\mathrm{Cu}_{2} \mathrm{O}$ ) is a ubiquitous co-catalyst in both photoelectrochemical and thermochemical $\mathrm{CO}_{2}$ reduction. Water oxidation (eqn.8) occurs over photo-anodes based on enhanced visible-absorbing single-phase oxides such as O-deficient $\mathrm{H}$-intercalated $\mathrm{WO}_{3}$ [179], $\alpha-\mathrm{Fe}_{2} \mathrm{O}_{3}[180,181]$, or better still $1^{\text {st }}$-row transition metal oxides $\mathrm{Co}, \mathrm{Fe}, \mathrm{Ni}$, preferably in mixed layered- 
double-hydroxide (LDH) form [182]. In $\mathrm{CO}_{2}$ activation and hydrogenation (eqn.9), there is growing evidence that $\mathrm{Cu}$-based $\left(\mathrm{Cu} / \mathrm{Cu}_{2} \mathrm{O}\right)$ photocathode materials are effective $[183,184]$. This is not surprising as eqn.9 is simply the electrochemical representation of methanol synthesis from $\left[\mathrm{CO}_{2}+3 \mathrm{H}_{2}\right]$, in which the simultaneous presence of metallic and oxidized $\mathrm{Cu}$ is key to the remarkable activity of the $\mathrm{Cu} / \mathrm{ZnO} / \mathrm{Al}_{2} \mathrm{O}_{3}$ industrial methanol synthesis catalyst [185]. Assuming that methanol is the preferred $\mathrm{C}_{1}$ solar fuel (over gaseous products like $\mathrm{CH}_{4}$ and $\mathrm{CO}$ ) [186] and in view of the known selectivity advantage of the thermochemical route [187], the best prospects for the practicable (Lab-based) early exploration of photo-thermo enhancement in artificial photosynthesis are in mild heating of $\mathrm{CO}_{2} / \mathrm{H}_{2} \mathrm{O}$ vapours at ambient pressure over a visible/NIR-responsive catalyst under a high-power solar simulator (up to 10 suns). Studies showing photo-thermo synergies in methanol synthesis from $\mathrm{CO}_{2} / \mathrm{H}_{2}$, as summarized in section 7.3.3. (above), should act as useful guidelines in catalyst development.
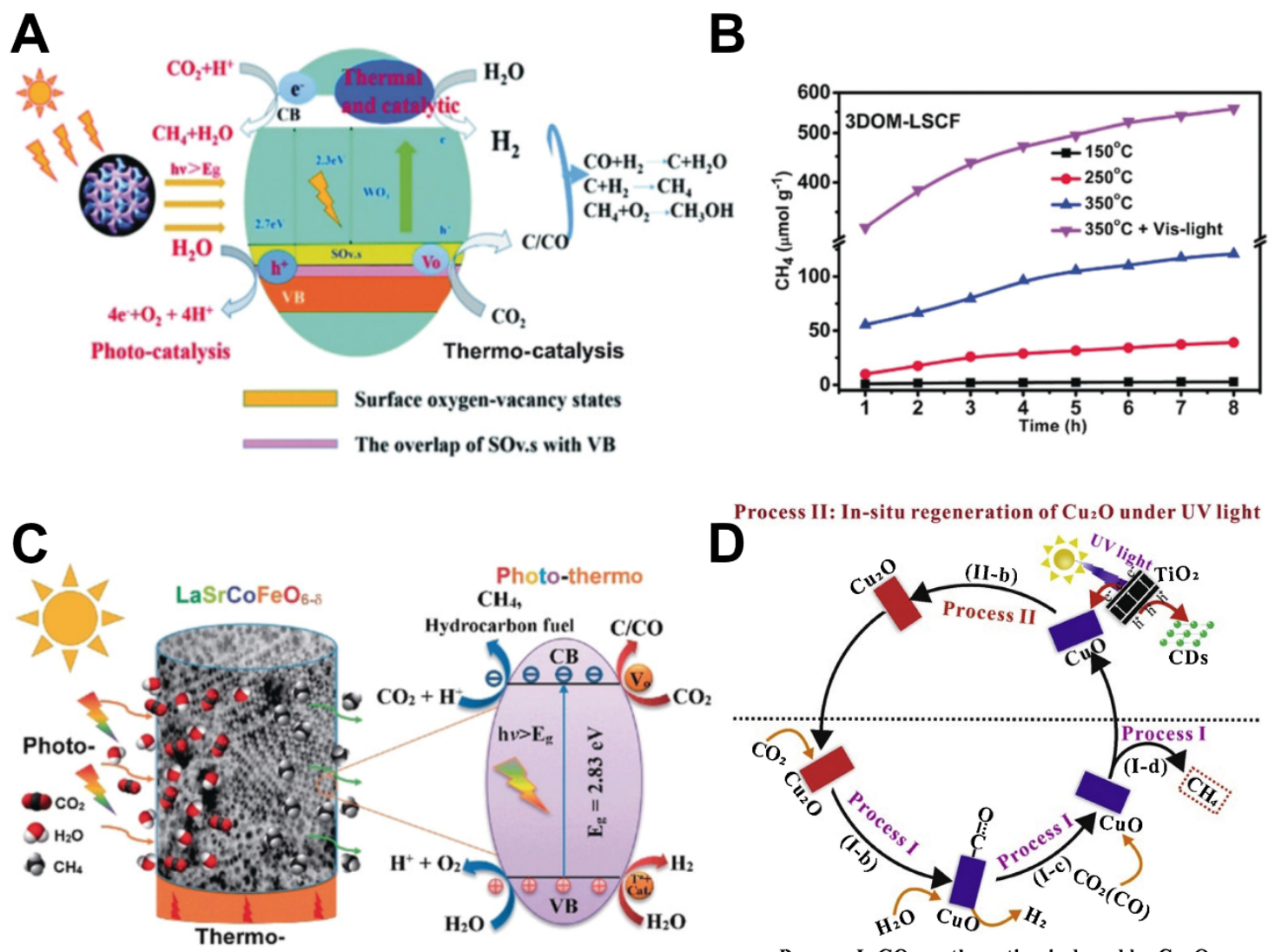

Process I: $\mathrm{CO}_{2}$ methanation induced by $\mathrm{Cu}_{2} \mathrm{O}$ 
Figure 31. Artificial photosynthesis with surface oxygen-deficient photo thermo catalysts. (A) Mechanism proposed by L. Wang et al. on oxygen-deficient $\mathrm{WO}_{3}$ [188]. (B) Striking photoenhancement of (thermo-catalytic) activity on oxygen-deficient 3D-ordered $\mathrm{LaSrCoFeO}_{6-\delta}$ double perovskites, and (C) the mechanism proposed by Ha et al. (reproduced from ref [189]with permission of Wiley-VCH). (D) Mechanism suggested by $\mathrm{K}$. Wang et al. on a $\mathrm{Cu}_{\mathrm{x}} \mathrm{O} / \mathrm{TiO}_{2}-\mathrm{CDs}$ catalyst, representing $\mathrm{CO}_{2}$ reduction by $\mathrm{Cu}_{2} \mathrm{O}$ above $150{ }^{\circ} \mathrm{C}$ (lower part), and the in-situ regeneration of $\mathrm{Cu}_{2} \mathrm{O}$ from $\mathrm{CuO}$ under $\mathrm{UV}$ irradiation (upper part) (reproduced from ref [61] with permission of Elsevier).

It is perhaps unsurprising that the limited progress achieved to date in this challenging field has come from studies on compounds chemically and structurally related to water oxidation electrocatalysts (eqn.8) [190]. Highly-engineered oxygen-deficient photo-thermo catalysts, e.g., $\mathrm{WO}_{3}$ or 3D-ordered $\mathrm{LaSrCoFeO}_{6-\delta}$ double perovskites have shown promise although both have poor selectivity, favouring $\mathrm{CH}_{4}$ evolution over $\mathrm{CH}_{3} \mathrm{OH}$.

In $\mathrm{H}$-reduced $\mathrm{WO}_{3}$, Wang et al. reported modest rates of $\mathrm{CH}_{4}$ and $\mathrm{CH}_{3} \mathrm{OH}$ production at $250^{\circ} \mathrm{C}$ under visible illumination, preferentially over the most O-deficient (black) samples at $\sim 10$ and $\sim 1$ $\mu$ mol.g.cat ${ }^{-1} \cdot \mathrm{h}^{-1}$, respectively [188]. However, these rates were only slightly higher than the dark controls. As shown in Fig. 31A, they proposed a mechanism in which the surface oxygen vacancies play the key-role in thermal activation, promoting dissociation of $\mathrm{CO}_{2}$ to $\mathrm{CO}$, while the coupling of thermal and photonic energy induces more favourable electron excitation and relaxation. Methanol is believed to form via $\mathrm{CO}$ hydrogenation.

In studies by $\mathrm{Ha}$ et al., 3D-ordered $\mathrm{LaSrCoFeO}_{6-\delta}$ double perovskites showed exceptional photo-thermo activity in $\mathrm{CH}_{4}$ evolution, reaching $\sim 100 \mu$ mol.g.cat ${ }^{-1} \cdot \mathrm{h}^{-1}$ at $350{ }^{\circ} \mathrm{C}$, due largely to a x5 visible photo-enhancement of the dark rate (Fig. 31B) [189]. As shown in Fig. 31C, photoexcitation is believed to be responsible for driving both $\mathrm{H}_{2}$ generation from $\mathrm{H}_{2} \mathrm{O}$ and subsequent $\mathrm{CO}_{2}$ methanation, for which ample evidence has already been reported in section 6.3.1. The Odeficient sites, believed to be sufficiently reactive to abstract $\mathrm{O}$ atoms from $\mathrm{CO}_{2}$ in the dark, may 
also be involved in the mechanism but probably in a non-catalytic manner as their regeneration appears problematic.

Wang et al. have reported on a carbon dot-grafted $\mathrm{Cu} / \mathrm{TiO}_{2}$ catalyst $\left(\mathrm{Cu} \mathrm{x}_{\mathrm{x}} \mathrm{O} / \mathrm{TiO}_{2}-\mathrm{C}\right)$ active in thermally-enhanced (UV) photo-methanation up to $250^{\circ} \mathrm{C}$, reaching $53 \mu \mathrm{mol}$.g.cat ${ }^{-1} \cdot \mathrm{h}^{-1}$, or $5 \mathrm{x}$ the dark rate [61]. As depicted in Fig. 31D, they proposed a 3-step mechanism in which $\mathrm{Cu}_{2} \mathrm{O}$ (formed during $\mathrm{H}_{2}$ pre-treatment of $\mathrm{CuO}$ ) reduces $\mathrm{CO}_{2}$ to $\mathrm{CO}$ and reverts to $\mathrm{CuO}$ under irradiation. The $\mathrm{CO}$ in turn generates $\mathrm{CO}_{2} / \mathrm{H}_{2}$ via the water-gas shift reaction in the dark at $150^{\circ} \mathrm{C}$. The syngas mixture then yields $\mathrm{CH}_{4}$ under irradiation. A promotional role of the carbon dot was ascribed to stabilization of the active $\mathrm{Cu}(\mathrm{I})$ form via trapping and storage of excess electrons that would otherwise reduce $\mathrm{Cu}(\mathrm{I})$ to inactive metallic $\mathrm{Cu}$. It should be noted that the photo-methanation rate over the $\mathrm{Cu} / \mathrm{TiO}{ }_{2}$ control under irradiation never exceeded $10 \mu \mathrm{mol} . \mathrm{g} . \mathrm{cat}^{-1} \cdot \mathrm{h}^{-1}$ at any temperature.

Following up on this work, the same (Zhao) group have explored Mo-modified $\mathrm{WO}_{3}$ [191], and $\mathrm{LaNi}_{x} \mathrm{Fe}_{1-x} \mathrm{O}_{3}(0 \leq x \leq 1)$ perovskites [192] in $\mathrm{CO}_{2}$ reduction by $\mathrm{H}_{2} \mathrm{O}$. As compared to $\mathrm{H}$-reduced $\mathrm{WO}_{3}$, the Mo-loaded variant tested under the same conditions $\left[\lambda_{\text {vis }}=420-780 \mathrm{~nm}(3.2\right.$ suns $), \mathrm{T}=$ $250^{\circ} \mathrm{C}$ ] produced $\mathrm{CH}_{3} \mathrm{OH}$ selectively in preference to $\mathrm{CH}_{4}$ but at the same low rate of $\sim 1$ $\mu$ mol.g.cat ${ }^{-1} \cdot h^{-1}$. For the $\mathrm{LaNi}_{\mathrm{x}} \mathrm{Fe}_{1-\mathrm{x}} \mathrm{O}_{3}$ perovskite, its performance in $\mathrm{CH}_{4}$ evolution peaked at the composition $\mathrm{LaNi}_{0.4} \mathrm{Fe}_{0.6} \mathrm{O}_{3}(\mathrm{x}=0.4)$, reaching $\sim 80 \mu \mathrm{mol}$.g.cat ${ }^{-1} \cdot \mathrm{h}^{-1}\left(471 \mu \mathrm{mol}\right.$.g.cat $\left.{ }^{-1} \cdot \mathrm{h}^{-1}\right)$ over $6 \mathrm{~h}$, but selectivity to methanol was very low $(<3 \%)$. The data cannot be compared directly with those for $\mathrm{WO}_{3}$ as a higher temperature $\left(350^{\circ} \mathrm{C}\right)$ was used here. However, among a wide range of perovskites evaluated for artificial photosynthesis in the literature, both $\mathrm{LaSrCoFeO}_{6-\delta}$ [189] and $\mathrm{LaNi}_{0.4} \mathrm{Fe}_{0.6} \mathrm{O}_{3}$ compare favourably.

Re-visiting the classic $\mathrm{Pt} / \mathrm{TiO}_{2}$ photocatalyst, $\mathrm{Yu}$ et al. [58] found that yellow O-deficient surface-disordered $\mathrm{TiO}_{2-\mathrm{x}}$ supporting small $\mathrm{Pt}$ nanoparticles $(\sim 2 \mathrm{~nm})$ showed photoactivity in $\mathrm{CO}_{2}$ reduction by $\mathrm{H}_{2} \mathrm{O}$ in high selectivity to $\mathrm{CH}_{4}(87 \%)$ along with a major thermal enhancement at $120^{\circ} \mathrm{C}$, raising yields nearly 100 -fold to $\sim 170 \mu \mathrm{mol}$.g.cat ${ }^{-1} \cdot \mathrm{h}^{-1}$. However no dark control tests at $120^{\circ} \mathrm{C}$ were reported. Similar behavior was observed over the pure oxide except that the dominant product was $\mathrm{CO}$. 
To summarize, although the evidence for photo-thermo-synergies in artificial photosynthesis are evidently real, the rates of $\mathrm{CO}_{2}$ reduction by $\mathrm{H}_{2} \mathrm{O}$ remain far below those achievable with $\mathrm{H}_{2}$ as reductant. Furthermore, the selectivity remains highly-restricted, being confined to $\mathrm{C}_{1}$ gases with little evidence for simple oxygenates like methanol. However artificial photosynthesis would clearly stand out from other processes by avoiding the consumption of high amount of renewable $\mathrm{H}_{2}$, and in consequence increasing the sustainability of the overall process.

\subsection{Fischer-Tropsch synthesis and $\mathrm{C}-\mathrm{C}$ coupling}

One of the greatest obstacles in the transition to a sustainable chemical economy will be how to maintain a workable supply of hydrocarbon fuels like synthetic gasoline, diesel, and aviation kerosene. While conventional (fossil) resources are dwindling or under regulatory constraints from environmental concerns, the sourcing of hydrocarbons from biomass, a highly oxygenated feedstock, implies a dramatic re-orientation in applied catalysis towards hydrodeoxygenation $[193,194]$ and a massive increase in supply of renewable $\mathrm{H}_{2}$, e.g., from solar-driven water electrolysis, to cover the limited amount obtainable by biomass gasification [195]. Alternatively, a sustainable route via steam-reforming of synthetic natural gas followed by Fischer-Tropsch (FT) catalysis (gasto-liquid, GtL) would circumvent major issues relating to feedstock incompatibility.

For example, renewable syngas comprising recycled industrial sources of $\mathrm{CO}_{2}$ mixed with renewable $\mathrm{H}_{2}$ is not immediately suitable for FT-synthesis (FTS) as the required chain growth (up to $\mathrm{C}_{30+}$ depending on the target fuel [196]), works best on CO. Alongside methanol and dimethyl ether (DME, substitute diesel), emerging power-to-liquid (PtL) technologies for FT-conversion of $\mathrm{H}_{2} / \mathrm{CO}_{2}$ are dependent on earth-abundant supported metals $\mathrm{Fe}$ and Co that also modify the feedstock composition in situ and generate CO via the reverse water-gas shift (RWGS) process [197]. In view of the large scale of operation ultimately necessary to supply these transportation fuels, the technological incentive to improve FT-process efficiency is substantial, e.g., by lowering operating temperatures $\left(300-340^{\circ} \mathrm{C}\right.$ in the case of $\left.\mathrm{Fe}[196]\right)$, or pressures (20-50 bar), etc., on both a cost and environmental basis (renewables are virtually sulphur-free). An early sign of the 'greening' of FT 
technology is a report by Xiao et al.on the use of water-soluble Ru nanoclusters active below $200^{\circ} \mathrm{C}$ [198].

Guo et al. designed a graphene-supported worm-like Ru nanostructured photo-thermo catalyst for excitation by visible light $\left(400-800 \mathrm{~nm}\right.$ ) from a $300 \mathrm{~W}$ Xe lamp at up to $0.5 \mathrm{~W} / \mathrm{cm}^{2}$ (5 suns) under syngas flow $\left(2 \mathrm{H}_{2}: 1 \mathrm{CO} ; \mathrm{P}_{\text {tot }}=30\right.$ bar $)$ [53]. Significant activity was already observed at the remarkably low temperature of $150{ }^{\circ} \mathrm{C}$ in the dark. Under increasing illumination power, a linear rise in $\mathrm{CO}$ conversion rate was observed (see Fig. $32 \mathrm{C}$ ), amounting to $14.4 \mathrm{~mol} \mathrm{COmol}{ }^{-1} \mathrm{Ru}^{-1} \mathrm{~h}^{-1}$, of which the visible component was $6.6 \mathrm{~mol}$, or a $43 \%$ increase. Studies with bandpass filters showed that the photo-enhancement was wavelength-dependent, mimicking the broad visible tail of the $\mathrm{Ru}$ falling off towards the infrared. As shown in Fig. 32A, they propose a mechanism in which hot electrons are created by interband transitions induced in shape-dependent $\mathrm{Ru}$ nanoparticles (see also Sastre et al. [151] - 7.3.1 Methanation). Product selectivity was little affected with 85\% hydrocarbons (peaking at $\left.\mathrm{C}_{5}-\mathrm{C}_{12}\right), 14 \%$ oxygenates, and with low levels of undesirable products $(<3$ $\% \mathrm{CH}_{4},<1 \% \mathrm{CO}_{2}$ ) (Fig. 32D). The graphene is believed to suppress the water-gas shift process responsible for $\mathrm{CO}_{2}$ production. Light olefins constituted $>50 \%$ of the $\mathrm{C}_{2}-\mathrm{C}_{4}$ fraction. As shown in Fig. 32B, the main kinetic effect was a lowering of the apparent activation energy from $c a .72$ $\mathrm{kJ} / \mathrm{mol}$ in the dark to $c a .56 \mathrm{~kJ} / \mathrm{mol}$ under illumination. 

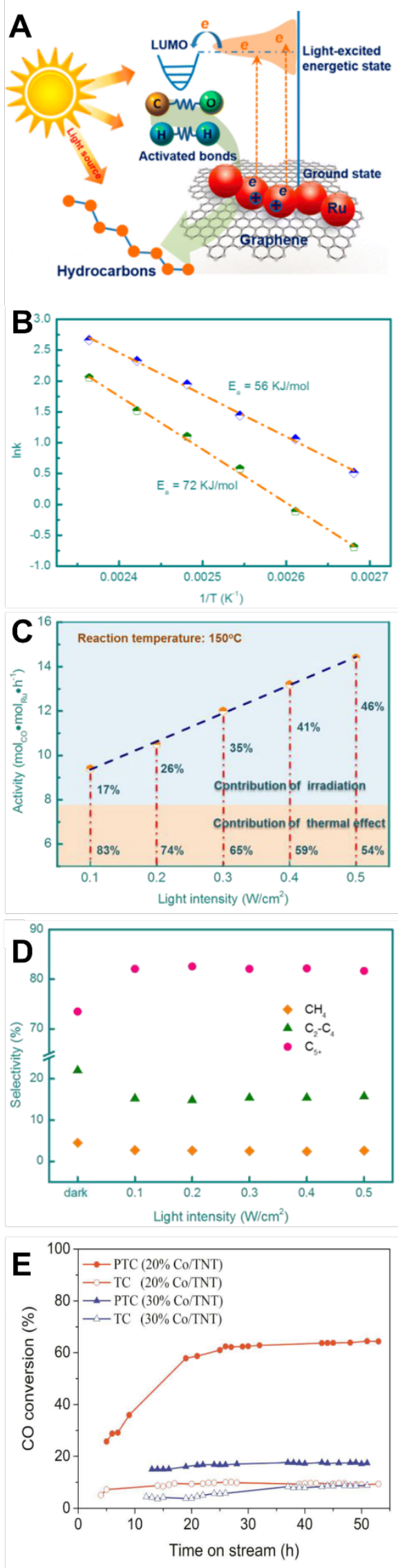
Figure 32. (A-D) Photo-enhanced Fischer-Tropsch synthesis on graphene-supported worm-like Ru nanostructures by visible light (400-800 nm) irradiation at up to $0.5 \mathrm{~W} / \mathrm{cm}^{2}$ (5 suns).(A) Proposed mechanism of Guo et al. [52], in which bound electrons of metallic Ru are energetically stimulated via interband transitions upon absorption; (B) influence of the irradiation on the Arrhenius plots for CO conversion ; (C) light intensity-dependence of the catalytic activity that reveals that the activity linearly increases with light intensity ; and (D) $\mathrm{C}_{5+}$ hydrocarbons, $\mathrm{CH}_{4}$ and $\mathrm{C}_{2}-\mathrm{C}_{4}$ selectivities obtained under different light intensities (reproduced from ref [52] with permission of ACS) ; (E) Plots of CO conversion against time on stream obtained in both thermal catalysis (TC) and photo-thermo catalysis (PTC) for $20 \% \mathrm{Co} / \mathrm{TNT}$ and $30 \%$ Co/TNT (TNT $=$ titania nanotubes) (reproduced from ref [199] with permission of RSC).

Wang et al. developed a photo-thermo-catalyst for enhanced FT synthesis by combining a Co thermal catalyst with a photo-sensitive support. $\mathrm{Co} / \mathrm{TiO}_{2}$ nanotubes with high metal loading (2030 wt.\%) were reported to strongly benefit from UV irradiation (500 W Hg lamp) when performing $\mathrm{CO}$ hydrogenation at $220^{\circ} \mathrm{C}$ and $20 \mathrm{bar}$, with a strong enhancement of both $\mathrm{CO}$ conversion and the selectivity to light paraffins [199]. As shown in Fig. 32E, notable increases in CO conversion from $9.2 \%$ to $63.9 \%$ and of light paraffin selectivity from $89.0 \%$ to $98.6 \%$ were observed for a Co loading of $20 \mathrm{wt} \%$. Upon UV illumination, the CO conversion enhancement was attributed to transfer of photogenerated electrons from the irradiated $\mathrm{TiO}_{2}$ to the active supported Co nanoparticles. The resulting increase in surface electron density at the Co sites enhanced the adsorption and activation/dissociation of the $\mathrm{CO}$ reactant. The increase in selectivity to light (low molecular weight) paraffins was attributed to the photo-promoted hydrogenation of olefins and to the hydrogenolysis of the long-chain hydrocarbons, whilst the reduced formation of unwanted $\mathrm{CO}_{2}$ was ascribed to the involvement of photogenerated holes in limiting the water gas shift reaction.

Following the works of $\mathrm{Ye}$ and coll. showing the ability of $\mathrm{NiO}$ and $\mathrm{Ni}-\mathrm{Al}_{2} \mathrm{O}_{3}$ catalysts to catalyze CO methanation under visible or UV/Vis light irradiation [41], Zhao et al. demonstrated that $\mathrm{Ni}$-based catalysts can be made to favour $\mathrm{C}-\mathrm{C}$ coupling reactions, with less methanation, especially at a low reaction temperature, by applying visible-light irradiation [200]. $\mathrm{A} \mathrm{NiO}_{x} / \mathrm{Ni}$ photocatalyst 
obtained by reducing calcinated Ni-containing layered double hydroxides, gave high selectivity for $\mathrm{C}_{2+}\left(\mathrm{C}_{2}-\mathrm{C}_{7}\right)$ hydrocarbons (maximum $80 \%$ ) in $\mathrm{CO}$ hydrogenation for the initial 15 min of irradiation, while hydrocarbon hydrogenolysis was favoured over longer-time irradiation in a reaction with no external heating. Under irradiation by a $300 \mathrm{~W}$ Xe lamp at $1.0 \mathrm{~W} / \mathrm{cm}^{2}$ (10 suns), the temperature of the catalyst bed rapidly stabilized at $150{ }^{\circ} \mathrm{C}$, a value much lower than that necessary for activating $\mathrm{CO}$ on a conventional Ni-based catalyst [201]. Under pure visible light irradiation, the better selectivity towards $\mathrm{C}_{2+}$ was attributed to a lower hydrogenolysis rate of hydrocarbons. The formation of discrete $\mathrm{NiO}_{x}$ overlayers at the metallic $\mathrm{Ni}$ nanoparticle surface was proposed to be the key feature driving catalytic efficiency under illumination. Besides its optical absorption properties, decoration by interfacial $\mathrm{NiO}_{\mathrm{x}}$ moderates the high activity of hydrogenation of the metallic $\mathrm{Ni}$ while simultaneously favouring $\mathrm{C}-\mathrm{C}$ coupling. The changes expected in the reaction path of the surface $\mathrm{CH}_{\mathrm{x}}$ species were supported by density functional theory (DFT) calculations. This opens up novel opportunities of using solar energy for the low temperature synthesis of fuels and addedvalue chemicals on $\mathrm{Ni}$ (photo)catalysts under mild reaction conditions.

Further evidence for a strong influence of simultaneous irradiation on selectivity in thermal FTS has been reported by Ma, Wen, and co-workers over O-decorated $\mathrm{Fe}_{5} \mathrm{C}_{2}$ (Fig. 33) [202]. Presumably in anticipation of its high impact, the same work has been previewed in communications elsewhere (Zhao et al. [39], Wang and Xia [203]). In the absence of external heating, this new (FTO) process achieved $>50 \% \mathrm{CO}$ conversion in $30 \mathrm{~min}$, and yielded $>90 \%$ olefins in the $\mathrm{C}_{2}-\mathrm{C}_{4}$ fraction, comprising $55 \%$ of the product with $30 \% \mathrm{CH}_{4}$ and $6 \% \mathrm{C}_{5+}$ hydrocarbons (see Fig. 33D). Perhaps its most striking feature is the drastic level of localized heating at the catalyst surface, attaining nearly $500^{\circ} \mathrm{C}$ when illuminated by the unfiltered "solar" beam from a $300 \mathrm{~W}$ Xe lamp at $2.9 \mathrm{~W} . \mathrm{cm}^{-}$ ${ }^{2}$ (29 suns), as shown in Fig. 33B. Such a remarkable and effective sourcing of potentially renewable heat appears to be due to the ultra-broad absorption spectrum of the catalyst (see Fig. 33C), the high lamp power (plus the unfiltered 'thermal' infrared component beyond $10 \mu \mathrm{m}$ ), the batchtype (static) reactor minimizing diffusional losses, and the exothermicity of the FT process itself (eqn.10), as below: 

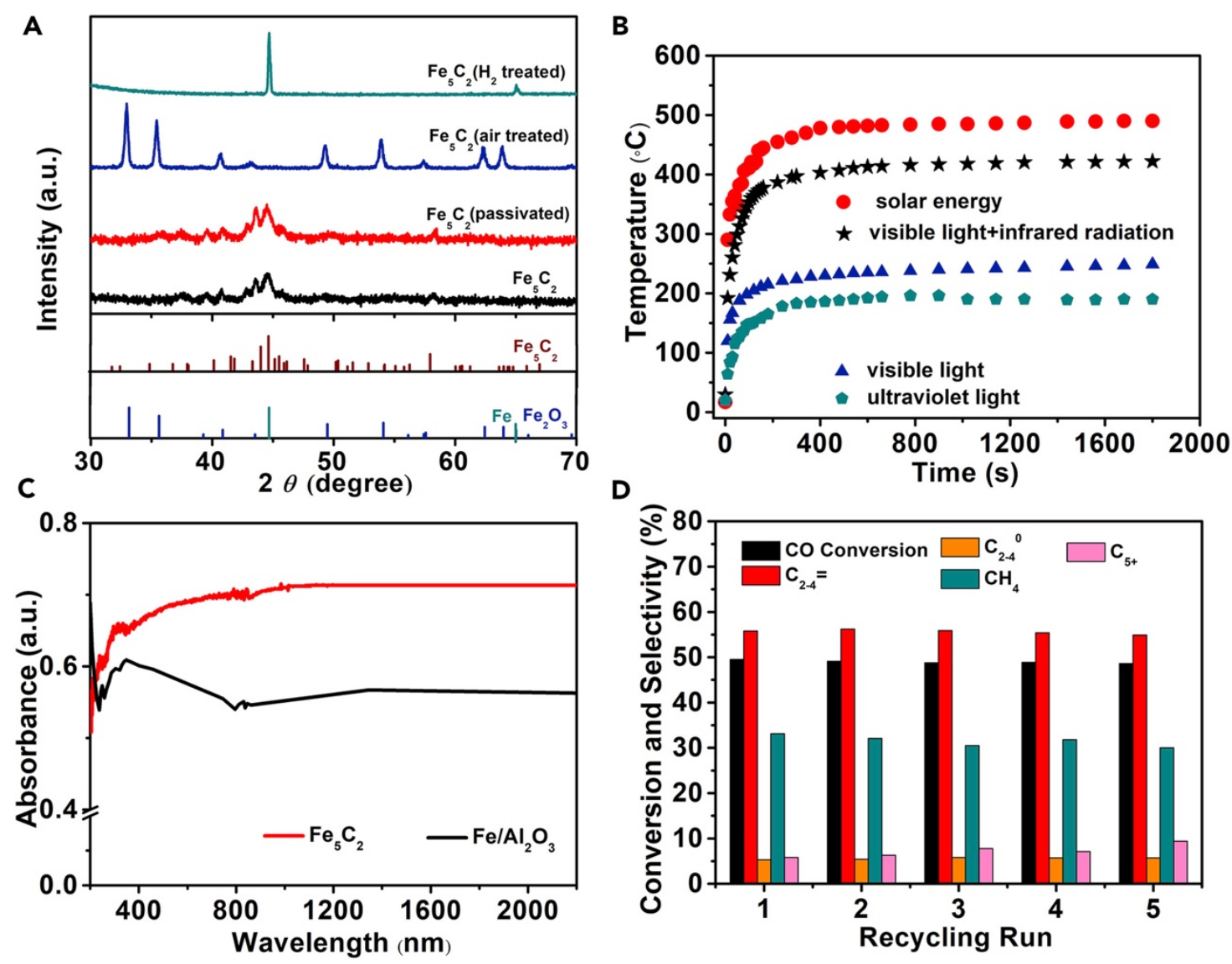

Figure 33. $\mathrm{Fe}_{5} \mathrm{C}_{2}$ catalyst characterization, Fischer-Tropsch selectivity (to olefins, FTO), and stability. (A) XRD patterns of $\mathrm{Fe}_{5} \mathrm{C}_{2}$ and reference catalysts. (B) Monitoring of the catalyst bed temperature under photoirradiation. (C) UV-vis-NIR spectra of $\mathrm{Fe}_{5} \mathrm{C}_{2}$ and reference catalysts. (D) Recycling of the $\mathrm{Fe}_{5} \mathrm{C}_{2}$ catalyst x5. (reproduced from ref. [202] with permission of Elsevier).

$$
\mathrm{CO}+2 \mathrm{H}_{2} \rightarrow\left[\mathrm{CH}_{2}\right]+\mathrm{H}_{2} \mathrm{O} \quad \Delta \mathrm{H}_{298 \mathrm{~K}}=-152 \mathrm{~kJ} \cdot \mathrm{mol}^{-1}
$$

Interconversion of platform oxygenates will become of increasing importance in consolidating operational flexibility in future solar biorefineries based on an industrial symbiosis between methanol and ethanol [164]. There is a potentially valuable role for photo-catalytic activation in driving uphill reactions, e.g., dehydrogenation, especially if combined with other useful transformations. This has been nicely demonstrated in recent work by Xie et al. on $\mathrm{C}-\mathrm{H}$ activation and $\mathrm{C}-\mathrm{C}$ coupling 
of methanol into ethylene glycol (EG) over a molybdenum disulfide nanofoam-modified cadmium sulfide (CdS) nanorod catalyst under visible light irradiation [204]. The coupling reaction generates $\mathrm{H}_{2}$ as co-product and is endothermic by roughly $25 \mathrm{~kJ} \mathrm{~mol}^{-1}$ (eqn.11).

$2 \mathrm{CH}_{3} \mathrm{OH} \rightarrow(\mathrm{HO}) \mathrm{H}_{2} \mathrm{C}-\mathrm{CH}_{2}(\mathrm{OH})+\mathrm{H}_{2}$

Since the thermodynamic equilibrium is insensitive to temperature, the reactant was illuminated directly in the liquid state (aqueous solution) and no exploration of simultaneous heating was made. A high (> 80\%) selectivity to EG was obtained and a good productivity of 6 mmol.g.cat ${ }^{-1} \cdot \mathrm{h}^{-1}$. A quantum yield of $\sim 5 \%$ was measured within the visible absorption band envelope of the CdS nanorods (up to $500 \mathrm{~nm}$ ) in the presence of a $\mathrm{MoS}_{2}$ foam co-catalyst at $5 \mathrm{wt} \%$ loading.

\section{Conclusions and outlook}

In the foregoing article, the authors have endeavoured to show that photo-thermo synergies in heterogeneous catalysis are ubiquitous and offer excellent prospects to boost the operating efficiency and flexibility in sustainable and greener industrial processing. Although here it is viewed in a specific context and illustrated by examples based on the advantageous coupling of renewable solar (hydrogen) and biomass (oxygenates, $\mathrm{CO}_{2}$ ) resources, the new phenomenology is clearly fundamental in origin and provides the basis of a new paradigm in applied catalysis. From a broader perspective, equally impressive reports from applications in other fields, e.g., environmental chemistry [205,206], fuel combustion [207], syngas production [208] or coupled solar PV/hydrogen generation [209], have appeared even during the drafting of this review.

We are presently seeing an opening wave of discovery, albeit mainly in Laboratory, (lampbased), experiments utilizing this novel approach, i.e., dual excitation by light and heat. Being only at its infancy, the field is clearly facing many challenges and there remains plenty of room for improvement. Key advances can be sub-divided into several distinct tasks as below.

Rapid transition from laboratory to scaled-up tests in the field using solar concentrators. 
First, its ultimate impact will depend largely on the aptitude of empirical scientists to forge rapid advances in scale-up and field testing with actual solar concentrators. While the process scaleup will be facilitated by the similarity between thermal heterogeneous catalysis and photo-thermo catalysis, the harnessing, integration and channeling of solar energy (solar photons) into the catalytic processing and (photo)reactors will clearly be a key-feature to optimize for fully exploiting the technology, whether the photonic excitation is performed in tandem with conventional heating or not.

\section{Rapid advances in mechanism(s) elucidation, model catalysts and computational methods.}

Second, it must also be admitted that fundamental interpretation is still at a rudimentary level and most of the studies do not identify the dominant physico-chemical mechanisms governing the reactions. Photo-thermo synergies are complex and exert an influence on the kinetics of catalytic processes via a range of mechanisms. Only those distinguishable by empirical means, designated as Types (A-C), have been considered here and the authors make no claim that this list is necessarily exhaustive. For example, a new report claims that heat stimulates positive non-linearities in photo-conversion efficiency, especially at high optical power, over plasmonic catalysts [210]. This finding arises from a major advance in experimental methodology, namely the ability to distinguish (and quantitate) thermal and non-thermal (hot carrier) effects, an urgently sought development in a hotly debated field $[71,95,99,211]$. Here the lack of model catalysts remains to date one of the main obstacles for deeper understanding on the nature of active sites and reaction mechanisms. Therefore, further advancements in photo-thermo- catalysis will go hand in hand with the application of modelling and computational tools, as well as with the implementation of in-situ/operando characterization techniques to provide fundamental information about photo-active sites, bulk and surface mechanisms, molecular structure-activity/selectivity relationships under varying and controlled optical stimulation.

\section{Development of methods for better thermal definition in powdered bed reactors.}

Third, a key contributor in this respect on overcoming these challenges is accurate and precise surface temperature measurement, that should provide highly valuable information, fundamental 
to the understanding of thermal catalytic phenomena. Since the foregoing work, based on conventional thermocouples, includes several reports of unexpectedly high ceiling temperatures attainable under illumination, nanoscale thermal measurements remain of huge importance in view of the discrimination between the thermo- and photo- chemical contributions to photo-thermo- catalysis, and in consequence of the demonstration of the mechanistic pathways and of the optimization of catalysts, reactors and overall processes. Advances were recently obtained towards this highly challenging objective through the development of spatially-resolved techniques, and good thermal definition might even allow in the future for the exploitation of temperature gradients deliberately applied for beneficial aims. Full details have been given in Section 6.

Advances in novel materials with pan-chromatic optical absorption.

Fourth, the field being only at its infancy, the catalyst preparation and engineering haven't beneficiated yet a dedicated attention, likely because most of the elaboration steps involved are extremely challenging to investigate, and most of the catalysts investigated to date are directly derived either from thermal heterogeneous catalysis or from low-temperature photocatalysis. Huge progress in catalyst preparation, and especially the tailoring of optical and thermal properties, e.g., by inclusion of expensive nano-plasmonic metals (or cheaper semi-conductors like TiN), metal blacks, and/or non-catalytic light absorbers (for remote temperature sensing or modification of thermal gradients) in new composite formulations, has to be realized. A wide span of (candidate) materials with pan-spectral optical response are in consequence expected to emerge for exploiting the widest possible range of solar energy harvesting, and providing an optimum balance of electronic effects, including notably non-metal and advanced 2D materials such as transition metal dichalcogenides, pnictogenides, perovskites, transition metal carbides and nitrides. Catalyst engineering will further need a strong input from model catalysts (plasmon- and non-plasmon) and insitu/operando characterization, in close relationship with the mechanistic understanding aspects previously mentioned. Nowadays, the incentive to take a more holistic approach to catalyst design is great and constitutes a major challenge in materials science. Thus, to the myriad criteria underpinning the successful development of a heterogeneous catalyst - and that likely differ whether the 
photonic excitation is combined with conventional heating or not - must now be added a photonics aspect.

Due attention to thermal stability of catalysts under conditions of photo-thermal activation.

Finally, photo-thermo catalysis requires clearly to pay much more attention to the (thermal) stability of the catalyst, in comparison to pure photocatalysis that is implemented most of the time at (or close to) ambient temperature, and for which stability aspects are less relevant and in consequence usually overlooked. The heating of the catalysts, whether it results from an induced (internal) light-to-heat effect or from a direct (external) heating, may induce changes in both the bulk and surface catalyst properties, such as for instance changes in the crystal phase(s) upon temperature increase, in the size distribution of the supported nanoparticles, in the metal/support interaction, or in the structure of the bimetallic nanoparticles if applicable. This is for instance critical when photo-assisted synthesis methods (i.e. photodeposition) are used for preparing metal supported catalysts or when structurally-defective materials are engineered. In consequence, characterization of the photothermal catalysts after reaction has unambiguously to be performed, first to check the stability of the catalysts, but also to draw more appropriate properties/behavior relationships by considering the properties of the catalysts after potential in-situ alteration. When applicable and relevant, in-situ/operando characterization are preferred, but in most of the cases they are difficult, if not impossible experimentally, to implement. By contrast, stability aspects are well-considered and integrated nowadays within the synthetic strategies in thermal heterogeneous catalysis, so that photothermal catalysts originally elaborated for performing thermal catalysis in the dark in heated reactors are usually prepared via synthesis methods providing them structural and chemical stability in the conditions encountered in the thermal catalytic reactions. They are prepared and therefore stabilized at high temperature, for instance through a final reductive treatment in temperature under hydrogen to disperse metallic nanoparticles on the support, so that those stability aspects are less relevant and pregnant, whether the bulk materials are decorated with supported nanoparticles or not.

Apart from the foregoing practical tasks, photo-thermo catalysis will only reach an acceptable state of maturity when a new and unified definition of terms (preferably by an international scientific body such as IUPAC) is made available. In addition, a highly desirable objective is the establishment of a standardized laboratory testing regime (under high-power broadband light sources, 
e.g., LED arrays or incandescent sources with output up to 25 suns), that is ultimately amenable for scale-up and integration with solar concentrators.

Finally, we hope that this report will serve to inspire cross-fertilization of ideas and new projects involving academic and industrial cooperation in this challenging inter-disciplinary field. We believe that photo-thermo catalysis will be central to the 'greening' and improved sustainability of industrial processing well into the future.

\section{Acknowledgements}

Javier Ivanez and Nicolas Keller are grateful to IdEx and International Doctoral Programme of the University of Strasbourg.

\section{References}

[1] R.E. Smalley, Future global energy prosperity: The terawatt challenge, MRS Bull. 30 (2005) 412417. https://doi.org/10.1557/mrs2005.124.

[2] R. Schlögl, S.B. Abd Hamid, Nanocatalysis: Mature Science Revisited or Something Really New?, Angew. Chem. Int. Ed. 43 (2004) 1628-1637. https://doi.org/10.1002/anie.200301684.

[3] J.K. Nørskov, T. Bligaard, J. Rossmeisl, C.H. Christensen, Towards the computational design of solid catalysts, Nat. Chem. 1 (2009) 37-46. https://doi.org/10.1038/nchem.121.

[4] A.M. Ruppert, K. Weinberg, R. Palkovits, Hydrogenolysis Goes Bio: From Carbohydrates and Sugar Alcohols to Platform Chemicals., Angew. Chem. Int. Ed. 51 (2012) 2564-2601. https://doi.org/10.1002/anie.201105125.

[5] J.Q. Bond, D.M. Alonso, D. Wang, R.M. West, J.A. Dumesic, Integrated Catalytic Conversion of $\gamma$-Valerolactone to Liquid Alkenes for Transportation Fuels, Science. 327 (2010) 1110-1114. https://doi.org/10.1126/science.1184362.

[6] D.M. Alonso, J.Q. Bond, J.A. Dumesic, Catalytic conversion of biomass to biofuels, Green Chem. 12 (2010) 1493. https://doi.org/10.1039/c004654j.

[7] P. Gallezot, Conversion of biomass to selected chemical products, Chem. Soc. Rev. 41 (2012) 1538-1558. https://doi.org/10.1039/C1CS15147A. 
[8] M. Besson, P. Gallezot, C. Pinel, Conversion of Biomass into Chemicals over Metal Catalysts, Chem. Rev. 114 (2014) 1827-1870. https://doi.org/10.1021/cr4002269.

[9] F. Schüth, R. Rinaldi, N. Meine, M. Käldström, J. Hilgert, M.D.K. Rechulski, Mechanocatalytic depolymerization of cellulose and raw biomass and downstream processing of the products, Catal. Today. 234 (2014) 24-30. https://doi.org/10.1016/j.cattod.2014.02.019.

[10] C.O. Tuck, E. Perez, I.T. Horvath, R.A. Sheldon, M. Poliakoff, Valorization of Biomass: Deriving More Value from Waste, Science. 337 (2012) 695-699. https://doi.org/10.1126/science.1218930.

[11] M.A. Fox, M.T. Dulay, Heterogeneous photocatalysis, Chem. Rev. 93 (1993) 341-357. https://doi.org/10.1021/cr00017a016.

[12] A.L. Linsebigler, G. Lu, J.T. Yates, Photocatalysis on $\mathrm{TiO}_{2}$ Surfaces: Principles, Mechanisms, and Selected Results, Chem. Rev. 95 (1995) 735-758. https://doi.org/10.1021/cr00035a013.

[13] M.R. Hoffmann, S.T. Martin, W. Choi, D.W. Bahnemann, Environmental Applications of Semiconductor Photocatalysis, Chem. Rev. 95 (1995) 69-96. https://doi.org/10.1021/cr00033a004.

[14] B. Ohtani, Photocatalysis A to Z-What we know and what we do not know in a scientific sense, J. Photochem. Photobiol., C . 11 (2010) 157-178. https://doi.org/10.1016/j.jphotochemrev.2011.02.001.

[15] A.G. Agrios, P. Pichat, State of the art and perspectives on materials and applications of photocatalysis over $\mathrm{TiO}_{2}$, J. Appl. Electrochem. 35 (2005) 655-663. https://doi.org/10.1007/s10800-005-1627-6.

[16] A. Fujishima, K. Hashimoto, T. Watanabe, $\mathrm{TiO}_{2}$ Photocatalysis: Fundamentals and Applications, BKC, Tokio, 1999.

[17] J. Schneider, D. Bahnemann, J. Ye, G. Li Puma, D.D. Dionysiou, eds., Photocatalysis: Fundamentals and perspectives, Royal Society of Chemistry, Cambridge, 2016. https://doi.org/10.1039/9781782622338.

[18] D.D. Dionysiou, G. Li Puma, J. Ye, J. Schneider, D. Bahnemann, eds., Photocatalysis:Applications, Royal Society of Chemistry, Cambridge, 2016. 
https://doi.org/10.1039/9781782627104.

[19] A. Kubacka, M. Fernández-García, G. Colón, Advanced Nanoarchitectures for Solar Photocatalytic Applications, Chem. Rev. 112 (2012) 1555-1614. https://doi.org/10.1021/cr100454n.

[20] C. Xu, P. Ravi Anusuyadevi, C. Aymonier, R. Luque, S. Marre, Nanostructured materials for photocatalysis, Chem. Soc. Rev. 48 (2019) 3868-3902. https://doi.org/10.1039/c9cs00102f.

[21] P.R. Harvey, R. Rudham, S. Ward, Photocatalytic oxidation of liquid propan-2-ol by titanium dioxide, J. Chem. Soc., Faraday Trans. 1 Phys. Chem. Condens. Phases. 79 (1983) 1381. https://doi.org/10.1039/f19837901381.

[22] K. Okamoto, Y. Yamamoto, H. Tanaka, A. Itaya, Kinetics of Heterogeneous Photocatalytic Decomposition of Phenol over Anatase $\mathrm{TiO}_{2}$ Powder, Bull. Chem. Soc. Jpn. 58 (1985) 20232028. https://doi.org/10.1246/bcsj.58.2023.

[23] L.C. Chen, T.C. Chou, Kinetics of photodecolorization of methylorange using titanium-dioxide as catalyst., Ind. Eng. Chem. Res. 32 (1993) 1520-1527.

[24] A.V. Vorontsov, I.V. Stoyanova, D.V. Kozlov, V.I. Simagina, E.N. Savinov, Kinetics of the Photocatalytic Oxidation of Gaseous Acetone over Platinized Titanium Dioxide, J. Catal. 189 (2000) 360-369. https://doi.org/10.1006/jcat.1999.2717.

[25] S. Yamazoe, Y. Hitomi, T. Shishido, T. Tanaka, Kinetic study of photo-oxidation of $\mathrm{NH}_{3}$ over $\mathrm{TiO}_{2}$, Appl. Catal. B Environ. 82 (2008) 67-76. https://doi.org/10.1016/j.apcatb.2007.12.023.

[26] F.H. Hussein, R. Rudham, Photocatalytic dehydrogenation of liquid alcohols by platinized anatase, J. Chem. Soc., Faraday Trans. I. 83 (1987) 1631-1639.

[27] S. Naito, Study of photocatalytic reaction of methanol with water over Rh-loaded, and Pd-loaded $\mathrm{TiO}_{2}$ catalysts - the role of added alkali-metal cations, Can. J. Chem. Rev. Can. Chim. 64 (1986) $1795-1799$.

[28] M. Ghoussoub, M. Xia, P.N. Duchesne, D. Segal, G. Ozin, Principles of photothermal gas-phase heterogeneous $\mathrm{CO}_{2}$ catalysis, Energy Environ. Sci. 12 (2019) 1122-1142. https://doi.org/10.1039/c8ee02790k. 
[29] Z. Wang, H. Song, H. Liu, J. Ye, Coupling of Solar Energy and Thermal Energy for Carbon Dioxide Reduction: Status and Prospects, Angew. Chem. Int. Ed. 59 (2020) 8016-8035. https://doi.org/10.1002/anie.201907443.

[30] S. Tang, J. Sun, H. Hong, Q. Liu, Solar fuel from photo-thermal catalytic reactions with spectrum-selectivity: a review, Front. Energy. 11 (2017) 437-451. https://doi.org/10.1007/s11708-017-0509-z.

[31] V. Nair, M.J. Muñoz-Batista, M. Fernández-García, R. Luque, J.C. Colmenares, ThermoPhotocatalysis: Environmental and Energy Applications, ChemSusChem. 12 (2019) 2098-2116. https://doi.org/10.1002/cssc.201900175.

[32] S.E. Braslavsky, A.M. Braun, A.E. Cassano, A. V. Emeline, M.I. Litter, L. Palmisano, V.N. Parmon, N. Serpone, Glossary of terms used in photocatalysis and radiation catalysis (IUPAC Recommendations 2011), Pure Appl. Chem. 83 (2011) 931-1014. https://doi.org/10.1351/PACREC-09-09-36.

[33] W. Wentworth, C. Batten, G. Wei, The photo-assisted thermal decomposition of methanol and isopropanol in a fluidized bed, Energy. 12 (1987) 319-331. https://doi.org/10.1016/03605442(87)90091-0.

[34] S.W. Verbruggen, $\mathrm{TiO}_{2}$ photocatalysis for the degradation of pollutants in gas phase: From morphological design to plasmonic enhancement, J. Photochem. Photobiol., C . 24 (2015) 64-82. https://doi.org/10.1016/j.jphotochemrev.2015.07.001.

[35] J.U. Menon, P. Jadeja, P. Tambe, K. Vu, B. Yuan, K.T. Nguyen, Nanomaterials for Photo-Based Diagnostic and Therapeutic Applications, Theranostics. 3 (2013) 152-166. https://doi.org/10.7150/thno.5327.

[36] E.C. Dreaden, S.C. Mwakwari, Q.H. Sodji, A.K. Oyelere, M.A. El-Sayed, Tamoxifen-Poly(ethylene glycol)-Thiol Gold Nanoparticle Conjugates: Enhanced Potency and Selective Delivery for Breast Cancer Treatment, Bioconjug. Chem. 20 (2009) 2247-2253. https://doi.org/10.1021/bc9002212.

[37] X. Huang, M.A. El-Sayed, Plasmonic photo-thermal therapy (PPTT), Alexandria J. Med. 47 (2011) 1-9. https://doi.org/10.1016/j.ajme.2011.01.001. 
[38] D. Jimenez de Aberasturi, A.B. Serrano-Montes, L.M. Liz-Marzán, Modern Applications of Plasmonic Nanoparticles: From Energy to Health, Adv. Opt. Mater. 3 (2015) 602-617. https://doi.org/10.1002/adom.201500053.

[39] Y. Zhao, W. Gao, S. Li, G.R. Williams, A.H. Mahadi, D. Ma, Solar- versus Thermal-Driven Catalysis for Energy Conversion, Joule. 3 (2019) 920-937. https://doi.org/10.1016/j.joule.2019.03.003.

[40] X. Meng, L. Liu, S. Ouyang, H. Xu, D. Wang, N. Zhao, J. Ye, Nanometals for Solar-to-Chemical Energy Conversion: From Semiconductor-Based Photocatalysis to Plasmon-Mediated Photocatalysis and Photo-Thermocatalysis, Adv. Mater. 28 (2016) 6781-6803. https://doi.org/10.1002/adma.201600305.

[41] X. Meng, T. Wang, L. Liu, S. Ouyang, P. Li, H. Hu, T. Kako, H. Iwai, A. Tanaka, J. Ye, Photothermal conversion of $\mathrm{CO}_{2}$ into $\mathrm{CH}_{4}$ with $\mathrm{H}_{2}$ over Group VIII nanocatalysts: An alternative approach for solar fuel production, Angew. Chem. - Int. Ed. 53 (2014) 11478-11482. https://doi.org/10.1002/anie.201404953.

[42] E.T. Kho, T.H. Tan, E. Lovell, R.J. Wong, J. Scott, R. Amal, A review on photo-thermal catalytic conversion of carbon dioxide, Green Energy Environ. 2 (2017) 204-217. https://doi.org/10.1016/j.gee.2017.06.003.

[43] M. Zeng, Y. Li, M. Mao, J. Bai, L. Ren, X. Zhao, Synergetic effect between photocatalysis on $\mathrm{TiO}_{2}$ and thermocatalysis on $\mathrm{CeO}_{2}$ for gas-phase oxidation of benzene on $\mathrm{TiO}_{2} / \mathrm{CeO}_{2}$ nanocomposites, ACS Catal. 5 (2015) 3278-3286. https://doi.org/10.1021/acscatal.5b00292.

[44] H. Song, X. Meng, T.D. Dao, W. Zhou, H. Liu, L. Shi, H. Zhang, T. Nagao, T. Kako, J. Ye, Light-Enhanced Carbon Dioxide Activation and Conversion by Effective Plasmonic Coupling Effect of Pt and Au Nanoparticles, ACS Appl. Mater. Interfaces. 10 (2018) 408-416. https://doi.org/10.1021/acsami.7b13043.

[45] S. Mubeen, J. Lee, N. Singh, S. Krämer, G.D. Stucky, M. Moskovits, An autonomous photosynthetic device in which all charge carriers derive from surface plasmons, Nat. Nanotechnol. 8 (2013) 247-251. https://doi.org/10.1038/nnano.2013.18. 
[46] J.B. Priebe, M. Karnahl, H. Junge, M. Beller, D. Hollmann, A. Brückner, Water Reduction with Visible Light: Synergy between Optical Transitions and Electron Transfer in $\mathrm{Au}^{-\mathrm{TiO}_{2}}$ Catalysts Visualized by In situ EPR Spectroscopy, Angew. Chem. 52 (2013) 11420-11424. https://doi.org/10.1002/anie.201306504.

[47] L. Zhu, M. Gao, C.K.N. Peh, G.W. Ho, Solar-driven photothermal nanostructured materials designs and prerequisites for evaporation and catalysis applications, Mater. Horizons. 5 (2018) 323-343. https://doi.org/10.1039/c7mh01064h.

[48] M. Rycenga, C.M. Cobley, J. Zeng, W. Li, C.H. Moran, Q. Zhang, D. Qin, Y. Xia, Controlling the Synthesis and Assembly of Silver Nanostructures for Plasmonic Applications, Chem. Rev. 111 (2011) 3669-3712. https://doi.org/10.1021/cr100275d.

[49] J.J. Mock, M. Barbic, D.R. Smith, D.A. Schultz, S. Schultz, Shape effects in plasmon resonance of individual colloidal silver nanoparticles, J. Chem. Phys. 116 (2002) 6755-6759. https://doi.org/10.1063/1.1462610.

[50] J.D. Xiao, H.L. Jiang, Metal-Organic Frameworks for Photocatalysis and Photothermal Catalysis, Acc. Chem. Res. 52 (2019) 356-366. https://doi.org/10.1021/acs.accounts.8b00521.

[51] P. Christopher, H. Xin, S. Linic, Visible-light-enhanced catalytic oxidation reactions on plasmonic silver nanostructures, Nat. Chem. 3 (2011) 467-472. https://doi.org/10.1038/nchem.1032.

[52] X.Y.X.N. Guo, Z.F. Jiao, G.Q. Jin, X.Y.X.N. Guo, Photocatalytic fischer-tropsch synthesis on graphene-supported worm-like ruthenium nanostructures, ACS Catal. 5 (2015) 3836-3840. https://doi.org/10.1021/acscatal.5b00697.

[53] C. Jiang, L. Yu, S. Yang, K. Li, J. Wang, P.D. Lund, Y. Zhang, A Review of the Compound Parabolic Concentrator (CPC) with a Tubular Absorber, Energies. 13 (2020) 695. https://doi.org/10.3390/en13030695.

[54] W. Chamsa-ard, S. Brundavanam, C. Fung, D. Fawcett, G. Poinern, Nanofluid Types, Their Synthesis, Properties and Incorporation in Direct Solar Thermal Collectors: A Review, Nanomaterials. 7 (2017) 131. https://doi.org/10.3390/nano7060131.

[55] J. Hou, Y. Li, M. Mao, Y. Yue, G. Neville Greaves, X. Zhao, Full solar spectrum light driven 
thermocatalysis with extremely high efficiency on nanostructured Ce ion substituted OMS-2 catalyst for VOCs purification, Nanoscale. 7 (2015) 2633-2640.

https://doi.org/10.1039/c4nr06410k.

[56] U. Caudillo-Flores, G. Agostini, C. Marini, A. Kubacka, M. Fernández-García, Hydrogen thermophoto production using $\mathrm{Ru} / \mathrm{TiO}_{2}$ : Heat and light synergistic effects, Appl. Catal. B Environ. 256 (2019) 117790. https://doi.org/10.1016/j.apcatb.2019.117790.

[57] S. Sarina, E.R. Waclawik, H. Zhu, Photocatalysis on supported gold and silver nanoparticles under ultraviolet and visible light irradiation ., Green Chem. 14 (2012) 3047. https://doi.org/10.1039/c2gc36073j.

[58] F. Yu, C. Wang, H. Ma, M. Song, D. Li, Y. Li, S. Li, X. Zhang, Y. Liu, Revisiting Pt/TiO 2 photocatalysts for thermally assisted photocatalytic reduction of $\mathrm{CO}_{2}$, Nanoscale. 12 (2020) 7000-7010. https://doi.org/10.1039/c9nr09743k.

[59] R. Fiorenza, M. Bellardita, L. Palmisano, S. Scirè, A comparison between photocatalytic and catalytic oxidation of 2-Propanol over $\mathrm{Au} / \mathrm{TiO} 2-\mathrm{CeO}_{2}$ catalysts, J. Mol. Catal. A Chem. 415 (2016) 56-64. https://doi.org/10.1016/j.molcata.2016.01.025.

[60] S. Fang, Z. Sun, Y.H. Hu, Insights into the Thermo-Photo Catalytic Production of Hydrogen from Water on a Low-Cost NiOx-Loaded TiO2 Catalyst, ACS Catal. 9 (2019) 5047-5056. https://doi.org/10.1021/acscatal.9b01110.

[61] K. Wang, R. Jiang, T. Peng, X. Chen, W. Dai, X. Fu, Modeling the effect of Cu doped TiO2 with carbon dots on $\mathrm{CO}_{2}$ methanation by $\mathrm{H}_{2} \mathrm{O}$ in a photo-thermal system, Appl. Catal. B Environ. 256 (2019) 117780. https://doi.org/10.1016/j.apcatb.2019.117780.

[62] Q. Fu, T. Wagner, Interaction of nanostructured metal overlayers with oxide surfaces, Surf. Sci. Rep. 62 (2007) 431-498. https://doi.org/10.1016/j.surfrep.2007.07.001.

[63] S. Sarina, E.R. Waclawik, H. Zhu, Photocatalysis on supported gold and silver nanoparticles under ultraviolet and visible light irradiation, Green Chem. 14 (2012) 3047. https://doi.org/10.1039/c2gc36073j.

[64] C. Wang, O. Ranasingha, S. Natesakhawat, P.R. Ohodnicki, M. Andio, J.P. Lewis, C. Matranga, 
Visible light plasmonic heating of $\mathrm{Au}-\mathrm{ZnO}$ for the catalytic reduction of $\mathrm{CO}_{2}$, Nanoscale. 5 (2013) 6968-6974. https://doi.org/10.1039/c3nr02001k.

[65] K.H. Kim, K. Watanabe, D. Mulugeta, H.J. Freund, D. Menzel, Enhanced photoinduced desorption from metal nanoparticles by photoexcitation of confined hot electrons using femtosecond laser pulses, Phys. Rev. Lett. 107 (2011) 20-23. https://doi.org/10.1103/PhysRevLett.107.047401.

[66] S. Navalon, M. De Miguel, R. Martin, M. Alvaro, H. Garcia, Enhancement of the catalytic activity of supported gold nanoparticles for the fenton reaction by light, J. Am. Chem. Soc. 133 (2011) 2218-2226. https://doi.org/10.1021/ja108816p.

[67] M.J. Landry, A. Gellé, B.Y. Meng, C.J. Barrett, A. Moores, Surface-Plasmon-Mediated Hydrogenation of Carbonyls Catalyzed by Silver Nanocubes under Visible Light, ACS Catal. 7 (2017) 6128-6133. https://doi.org/10.1021/acscatal.7b02128.

[68] P. Christopher, H. Xin, A. Marimuthu, S. Linic, Singular characteristics and unique chemical bond activation mechanisms of photocatalytic reactions on plasmonic nanostructures, Nat. Mater. 11 (2012) 1044-1050. https://doi.org/10.1038/nmat3454.

[69] X. Zhang, X. Li, D. Zhang, N.Q. Su, W. Yang, H.O. Everitt, J. Liu, Product selectivity in plasmonic photocatalysis for carbon dioxide hydrogenation, Nat. Commun. 8 (2017) 14542. https://doi.org/10.1038/ncomms14542.

[70] D. Mateo, J.L. Cerrillo, S. Durini, J. Gascon, Fundamentals and applications of photo-thermal catalysis, Chem. Soc. Rev. (2021). https://doi.org/10.1039/d0cs00357c.

[71] G. Baffou, I. Bordacchini, A. Baldi, R. Quidant, Simple experimental procedures to distinguish photothermal from hot-carrier processes in plasmonics, Light Sci. Appl. 9 (2020). https://doi.org/10.1038/s41377-020-00345-0.

[72] H. Song, X. Meng, Z.J. Wang, Z. Wang, H. Chen, Y. Weng, F. Ichihara, M. Oshikiri, T. Kako, J. Ye, Visible-Light-Mediated Methane Activation for Steam Methane Reforming under Mild Conditions: A Case Study of Rh/ $\mathrm{TiO}_{2}$ Catalysts, ACS Catal. 8 (2018) 7556-7565. https://doi.org/10.1021/acscatal.8b01787.

[73] U. Aslam, V.G. Rao, S. Chavez, S. Linic, Catalytic conversion of solar to chemical energy on 
plasmonic metal nanostructures, Nat. Catal. 1 (2018) 656-665. https://doi.org/10.1038/s41929018-0138-x.

[74] G.C. Roda, V. Loddo, L. Palmisano, F. Parrino, Chapter 6. Special needs and characteristic features of (photo)catalytic reactors with a review of the proposed Solutions, in: Heterog. Photocatal. Relationships with Heterog. Catal. Perspect., Elsevier B.V., 2019: pp. 177-213. https://doi.org/10.1016/B978-0-444-64015-4.00006-7.

[75] S. Malato Rodríguez, J. Blanco Gálvez, M.I. Maldonado Rubio, P. Fernández Ibáñez, D. Alarcón Padilla, M. Collares Pereira, J. Farinha Mendes, J. Correia de Oliveira, Engineering of solar photocatalytic collectors, Sol. Energy. 77 (2004) 513-524. https://doi.org/10.1016/j.solener.2004.03.020.

[76] A. Rabl, Active Solar Collectors and their Application, Oxford University Press, New York, 1985.

[77] W.T. Welford, R. Winston, D.C. Sinclair, The Optics of Nonimaging Concentrators: Light and Solar Energy, Phys. Today. 33 (1980) 56-57. https://doi.org/10.1063/1.2914121.

[78] S.E. Berrizbeitia, E. Jadraque Gago, T. Muneer, Empirical Models for the Estimation of Solar Sky-Diffuse Radiation. A Review and Experimental Analysis, Energies. 13 (2020) 701. https://doi.org/10.3390/en13030701.

[79] M. Geyer, V. Quaschning, Solar thermal power: the seamless solar link to the conventional power world, Renew. Energy World. 3 (2000) 184-191.

[80] M. Gao, P.K.N. Connor, G.W. Ho, Plasmonic photothermic directed broadband sunlight harnessing for seawater catalysis and desalination, Energy Environ. Sci. 9 (2016) 3151-3160. https://doi.org/10.1039/C6EE00971A.

[81] Y.L. He, J. Xiao, Z.D. Cheng, Y.B. Tao, A MCRT and FVM coupled simulation method for energy conversion process in parabolic trough solar collector, Renew. Energy. 36 (2011) 976985. https://doi.org/10.1016/j.renene.2010.07.017.

[82] Z.D. Cheng, Y.L. He, F.Q. Cui, R.J. Xu, Y.B. Tao, Numerical simulation of a parabolic trough solar collector with nonuniform solar flux conditions by coupling FVM and MCRT method, Sol. 
Energy. 86 (2012) 1770-1784. https://doi.org/10.1016/j.solener.2012.02.039.

[83] A. Castedo, E. Mendoza, I. Angurell, J. Llorca, Silicone microreactors for the photocatalytic generation of hydrogen, Catal. Today. 273 (2016) 106-111.

https://doi.org/10.1016/j.cattod.2016.02.053.

[84] A. Castedo, A. Casanovas, I. Angurell, L. Soler, J. Llorca, Effect of temperature on the gas-phase photocatalytic $\mathrm{H}_{2}$ generation using microreactors under UVA and sunlight irradiation, Fuel. 222 (2018) 327-333. https://doi.org/10.1016/j.fuel.2018.02.128.

[85] E. Taboada, I. Angurell, J. Llorca, Dynamic photocatalytic hydrogen production from ethanolwater mixtures in an optical fiber honeycomb reactor loaded with $\mathrm{Au} / \mathrm{TiO}_{2}$, J. Catal. 309 (2014) 460-467. https://doi.org/10.1016/j.jcat.2013.10.025.

[86] M. Oelgemöller, Solar Photochemical Synthesis: From the Beginnings of Organic Photochemistry to the Solar Manufacturing of Commodity Chemicals, Chem. Rev. 116 (2016) 9664-9682. https://doi.org/10.1021/acs.chemrev.5b00720.

[87] B. Han, Y.H. Hu, Highly Efficient Temperature-Induced Visible Light Photocatalytic Hydrogen Production from Water, J. Phys. Chem. C. 119 (2015) 18927-18934. https://doi.org/10.1021/acs.jpcc.5b04894.

[88] K.K. Ghuman, T.E. Wood, L.B. Hoch, C.A. Mims, G.A. Ozin, C.V. Singh, Illuminating CO2 reduction on frustrated Lewis pair surfaces: investigating the role of surface hydroxides and oxygen vacancies on nanocrystalline $\operatorname{In}_{2} \mathrm{O}_{3-\mathrm{x}}(\mathrm{OH})_{\mathrm{y}}$, Phys. Chem. Chem. Phys. 17 (2015) 1462314635. https://doi.org/10.1039/C5CP02613J.

[89] M.J. Muñoz-Batista, A.M. Eslava-Castillo, A. Kubacka, M. Fernández-García, Thermo-photo degradation of 2-propanol using a composite ceria-titania catalyst: Physico-chemical interpretation from a kinetic model, Appl. Catal. B Environ. 225 (2018) 298-306. https://doi.org/10.1016/j.apcatb.2017.11.073.

[90] A.A. Upadhye, I. Ro, X. Zeng, H.J. Kim, I. Tejedor, M.A. Anderson, J.A. Dumesic, G.W. Huber, Plasmon-enhanced reverse water gas shift reaction over oxide supported Au catalysts, Catal. Sci. Technol. 5 (2015) 2590-2601. https://doi.org/10.1039/c4cy01183j.

[91] X. Zhang, X. Li, M.E. Reish, D. Zhang, N.Q. Su, Y. Gutiérrez, F. Moreno, W. Yang, H.O. 
Everitt, J. Liu, Plasmon-Enhanced Catalysis: Distinguishing Thermal and Nonthermal Effects, Nano Lett. 18 (2018) 1714-1723. https://doi.org/10.1021/acs.nanolett.7b04776.

[92] B. Xie, R.J. Wong, T.H. Tan, M. Higham, E.K. Gibson, D. Decarolis, J. Callison, K.-F. AgueyZinsou, M. Bowker, C.R.A. Catlow, J. Scott, R. Amal, Synergistic ultraviolet and visible light photo-activation enables intensified low-temperature methanol synthesis over copper/zinc oxide/alumina, Nat. Commun. 11 (2020) 1615. https://doi.org/10.1038/s41467-020-15445-z.

[93] S. Mukherjee, F. Libisch, N. Large, O. Neumann, L. V. Brown, J. Cheng, J.B. Lassiter, E.A. Carter, P. Nordlander, N.J. Halas, Hot Electrons Do the Impossible: Plasmon-Induced Dissociation of $\mathrm{H}_{2}$ on Au, Nano Lett. 13 (2013) 240-247. https://doi.org/10.1021/n1303940z.

[94] H. Li, M. Rivallan, F. Thibault-Starzyk, A. Travert, F.C. Meunier, Effective bulk and surface temperatures of the catalyst bed of FT-IR cells used for in situ and operando studies, Phys. Chem. Chem. Phys. 15 (2013) 7321. https://doi.org/10.1039/c3cp50442e.

[95] J.G. Highfield, M. Prairie, A. Renken, In-situ drift spectroscopy in a continuous recycle reactor: a versatile tool for catalytic process research, Catal. Today. 9 (1991) 39-46. https://doi.org/10.1016/0920-5861(91)85005-S.

[96] J.A. Webb, R. Bardhan, Emerging advances in nanomedicine with engineered gold nanostructures, Nanoscale. 6 (2014) 2502. https://doi.org/10.1039/c3nr05112a.

[97] Y. Dubi, I.W. Un, Y. Sivan, Thermal effects - an alternative mechanism for plasmon-assisted photocatalysis, Chem. Sci. 11 (2020) 5017-5027. https://doi.org/10.1039/C9SC06480J.

[98] P.K. Jain, Comment on "Thermal effects - an alternative mechanism for plasmon-assisted photocatalysis" by Y. Dubi, I. W. Un and Y. Sivan, Chem. Sci. , 2020, 11 , 5017, Chem. Sci. 11 (2020) 9022-9023. https://doi.org/10.1039/D0SC02914A.

[99] A.J. Leenheer, P. Narang, N.S. Lewis, H.A. Atwater, Solar energy conversion via hot electron internal photoemission in metallic nanostructures: Efficiency estimates, J. Appl. Phys. 115 (2014) 134301. https://doi.org/10.1063/1.4870040.

[100] R. Kamarudheen, G.W. Castellanos, L.P.J. Kamp, H.J.H. Clercx, A. Baldi, Quantifying Photothermal and Hot Charge Carrier Effects in Plasmon-Driven Nanoparticle Syntheses, ACS 
Nano. 12 (2018) 8447-8455. https://doi.org/10.1021/acsnano.8b03929.

[101] R.M. Sarhan, W. Koopman, R. Schuetz, T. Schmid, F. Liebig, J. Koetz, M. Bargheer, The importance of plasmonic heating for the plasmon-driven photodimerization of 4-nitrothiophenol, Sci. Rep. 9 (2019) 1-8. https://doi.org/10.1038/s41598-019-38627-2.

[102] D.G. Cahill, P. V. Braun, G. Chen, D.R. Clarke, S. Fan, K.E. Goodson, P. Keblinski, W.P. King, G.D. Mahan, A. Majumdar, H.J. Maris, S.R. Phillpot, E. Pop, L. Shi, Nanoscale thermal transport. II. 2003-2012, Appl. Phys. Rev. 1 (2014) 011305. https://doi.org/10.1063/1.4832615.

[103] F. Menges, P. Mensch, H. Schmid, H. Riel, A. Stemmer, B. Gotsmann, Temperature mapping of operating nanoscale devices by scanning probe thermometry, Nat. Commun. 7 (2016) 1-6. https://doi.org/10.1038/ncomms10874.

[104] M. Mecklenburg, W.A. Hubbard, E.R. White, R. Dhall, S.B. Cronin, S. Aloni, B.C. Regan, Nanoscale temperature mapping in operating microelectronic devices, Science. 347 (2015) 629632. https://doi.org/10.1126/science.aaa2433.

[105] J.C. Idrobo, A.R. Lupini, T. Feng, R.R. Unocic, F.S. Walden, D.S. Gardiner, T.C. Lovejoy, N. Dellby, S.T. Pantelides, O.L. Krivanek, Temperature Measurement by a Nanoscale Electron Probe Using Energy Gain and Loss Spectroscopy, Phys. Rev. Lett. 120 (2018) 95901. https://doi.org/10.1103/PhysRevLett.120.095901.

[106] M.V. Balois, N. Hayazawa, F.C. Catalan, S. Kawata, T.A. Yano, T. Hayashi, Tip-enhanced THz Raman spectroscopy for local temperature determination at the nanoscale Nanospectroscopy, Anal. Bioanal. Chem. 407 (2015) 8205-8213. https://doi.org/10.1007/s00216-015-8866-0.

[107] S. Xie, E. Iglesia, A.T. Bell, Effects of temperature on the raman spectra and dispersed oxides, J. Phys. Chem. B. 105 (2001) 5144-5152. https://doi.org/10.1021/jp004434s.

[108] W. Sun, G. Zhong, C. Kübel, A.A. Jelle, C. Qian, L. Wang, M. Ebrahimi, L.M. Reyes, A.S. Helmy, G.A. Ozin, Size-Tunable Photothermal Germanium Nanocrystals, Angew. Chem. - Int. Ed. 56 (2017) 6329-6334. https://doi.org/10.1002/anie.201701321.

[109] J. Jia, H. Wang, Z. Lu, P.G. O’Brien, M. Ghoussoub, P. Duchesne, Z. Zheng, P. Li, Q. Qiao, L. Wang, A. Gu, A.A. Jelle, Y. Dong, Q. Wang, K.K. Ghuman, T. Wood, C. Qian, Y. Shao, C. Qiu, M. Ye, Y. Zhu, Z.-H. Lu, P. Zhang, A.S. Helmy, C.V. Singh, N.P. Kherani, D.D. Perovic, G.A. 
Ozin, Photothermal Catalyst Engineering: Hydrogenation of Gaseous $\mathrm{CO}_{2}$ with High Activity and Tailored Selectivity, Adv. Sci. 4 (2017) 1700252. https://doi.org/10.1002/advs.201700252.

[110] T. Hartman, R.G. Geitenbeek, C.S. Wondergem, W. van der Stam, B.M. Weckhuysen, Operando Nanoscale Sensors in Catalysis: All Eyes on Catalyst Particles, ACS Nano. 14 (2020) 3725-3735. https://doi.org/10.1021/acsnano.9b09834.

[111] R.G. Geitenbeek, A.E. Nieuwelink, T.S. Jacobs, B.B.V. Salzmann, J. Goetze, A. Meijerink, B.M. Weckhuysen, In Situ Luminescence Thermometry to Locally Measure Temperature Gradients during Catalytic Reactions, ACS Catal. 8 (2018) 2397-2401. https://doi.org/10.1021/acscatal.7b04154.

[112] M. Runowski, P. Wozny, N. Stopikowska, I.R. Martín, V. Lavín, S. Lis, Luminescent nanothermometer operating at very high temperature-sensing up to $1000 \mathrm{~K}$ with upconverting nanoparticles $\left(\mathrm{Yb}^{3+} / \mathrm{Tm}^{3+}\right)$, ACS Appl. Mater. Interfaces. 12 (2020) 43933-43941. https://doi.org/10.1021/acsami.0c13011.

[113] C.D.S. Brites, P.P. Lima, N.J.O. Silva, A. Millán, V.S. Amaral, F. Palacio, L.D. Carlos, Thermometry at the nanoscale, Nanoscale. 4 (2012) 4799-4829. https://doi.org/10.1039/c2nr30663h.

[114] X. Li, X. Zhang, H.O. Everitt, J. Liu, Light-Induced Thermal Gradients in Ruthenium Catalysts Significantly Enhance Ammonia Production, Nano Lett. 19 (2019) 1706-1711. https://doi.org/10.1021/acs.nanolett.8b04706.

[115] C. Mao, L. Yu, J. Li, J. Zhao, L. Zhang, Energy-confined solar thermal ammonia synthesis with $\mathrm{K} / \mathrm{Ru} / \mathrm{TiO}_{2-\mathrm{x}} \mathrm{H}_{\mathrm{x}}$, Appl. Catal. B Environ. 224 (2018) 612-620. https://doi.org/10.1016/j.apcatb.2017.11.010.

[116] Y. Lu, Y. Yang, T. Zhang, Z. Ge, H. Chang, P. Xiao, Y. Xie, L. Hua, Q. Li, H. Li, B. Ma, N. Guan, Y. Ma, Y. Chen, Photoprompted Hot Electrons from Bulk Cross-Linked Graphene Materials and Their Efficient Catalysis for Atmospheric Ammonia Synthesis, ACS Nano. 10 (2016) 10507-10515. https://doi.org/10.1021/acsnano.6b06472.

[117] J.J. Li, E.Q. Yu, S.C. Cai, X. Chen, J. Chen, H.P. Jia, Y.J. Xu, Noble metal free, $\mathrm{CeO}_{2} / \mathrm{LaMnO}_{3}$ 
hybrid achieving efficient photo-thermal catalytic decomposition of volatile organic compounds under IR light, Appl. Catal. B Environ. 240 (2019) 141-152.

https://doi.org/10.1016/j.apcatb.2018.08.069.

[118] Y. Ma, Y. Li, M. Mao, J. Hou, M. Zeng, X. Zhao, Synergetic effect between photocatalysis on $\mathrm{TiO}_{2}$ and solar light-driven thermocatalysis on $\mathrm{MnO}_{\mathrm{x}}$ for benzene purification on $\mathrm{MnOx} / \mathrm{TiO}_{2}$ nanocomposites, J. Mater. Chem. A. 3 (2015) 5509-5516. https://doi.org/10.1039/c5ta00126a.

[119] Y. Zhou, D.E. Doronkin, Z. Zhao, P.N. Plessow, J. Jelic, B. Detlefs, T. Pruessmann, F. Studt, J.D. Grunwaldt, Photothermal Catalysis over Nonplasmonic $\mathrm{Pt} / \mathrm{TiO}_{2}$ Studied by Operando HERFDXANES, Resonant XES, and DRIFTS, ACS Catal. 8 (2018) 11398-11406. https://doi.org/10.1021/acscatal.8b03724.

[120] J.G. Highfield, M.H. Chen, P.T. Nguyen, Z. Chen, Mechanistic investigations of photo-driven processes over $\mathrm{TiO}_{2}$ by in-situ DRIFTS-MS: Part 1. Platinization and methanol reforming, Energy Environ. Sci. 2 (2009) 991-1002. https://doi.org/10.1039/b907781m.

[121] T. Shido, Y. Iwasawa, Reactant-promoted reaction mechanism for water-gas shift reaction on Rhdoped CeO2, J. Catal. 141 (1993) 71-81. https://doi.org/10.1006/jcat.1993.1119.

[122] T. Shido, Y. Iwasawa, Regulation of reaction intermediate by reactant in the water-gas shift reaction on $\mathrm{CeO}_{2}$, in relation to reactant-promoted mechanism, J. Catal. 136 (1992) 493-503. https://doi.org/10.1016/0021-9517(92)90079-W.

[123] L. Ye, K.H. Chu, B. Wang, D. Wu, H. Xie, G. Huang, H.Y. Yip, P.K. Wong, Noble-metal loading reverses temperature dependent photocatalytic hydrogen generation in methanol-water solutions, Chem. Commun. 52 (2016) 11657-11660. https://doi.org/10.1039/C6CC05689J.

[124] X. Liu, L. Ye, Z. Ma, C. Han, L. Wang, Z. Jia, F. Su, H. Xie, Photothermal effect of infrared light to enhance solar catalytic hydrogen generation, Catal. Commun. 102 (2017) 13-16. https://doi.org/10.1016/j.catcom.2017.08.014.

[125] X. Chen, L. Liu, P.Y. Yu, S.S. Mao, Increasing Solar Absorption for Photocatalysis with Black Hydrogenated Titanium Dioxide Nanocrystals, Science. 331 (2011) 746-750. https://doi.org/10.1126/science.1200448.

[126] X. Han, L. Song, H. Xu, S. Ouyang, Light-driven low-temperature syngas production from 
$\mathrm{CH}_{3} \mathrm{OH}$ and $\mathrm{H}_{2} \mathrm{O}$ over a Pt@SrTiO 3 photothermal catalyst, Catal. Sci. Technol. 8 (2018) 25152518. https://doi.org/10.1039/C8CY00539G.

[127] S. Fang, Y. Liu, Z. Sun, J. Lang, C. Bao, Y.H. Hu, Photocatalytic hydrogen production over Rhloaded $\mathrm{TiO}_{2}$ : What is the origin of hydrogen and how to achieve hydrogen production from water?, Appl. Catal. B Environ. 278 (2020) 119316. https://doi.org/10.1016/j.apcatb.2020.119316.

[128] S.I. Nikitenko, T. Chave, C. Cau, H.P. Brau, V. Flaud, Photothermal Hydrogen Production Using Noble-Metal-Free Ti@ $\mathrm{TiO}_{2}$ Core-Shell Nanoparticles under Visible-NIR Light Irradiation, ACS Catal. 5 (2015) 4790-4795. https://doi.org/10.1021/acscatal.5b01401.

[129] L. V. Mattos, G. Jacobs, B.H. Davis, F.B. Noronha, Production of Hydrogen from Ethanol: Review of Reaction Mechanism and Catalyst Deactivation, Chem. Rev. 112 (2012) 4094-4123. https://doi.org/10.1021/cr2000114.

[130] T. Maihom, M. Probst, J. Limtrakul, Density Functional Theory Study of the Dehydrogenation of Ethanol to Acetaldehyde over the Au-Exchanged ZSM-5 Zeolite: Effect of Surface Oxygen, J. Phys. Chem. C. 118 (2014) 18564-18572. https://doi.org/10.1021/jp505002u.

[131] M. Murdoch, G.I.N. Waterhouse, M.A. Nadeem, J.B. Metson, M.A. Keane, R.F. Howe, J. Llorca, H. Idriss, The effect of gold loading and particle size on photocatalytic hydrogen production from ethanol over $\mathrm{Au} / \mathrm{TiO}_{2}$ nanoparticles, Nat. Chem. 3 (2011) 489-492. https://doi.org/10.1038/nchem.1048.

[132] M.A. Nadeem, H. Idriss, Photo-thermal reactions of ethanol over $\mathrm{Ag} / \mathrm{TiO}_{2}$ catalysts. The role of silver plasmon resonance in the reaction kinetics, Chem. Commun. 54 (2018) 5197-5200. https://doi.org/10.1039/C8CC01814F.

[133] D.A. Morgenstern, J.P. Fornango, Low-Temperature Reforming of Ethanol over Copper-Plated Raney Nickel: A New Route to Sustainable Hydrogen for Transportation, Energy \& Fuels. 19 (2005) 1708-1716. https://doi.org/10.1021/ef049692t.

[134] S. Luo, H. Song, D. Philo, M. Oshikiri, T. Kako, J. Ye, Solar-driven production of hydrogen and acetaldehyde from ethanol on Ni-Cu bimetallic catalysts with solar-to-fuels conversion efficiency 
up to $3.8 \%$, Appl. Catal. B Environ. 272 (2020) 118965.

https://doi.org/10.1016/j.apcatb.2020.118965.

[135] E.J. Evans, H. Li, W.-Y. Yu, G.M. Mullen, G. Henkelman, C.B. Mullins, Mechanistic insights on ethanol dehydrogenation on Pd-Au model catalysts: a combined experimental and DFT study, Phys. Chem. Chem. Phys. 19 (2017) 30578-30589. https://doi.org/10.1039/C7CP05097F.

[136] T.S. Khan, F. Jalid, M.A. Haider, First-Principle Microkinetic Modeling of Ethanol Dehydrogenation on Metal Catalyst Surfaces in Non-oxidative Environment: Design of Bimetallic Alloys, Top. Catal. 61 (2018) 1820-1831. https://doi.org/10.1007/s11244-018-1028-9.

[137] M. Ouyang, S. Cao, S. Yang, M. Li, M. Flytzani-Stephanopoulos, Atomically Dispersed Pd Supported on Zinc Oxide for Selective Nonoxidative Ethanol Dehydrogenation, Ind. Eng. Chem. Res. 59 (2020) 2648-2656. https://doi.org/10.1021/acs.iecr.9b05202.

[138] J. Zhang, S. Meng, X. Ye, C. Ling, S. Zhang, X. Fu, S. Chen, Synergistic effect of photocatalysis and thermocatalysis for selective oxidation of aromatic alcohols to aromatic aldehydes using Zn $\mathrm{In}_{2} \mathrm{~S}_{6} @ Z \mathrm{ZnO}$ composite, Appl. Catal. B Environ. 218 (2017) 420-429. https://doi.org/10.1016/j.apcatb.2017.06.078.

[139] Y. Zhang, H. Guo, W. Weng, M.-L. Fu, The surface plasmon resonance, thermal, support and size effect induced photocatalytic activity enhancement of Au/reduced graphene oxide for selective oxidation of benzylic alcohols, Phys. Chem. Chem. Phys. 19 (2017) 31389-31398. https://doi.org/10.1039/C7CP05378A.

[140] Q. Yang, Q. Xu, S.H. Yu, H.L. Jiang, Pd Nanocubes@ZIF-8: Integration of Plasmon-Driven Photothermal Conversion with a Metal-Organic Framework for Efficient and Selective Catalysis, Angew. Chem. Int. Ed. 55 (2016) 3685-3689. https://doi.org/10.1002/anie.201510655.

[141] F. Wang, Y. Huang, Z. Chai, M. Zeng, Q. Li, Y. Wang, D. Xu, Photothermal-enhanced catalysis in core-shell plasmonic hierarchical $\mathrm{Cu}_{7} \mathrm{~S}_{4}$ microsphere@zeolitic imidazole framework-8, Chem. Sci. 7 (2016) 6887-6893. https://doi.org/10.1039/C6SC03239G.

[142] S. Ali, J. Lee, H. Kim, Y. Hwang, A. Razzaq, J.-W. Jung, C.-H. Cho, S.-I. In, Sustained, photocatalytic $\mathrm{CO}_{2}$ reduction to $\mathrm{CH}_{4}$ in a continuous flow reactor by earth-abundant materials: Reduced titania- $\mathrm{Cu}_{2} \mathrm{O}$ Z-scheme heterostructures, Appl. Catal. B Environ. 279 (2020) 119344. 
https://doi.org/10.1016/j.apcatb.2020.119344.

[143] K.R. Thampi, J. Kiwi, M. Grätzel, Methanation and photo-methanation of carbon dioxide at room temperature and atmospheric pressure, Nature. 327 (1987) 506-508.

https://doi.org/10.1038/327506a0.

[144] J. Melsheimer, W. Guo, D. Ziegler, M. Wesemann, R. Schlögl, Methanation of carbon dioxide over $\mathrm{Ru}$ /Titania at room temperature: explorations for a photoassisted catalytic reaction, Catal. Letters. 11 (1991) 157-168. https://doi.org/10.1007/BF00764081.

[145] P. Frontera, A. Macario, M. Ferraro, P.L. Antonucci, Supported catalysts for $\mathrm{CO}_{2}$ methanation: A review, Catalysts. 7 (2017) 1-28. https://doi.org/10.3390/catal7020059.

[146] S.N. Habisreutinger, L. Schmidt-Mende, J.K. Stolarczyk, Photocatalytic reduction of $\mathrm{CO}_{2}$ on $\mathrm{TiO}_{2}$ and other semiconductors, Angew. Chem. - Int. Ed. 52 (2013) 7372-7408. https://doi.org/10.1002/anie.201207199.

[147] S. Navalón, A. Dhakshinamoorthy, M. Álvaro, H. Garcia, Photocatalytic $\mathrm{CO}_{2}$ reduction using non-itanium metal oxides and sulfides, ChemSusChem. 6 (2013) 562-577. https://doi.org/10.1002/cssc.201200670.

[148] V.P. Indrakanti, J.D. Kubicki, H.H. Schobert, Photoinduced activation of $\mathrm{CO}_{2}$ on Ti-based heterogeneous catalysts: Current state, chemical physics-based insights and outlook, Energy Environ. Sci. 2 (2009) 745-758. https://doi.org/10.1039/b822176f.

[149] X. Wang, F. Wang, Y. Sang, H. Liu, Full-Spectrum Solar-Light-Activated Photocatalysts for Light-Chemical Energy Conversion, Adv. Energy Mater. 7 (2017) 1700473. https://doi.org/10.1002/aenm.201700473.

[150] P.G. O'Brien, A. Sandhel, T.E. Wood, A.A. Jelle, L.B. Hoch, D.D. Perovic, C.A. Mims, G.A. Ozin, Photomethanation of gaseous $\mathrm{CO}_{2}$ over ru/silicon nanowire catalysts with visible and nearinfrared photons, Adv. Sci. 1 (2014) 1-7. https://doi.org/10.1002/advs.201400001.

[151] F. Sastre, C. Versluis, N. Meulendijks, J. Rodríguez-Fernández, J. Sweelssen, K. Elen, M.K. Van Bael, T. den Hartog, M.A. Verheijen, P. Buskens, Sunlight-Fueled, Low-Temperature RuCatalyzed Conversion of $\mathrm{CO}_{2}$ and $\mathrm{H}_{2}$ to $\mathrm{CH}_{4}$ with a High Photon-to-Methane Efficiency, ACS 
Omega. 4 (2019) 7369-7377. https://doi.org/10.1021/acsomega.9b00581.

[152] C. Wang, S. Fang, S. Xie, Y. Zheng, Y.H. Hu, Thermo-photo catalytic $\mathrm{CO}_{2}$ hydrogenation over Ru/TiO 2 , J. Mater. Chem. A. 8 (2020) 7390-7394. https://doi.org/10.1039/C9TA13275A.

[153] J. Ren, S. Ouyang, H. Xu, X. Meng, T. Wang, D. Wang, J. Ye, Targeting Activation of $\mathrm{CO}_{2}$ and $\mathrm{H}_{2}$ over Ru-Loaded Ultrathin Layered Double Hydroxides to Achieve Efficient Photothermal $\mathrm{CO}_{2}$ Methanation in Flow-Type System, Adv. Energy Mater. 7 (2017) 1-7. https://doi.org/10.1002/aenm.201601657.

[154] S. Kattel, W. Yu, X. Yang, B. Yan, Y. Huang, W. Wan, P. Liu, J.G. Chen, $\mathrm{CO}_{2}$ Hydrogenation over Oxide-Supported PtCo Catalysts: The Role of the Oxide Support in Determining the Product Selectivity, Angew. Chem. - Int. Ed. 55 (2016) 7968-7973. https://doi.org/10.1002/anie.201601661.

[155] L. He, T.E. Wood, B. Wu, Y. Dong, L.B. Hoch, L.M. Reyes, D. Wang, C. Kübel, C. Qian, J. Jia, K. Liao, P.G. O’Brien, A. Sandhel, J.Y.Y. Loh, P. Szymanski, N.P. Kherani, T.C. Sum, C.A. Mims, G.A. Ozin, Spatial Separation of Charge Carriers in $\operatorname{In}_{2} \mathrm{O}_{3-\mathrm{x}}(\mathrm{OH})_{\mathrm{y}}$ Nanocrystal Superstructures for Enhanced Gas-Phase Photocatalytic Activity, ACS Nano. 10 (2016) 55785586. https://doi.org/10.1021/acsnano.6b02346.

[156] H. Robatjazi, H. Zhao, D.F. Swearer, N.J. Hogan, L. Zhou, A. Alabastri, M.J. McClain, P. Nordlander, N.J. Halas, Plasmon-induced selective carbon dioxide conversion on earth-abundant aluminum-cuprous oxide antenna-reactor nanoparticles, Nat. Commun. 8 (2017) 1-9. https://doi.org/10.1038/s41467-017-00055-z.

[157] H. Zhang, T. Wang, J. Wang, H. Liu, T.D. Dao, M. Li, G. Liu, X. Meng, K. Chang, L. Shi, T. Nagao, J. Ye, Surface-Plasmon-Enhanced Photodriven $\mathrm{CO}_{2}$ Reduction Catalyzed by MetalOrganic-Framework-Derived Iron Nanoparticles Encapsulated by Ultrathin Carbon Layers, Adv. Mater. 28 (2016) 3703-3710. https://doi.org/10.1002/adma.201505187.

[158] B. Lu, F. Quan, Z. Sun, F. Jia, L. Zhang, Photothermal reverse-water-gas-shift over $\mathrm{Au} / \mathrm{CeO}_{2}$ with high yield and selectivity in $\mathrm{CO}_{2}$ conversion, Catal. Commun. 129 (2019) 105724. https://doi.org/10.1016/j.catcom.2019.105724.

[159] L. Wang, M. Ghoussoub, H. Wang, Y. Shao, W. Sun, A.A. Tountas, T.E. Wood, H. Li, J.Y.Y. 
Loh, Y. Dong, M. Xia, Y. Li, S. Wang, J. Jia, C. Qiu, C. Qian, N.P. Kherani, L. He, X. Zhang, G.A. Ozin, Photocatalytic Hydrogenation of Carbon Dioxide with High Selectivity to Methanol at Atmospheric Pressure, Joule. 2 (2018) 1369-1381. https://doi.org/10.1016/j.joule.2018.03.007.

[160] Z. jun Wang, H. Song, H. Pang, Y. Ning, T.D. Dao, Z. Wang, H. Chen, Y. Weng, Q. Fu, T. Nagao, Y. Fang, J. Ye, Photo-assisted methanol synthesis via $\mathrm{CO}_{2}$ reduction under ambient pressure over plasmonic $\mathrm{Cu} / \mathrm{ZnO}$ catalysts, Appl. Catal. B Environ. 250 (2019) 10-16. https://doi.org/10.1016/j.apcatb.2019.03.003.

[161] S. Kattel, P.J. Ramírez, J.G. Chen, J.A. Rodriguez, P. Liu, Active sites for $\mathrm{CO}_{2}$ hydrogenation to methanol on $\mathrm{Cu} / \mathrm{ZnO}$ catalysts, Science. 355 (2017) 1296-1299. https://doi.org/10.1126/science.aal3573.

[162] S. Kattel, P. Liu, J.G. Chen, Tuning Selectivity of $\mathrm{CO}_{2}$ Hydrogenation Reactions at the Metal/Oxide Interface, J. Am. Chem. Soc. 139 (2017) 9739-9754. https://doi.org/10.1021/jacs.7b05362.

[163] M. Ao, G.H. Pham, J. Sunarso, M.O. Tade, S. Liu, Active Centers of Catalysts for Higher Alcohol Synthesis from Syngas: A Review, ACS Catal. 8 (2018) 7025-7050. https://doi.org/10.1021/acscatal.8b01391.

[164] S. Abate, G. Centi, P. Lanzafame, S. Perathoner, The energy-chemistry nexus: A vision of the future from sustainability perspective, J. Energy Chem. 24 (2015) 535-547. https://doi.org/10.1016/j.jechem.2015.08.005.

[165] R. Schlögl, 1.1 The Solar Refinery, in: R. Schlögl (Ed.), Chem. Energy Storage, De Gruyter, Berlin, Boston, 2012: pp. 1-34. https://doi.org/10.1515/9783110266320.1.

[166] L. Liu, A. V. Puga, J. Cored, P. Concepción, V. Pérez-Dieste, H. García, A. Corma, Sunlightassisted hydrogenation of $\mathrm{CO}_{2}$ into ethanol and $\mathrm{C}_{2}$ hydrocarbons by sodium-promoted $\mathrm{Co} @ \mathrm{C}$ nanocomposites, Appl. Catal. B Environ. 235 (2018) 186-196. https://doi.org/10.1016/j.apcatb.2018.04.060.

[167] U. Aslam, V.G. Rao, S. Chavez, S. Linic, Catalytic conversion of solar to chemical energy on plasmonic metal nanostructures, Nat. Catal. 1 (2018) 656-665. https://doi.org/10.1038/s41929- 
018-0138-x.

[168] S. Linic, P. Christopher, D.B. Ingram, Plasmonic-metal nanostructures for efficient conversion of solar to chemical energy, Nat. Mater. 10 (2011) 911-921. https://doi.org/10.1038/nmat3151.

[169] S. Linic, U. Aslam, C. Boerigter, M. Morabito, Photochemical transformations on plasmonic metal nanoparticles, Nat. Mater. 14 (2015) 567-576. https://doi.org/10.1038/nmat4281.

[170] H. Liu, X. Meng, T.D. Dao, H. Zhang, P. Li, K. Chang, T. Wang, M. Li, T. Nagao, J. Ye, Conversion of Carbon Dioxide by Methane Reforming under Visible-Light Irradiation: SurfacePlasmon-Mediated Nonpolar Molecule Activation, Angew. Chem. Int. Ed. 54 (2015) 1154511549. https://doi.org/10.1002/anie.201504933.

[171] H. Liu, M. Li, T.D. Dao, Y. Liu, W. Zhou, L. Liu, X. Meng, T. Nagao, J. Ye, Design of PdAu alloy plasmonic nanoparticles for improved catalytic performance in $\mathrm{CO}_{2}$ reduction with visible light irradiation, Nano Energy. 26 (2016) 398-404. https://doi.org/10.1016/j.nanoen.2016.05.045.

[172] H. Liu, H. Song, X. Meng, L. Yang, J. Ye, Light irradiation enhanced $\mathrm{CO}_{2}$ reduction with methane: A case study in size-dependent optical property of Ni nanoparticles, Catal. Today. 335 (2019) 187-192. https://doi.org/10.1016/j.cattod.2018.11.005.

[173] B. Han, W. Wei, L. Chang, P. Cheng, Y.H. Hu, Efficient Visible Light Photocatalytic $\mathrm{CO}_{2}$ Reforming of $\mathrm{CH}_{4}$, ACS Catal. 6 (2016) 494-497. https://doi.org/10.1021/acscatal.5b02653.

[174] F. Pan, X. Xiang, W. Deng, H. Zhao, X. Feng, Y. Li, A Novel Photo-thermochemical Approach for Enhanced Carbon Dioxide Reforming of Methane, ChemCatChem. 10 (2018) 940-945. https://doi.org/10.1002/cctc.201701565.

[175] H. Liu, H. Song, W. Zhou, X. Meng, J. Ye, A Promising Application of Optical Hexagonal TaN in Photocatalytic Reactions, Angew. Chem. Int. Ed. 57 (2018) 16781-16784. https://doi.org/10.1002/anie.201810886.

[176] J. Barber, P.D. Tran, From natural to artificial photosynthesis, J. R. Soc., Interface. 10 (2013) 20120984. https://doi.org/https://doi.org/10.1098/rsif.2012.0984.

[177] M.J. Kale, P. Christopher, Plasmons at the interface, Science. 349 (2015) 587-588. https://doi.org/10.1126/science.aac8522.

[178] K. Li, B. Peng, T. Peng, Recent Advances in Heterogeneous Photocatalytic $\mathrm{CO}_{2}$ Conversion to 
Solar Fuels, ACS Catal. 6 (2016) 7485-7527. https://doi.org/10.1021/acscatal.6b02089.

[179] Z. Gu, L. Zhang, B. Wen, X. An, H. Lan, L.-M. Liu, T. Chen, J. Zhang, X. Cao, J. Tang, H. Liu, J. Qu, Efficient design principle for interfacial charge separation in hydrogen-intercalated nonstoichiometric oxides, Nano Energy. 53 (2018) 887-897. https://doi.org/10.1016/j.nanoen.2018.09.019.

[180] A.G. Tamirat, J. Rick, A.A. Dubale, W.-N. Su, B.-J. Hwang, Using hematite for photoelectrochemical water splitting: a review of current progress and challenges, Nanoscale Horizons. 1 (2016) 243-267. https://doi.org/10.1039/C5NH00098J.

[181] G. Segev, H. Dotan, K.D. Malviya, A. Kay, M.T. Mayer, M. Grätzel, A. Rothschild, High Solar Flux Concentration Water Splitting with Hematite ( $\alpha$-Fe 2 O 3 ) Photoanodes, Adv. Energy Mater. 6 (2016) 1500817. https://doi.org/10.1002/aenm.201500817.

[182] B.M. Hunter, H.B. Gray, A.M. Müller, Earth-Abundant Heterogeneous Water Oxidation Catalysts, Chem. Rev. 116 (2016) 14120-14136. https://doi.org/10.1021/acs.chemrev.6b00398.

[183] K.P. Kuhl, E.R. Cave, D.N. Abram, T.F. Jaramillo, New insights into the electrochemical reduction of carbon dioxide on metallic copper surfaces, Energy Environ. Sci. 5 (2012) 7050. https://doi.org/10.1039/c2ee21234j.

[184] X. Chang, T. Wang, Z. Zhao, P. Yang, J. Greeley, R. Mu, G. Zhang, Z. Gong, Z. Luo, J. Chen, Y. Cui, G.A. Ozin, J. Gong, Tuning $\mathrm{Cu} / \mathrm{Cu}_{2} \mathrm{O}$ Interfaces for the Reduction of Carbon Dioxide to Methanol in Aqueous Solutions, Angew. Chem. Int. Ed. 57 (2018) 15415-15419. https://doi.org/10.1002/anie.201805256.

[185] R. Guil-López, N. Mota, J. Llorente, E. Millán, B. Pawelec, J.L.G. Fierro, R.M. Navarro, Methanol Synthesis from $\mathrm{CO}_{2}$ : A Review of the Latest Developments in Heterogeneous Catalysis, Materials (Basel). 12 (2019) 3902. https://doi.org/10.3390/ma12233902.

[186] A.A. Tountas, X. Peng, A. V. Tavasoli, P.N. Duchesne, T.L. Dingle, Y. Dong, L. Hurtado, A. Mohan, W. Sun, U. Ulmer, L. Wang, T.E. Wood, C.T. Maravelias, M.M. Sain, G.A. Ozin, Towards Solar Methanol: Past, Present, and Future, Adv. Sci. 6 (2019) 1801903. https://doi.org/10.1002/advs.201801903. 
[187] J. Highfield, Advances and Recent Trends in Heterogeneous Photo(Electro)-Catalysis for Solar Fuels and Chemicals, Molecules. 20 (2015) 6739-6793.

https://doi.org/10.3390/molecules20046739.

[188] L. Wang, Y. Wang, Y. Cheng, Z. Liu, Q. Guo, M.N. Ha, Z. Zhao, Hydrogen-treated mesoporous $\mathrm{WO}_{3}$ as a reducing agent of $\mathrm{CO}_{2}$ to fuels $\left(\mathrm{CH}_{4}\right.$ and $\left.\mathrm{CH}_{3} \mathrm{OH}\right)$ with enhanced photothermal catalytic performance, J. Mater. Chem. A. 4 (2016) 5314-5322. https://doi.org/10.1039/C5TA10180H.

[189] M.N. Ha, G. Lu, Z. Liu, L. Wang, Z. Zhao, 3DOM-LaSrCoFeO ${ }_{6-\delta}$ as a highly active catalyst for the thermal and photothermal reduction of $\mathrm{CO}_{2}$ with $\mathrm{H}_{2} \mathrm{O}$ to $\mathrm{CH}_{4}$, J. Mater. Chem. A. 4 (2016) 13155-13165. https://doi.org/10.1039/C6TA05402A.

[190] E. Fabbri, A. Habereder, K. Waltar, R. Kötz, T.J. Schmidt, Developments and perspectives of oxide-based catalysts for the oxygen evolution reaction, Catal. Sci. Technol. 4 (2014) 3800-3821. https://doi.org/10.1039/C4CY00669K.

[191] L. Wang, M.N. Ha, Z. Liu, Z. Zhao, Mesoporous $\mathrm{WO}_{3}$ modified by Mo for enhancing reduction of $\mathrm{CO}_{2}$ to solar fuels under visible light and thermal conditions, Integr. Ferroelectr. 172 (2016) 97-108. https://doi.org/10.1080/10584587.2016.1176507.

[192] D. Zheng, G. Wei, L. Xu, Q. Guo, J. Hu, N. Sha, Z. Zhao, $\mathrm{LaNi}_{\mathrm{x}} \mathrm{Fe}_{1-\mathrm{x}} \mathrm{O}_{3}(0 \leq \mathrm{x} \leq 1)$ as photothermal catalysts for hydrocarbon fuels production from $\mathrm{CO}_{2}$ and $\mathrm{H}_{2} \mathrm{O}$, J. Photochem. Photobiol. A Chem. 377 (2019) 182-189. https://doi.org/10.1016/j.jphotochem.2019.03.045.

[193] P.S. Shuttleworth, M. De bruyn, H.L. Parker, A.J. Hunt, V.L. Budarin, A.S. Matharu, J.H. Clark, Applications of nanoparticles in biomass conversion to chemicals and fuels, Green Chem. 16 (2014) 573-584. https://doi.org/10.1039/C3GC41555D.

[194] P.N.R. Vennestrøm, C.M. Osmundsen, C.H. Christensen, E. Taarning, Beyond Petrochemicals: The Renewable Chemicals Industry, Angew. Chem. Int. Ed. 50 (2011) 10502-10509. https://doi.org/10.1002/anie.201102117.

[195] J. Hu, F. Yu, Y. Lu, Application of Fischer-Tropsch Synthesis in Biomass to Liquid Conversion, Catalysts. 2 (2012) 303-326. https://doi.org/10.3390/catal2020303.

[196] D. Leckel, Diesel Production from Fischer-Tropsch: The Past, the Present, and New Concepts, Energy \& Fuels. 23 (2009) 2342-2358. https://doi.org/10.1021/ef900064c. 
[197] V. Dieterich, A. Buttler, A. Hanel, H. Spliethoff, S. Fendt, Power-to-liquid via synthesis of methanol, DME or Fischer-Tropsch-fuels: a review, Energy Environ. Sci. 13 (2020) 3207-3252. https://doi.org/10.1039/D0EE01187H.

[198] C. Xiao, Z. Cai, T. Wang, Y. Kou, N. Yan, Aqueous-Phase Fischer-Tropsch Synthesis with a Ruthenium Nanocluster Catalyst, Angew. Chem. Int. Ed. 47 (2008) 746-749. https://doi.org/10.1002/anie.200703481.

[199] L. Wang, Y. Zhang, X. Gu, Y. Zhang, H. Su, Insight into the role of UV-irradiation in photothermal catalytic Fischer-Tropsch synthesis over $\mathrm{TiO}_{2}$ nanotube-supported cobalt nanoparticles, Catal. Sci. Technol. 8 (2018) 601-610. https://doi.org/10.1039/C7CY02304A.

[200] Y. Zhao, B. Zhao, J. Liu, G. Chen, R. Gao, S. Yao, M. Li, Q. Zhang, L. Gu, J. Xie, X. Wen, L.-Z. Wu, C.-H. Tung, D. Ma, T. Zhang, Oxide-Modified Nickel Photocatalysts for the Production of Hydrocarbons in Visible Light, Angew. Chem. Int. Ed. 55 (2016) 4215-4219. https://doi.org/10.1002/anie.201511334.

[201] B.C. Enger, A. Holmen, Nickel and Fischer-Tropsch Synthesis, Catal. Rev. 54 (2012) 437-488. https://doi.org/10.1080/01614940.2012.670088.

[202] W. Gao, R. Gao, Y. Zhao, M. Peng, C. Song, M. Li, S. Li, J. Liu, W. Li, Y. Deng, M. Zhang, J. Xie, G. Hu, Z. Zhang, R. Long, X.-D. Wen, D. Ma, Photo-Driven Syngas Conversion to Lower Olefins over Oxygen-Decorated $\mathrm{Fe}_{5} \mathrm{C}_{2}$ Catalyst, Chem. 4 (2018) 2917-2928. https://doi.org/10.1016/j.chempr.2018.09.017.

[203] Y. Wang, Q. Xia, Fischer-Tropsch Synthesis Steps into the Solar Era: Lower Olefins from Syngas, Chem. 4 (2018) 2741-2743. https://doi.org/10.1016/j.chempr.2018.11.020.

[204] S. Xie, Z. Shen, J. Deng, P. Guo, Q. Zhang, H. Zhang, C. Ma, Z. Jiang, J. Cheng, D. Deng, Y. Wang, Visible light-driven $\mathrm{C}-\mathrm{H}$ activation and $\mathrm{C}-\mathrm{C}$ coupling of methanol into ethylene glycol, Nat. Commun. 9 (2018) 1181. https://doi.org/10.1038/s41467-018-03543-y.

[205] M. Bellardita, R. Fiorenza, L. D’Urso, L. Spitaleri, A. Gulino, G. Compagnini, S. Scirè, L. Palmisano, Exploring the Photothermo-Catalytic Performance of Brookite $\mathrm{TiO}_{2}-\mathrm{CeO}_{2}$ Composites, Catalysts. 10 (2020) 765. https://doi.org/10.3390/catal10070765. 
[206] R. Fiorenza, M. Condorelli, L. D’Urso, G. Compagnini, M. Bellardita, L. Palmisano, S. Scirè, Catalytic and Photothermo-catalytic Applications of $\mathrm{TiO}_{2}-\mathrm{CoO}_{x}$ Composites, J. Photocatal. 1 (2020) 3-15. https://doi.org/10.2174/2665976x01666200219113505.

[207] L. Kang, X.Y. Liu, A. Wang, L. Li, Y. Ren, X. Li, X. Pan, Y. Li, X. Zong, H. Liu, A.I. Frenkel, T. Zhang, Photo-thermo Catalytic Oxidation over a $\mathrm{TiO}_{2}-\mathrm{WO}_{3}$-Supported Platinum Catalyst, Angew. Chem. 132 (2020) 13009-13016. https://doi.org/10.1002/ange.202001701.

[208] B. Han, W. Wei, M. Li, K. Sun, Y.H. Hu, A thermo-photo hybrid process for steam reforming of methane: Highly efficient visible light photocatalysis, Chem. Commun. 55 (2019) 7816-7819. https://doi.org/10.1039/c9cc04193a.

[209] S. Tang, X. Xing, W. Yu, J. Sun, Y. Xuan, L. Wang, Y. Xu, H. Hong, H. Jin, Synergizing PhotoThermal $\mathrm{H}_{2}$ and Photovoltaics into a Concentrated Sunlight Use, IScience. 23 (2020) 101012. https://doi.org/10.1016/j.isci.2020.101012.

[210] X. Li, H.O. Everitt, J. Liu, Synergy between thermal and nonthermal effects in plasmonic photocatalysis, Nano Res. 13 (2020) 1268-1280. https://doi.org/10.1007/s12274-020-2694-z.

[211] Y. Sivan, J. Baraban, I.W. Un, Y. Dubi, Comment on "Quantifying hot carrier and thermal contributions in plasmonic photocatalysis," Science. 364 (2019) eaaw9367. https://doi.org/10.1126/science.aaw9367. 